Supplementary information

\title{
Indirubin Derivatives as Dual Inhibitors Targeting Cyclin-Dependent Kinase and Histone Deacetylase for Treating Cancer
}

Zhuoxian Cao, ${ }^{+, \S}$ Fenfen Yang, ${ }^{+, \S}$ Jie Wang, ${ }^{+}$Zhicheng Gu, ${ }^{+}$Shuxian Lin, ${ }^{+}$Pan Wang, ${ }^{\dagger}$ Jianxiong An, ${ }^{+}$Ting $\mathrm{Liu}^{+}{ }^{+}$Yan $\mathrm{Li}^{+}{ }^{+}$Yongjun $\mathrm{Li}^{+}{ }^{+}$Hening Lin, ${ }^{\ddagger}$ Yonglong Zhao, ${ }^{+}{ }^{*}$ and Bin $\mathrm{He}^{+, *}$

†State Key Laboratory of Functions and Applications of Medicinal Plants, Engineering Research Center for the Development and Application of Ethnic Medicine and TCM (Ministry of Education), Guizhou Provincial Key Laboratory of Pharmaceutics, School of Pharmacy, School of Basic Medicine, Guizhou Medical University, Guiyang 550004, China.

${ }^{\ddagger}$ Howard Hughes Medical Institute; Department of Chemistry and Chemical Biology, Cornell University, Ithaca, New York 14853, United States.

* Corresponding authors: Bin He*: E-mail: binhe@gmc.edu.cn.

${ }^{\S}$ Author Contributions: ${ }^{\S}$ Zhuoxian Cao and Fenfen Yang contributed equally to this work. 


\section{Table of Contents}

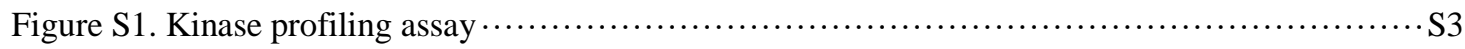

Figure S2. Synergistic Inhibition of cell proliferation by Vorinostat and Palbociclib $\ldots \ldots \ldots \ldots \ldots \ldots \ldots . . . . .33$

Figure S3. Synergistic Inhibition of cell proliferation by Tubastatin A and Palbociclib $\cdots \cdots \cdots \cdots \cdots \cdots \cdots \cdot$ S4

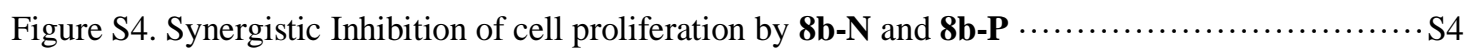

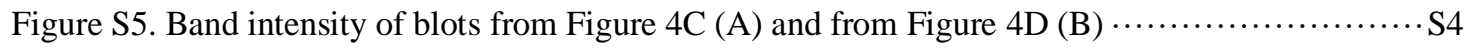

Figure S6. Pathway of A549 apoptosis after combined treatment with $\mathbf{8 b}-\mathbf{N}$ and $\mathbf{8 b}-\mathbf{P} \ldots \ldots \ldots \ldots \ldots \ldots$. S5

Figure S7. Antitumor potency of compound 8b against A549 xenografts models(IT) $\cdots \cdots \cdots \cdots \cdots \cdots \cdots \cdots$ S5

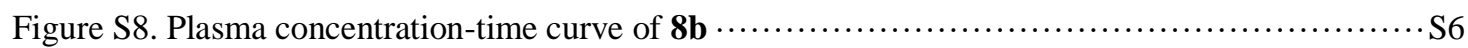

Table S1. The basic pharmacokinetic (PK) properties of $\mathbf{8 b}$ in Sprague-Dawley rats $\cdots \ldots \ldots \ldots \ldots \ldots . . . . .67$

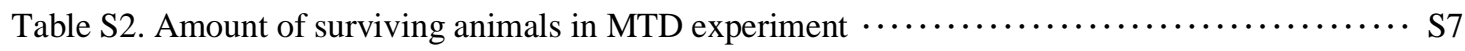

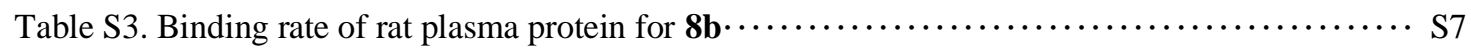

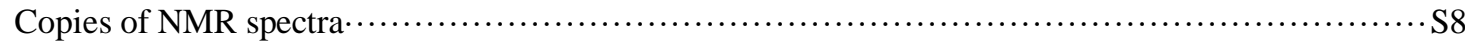

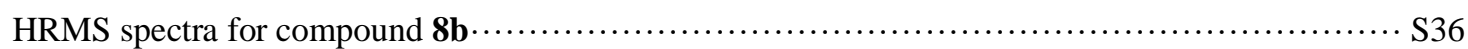

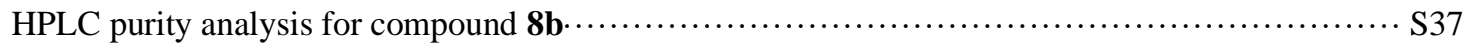




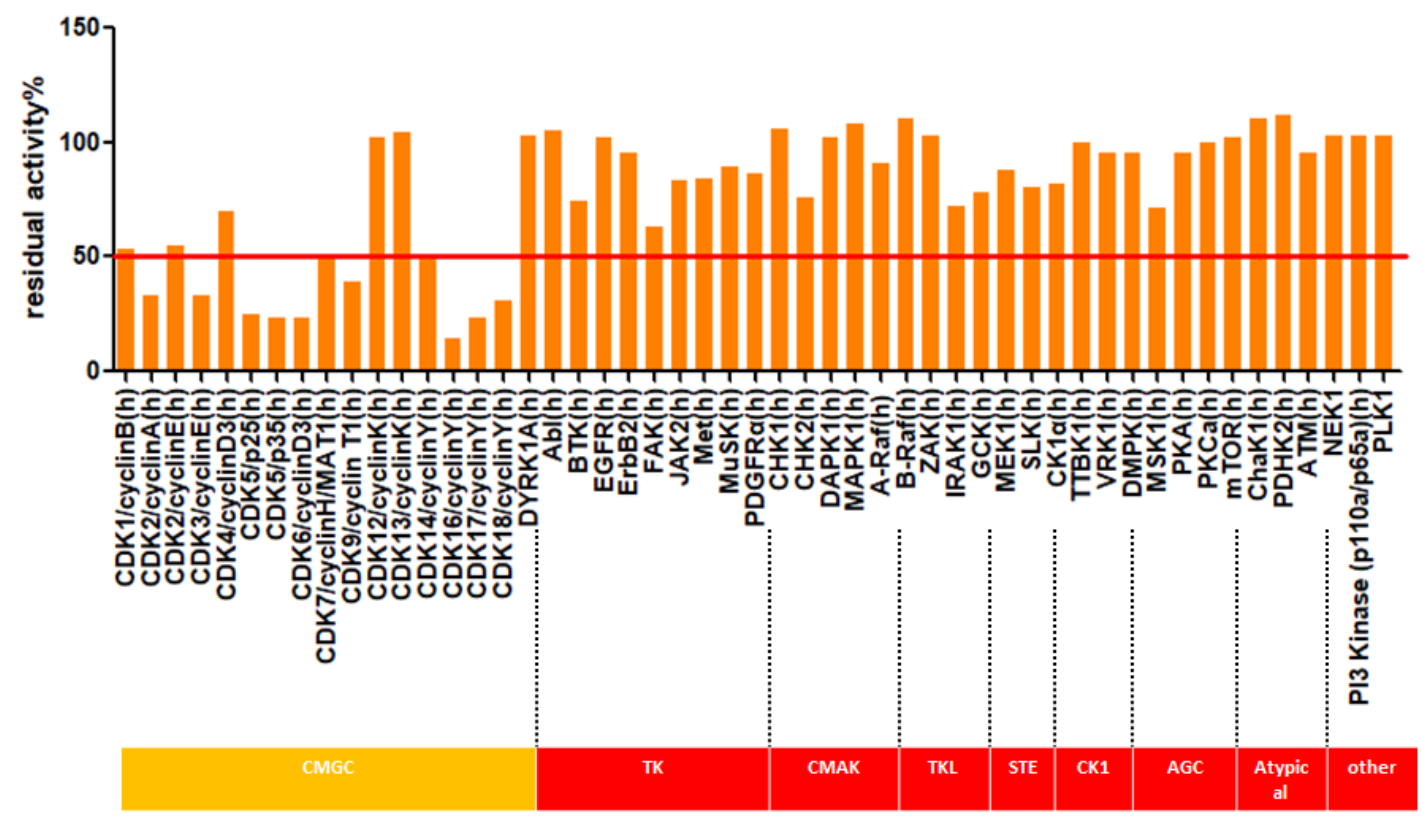

Figure S1. Kinase profiling assay was performed by Eurofins. The residual activities of 51 kinases were measured.

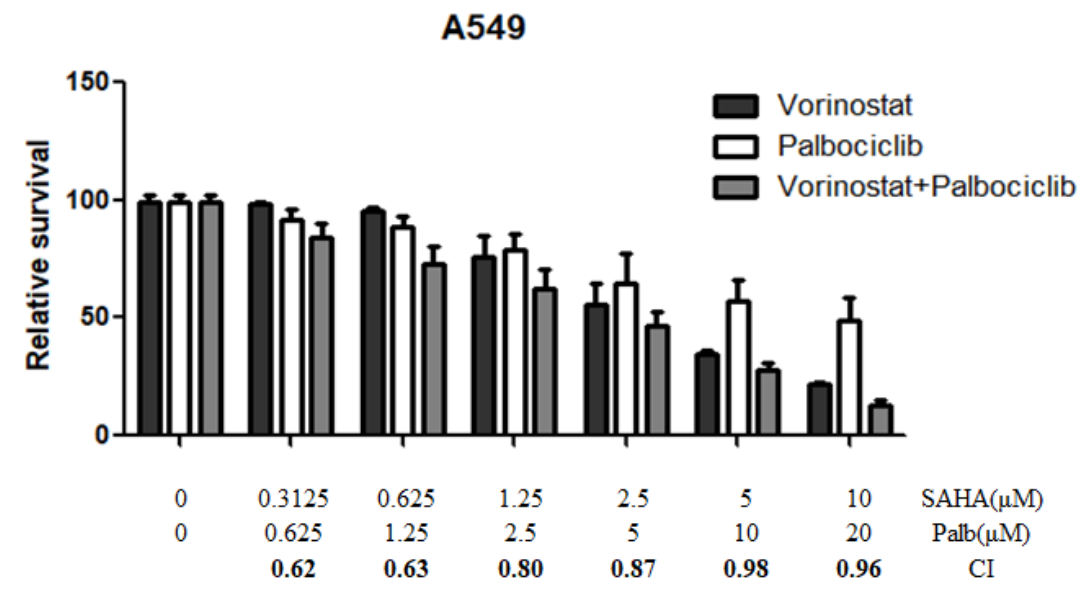

Figure S2. Synergistic Inhibition of cell proliferation by Vorinostat and Palbociclib 


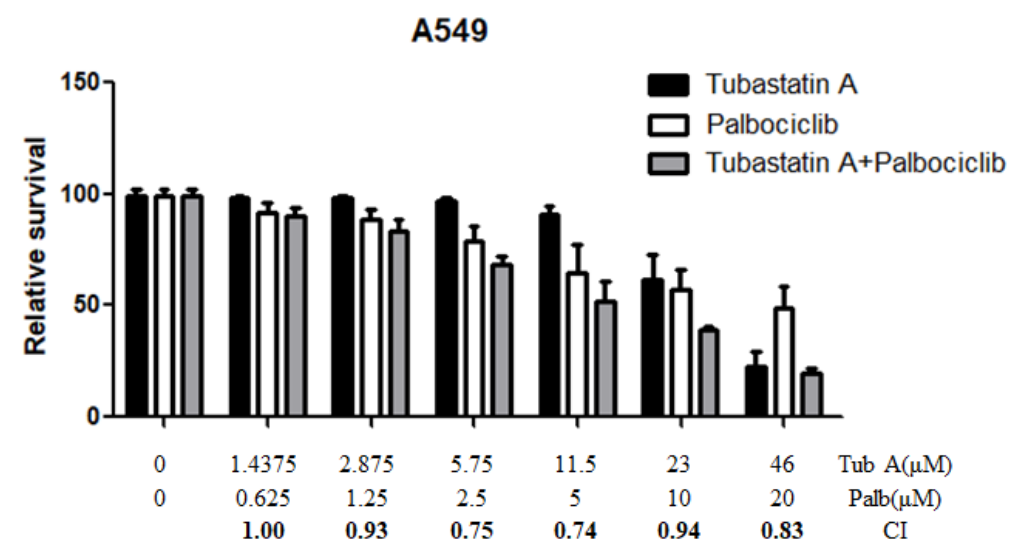

Figure S3. Synergistic Inhibition of cell proliferation by Tubastatin A and Palbociclib

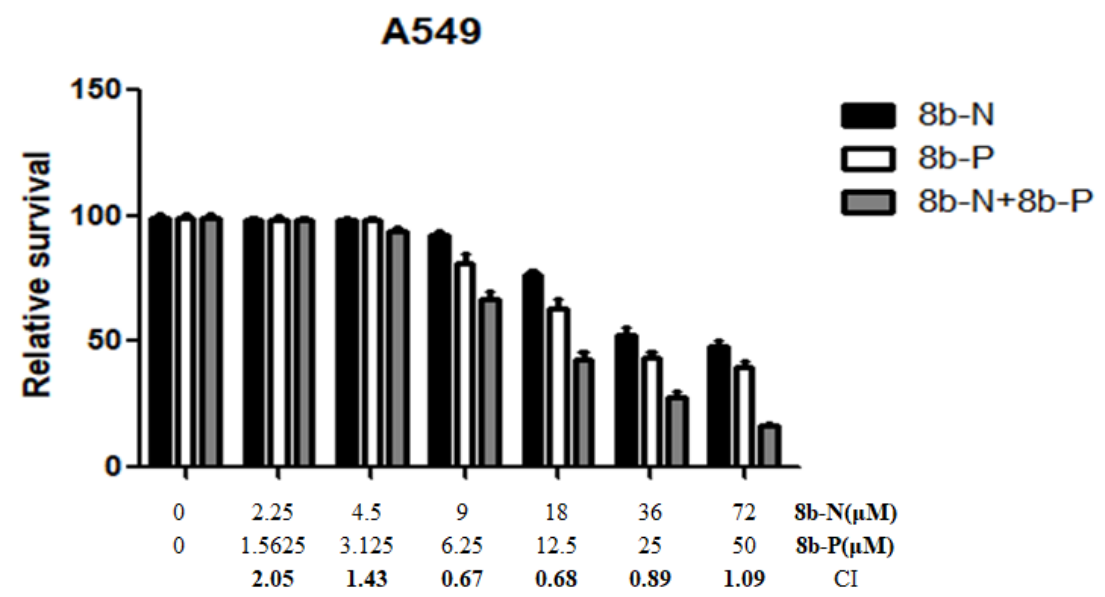

Figure S4. Synergistic Inhibition of cell proliferation by $\mathbf{8 b - N}$ and $\mathbf{8 b - P}$.

A

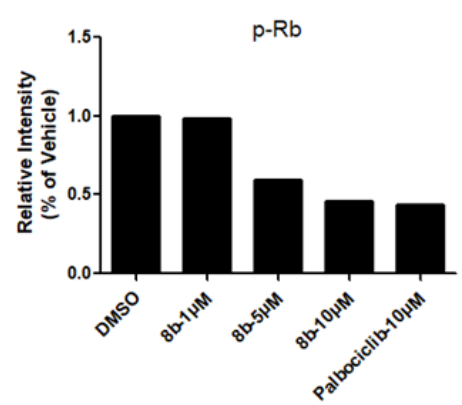

B

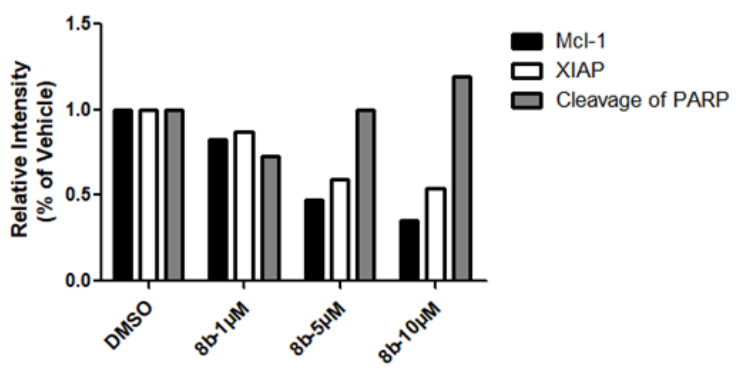

Figure S5. Band intensity of blots from Figure 4C (A) and from Figure 4D (B) calculated by Quantity One.

$$
\begin{aligned}
& \text { Intensity }=\left(\frac{\text { intensity of target protein }}{\text { intensity of GAPDH or } \alpha-\text { Tubulin }}\right) \\
& \text { Relative Intensity }=\left(\frac{\text { intensity of treated group }}{\text { intensity of DMSO group }}\right) \times 100 \%
\end{aligned}
$$



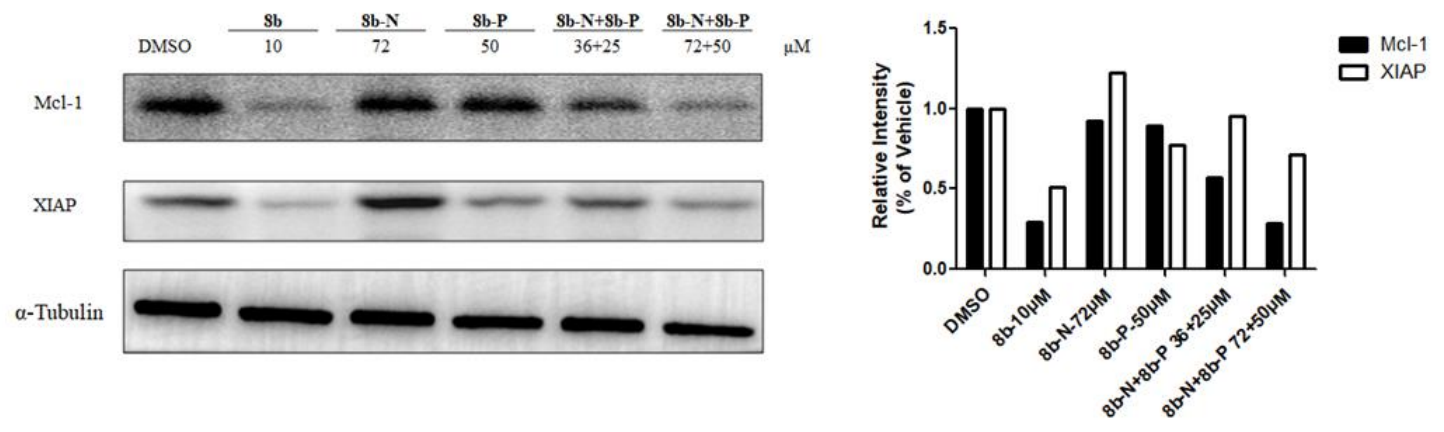

Figure S6. Pathway of A549 apoptosis after combined treatment with 8b-N (a CDK inhibitor) and 8b-P (a HDAC6 inhibitor).

Intensity $=\left(\frac{\text { intensity of target protein }}{\text { intensity of } \alpha-\text { Tubulin }}\right)$

Relative Intensity $=\left(\frac{\text { intensity of treated group }}{\text { intensity of DMSO group }}\right) \times 100 \%$

A

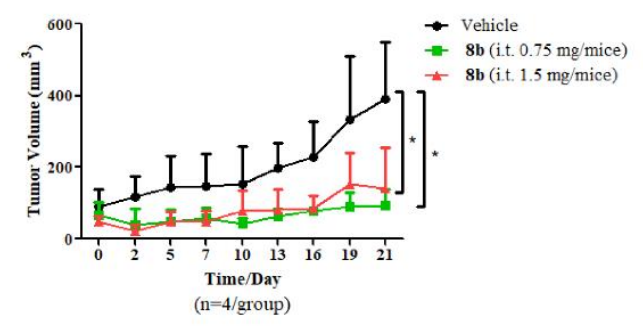

C

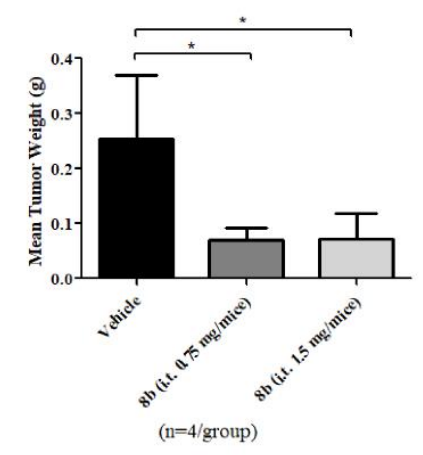

B

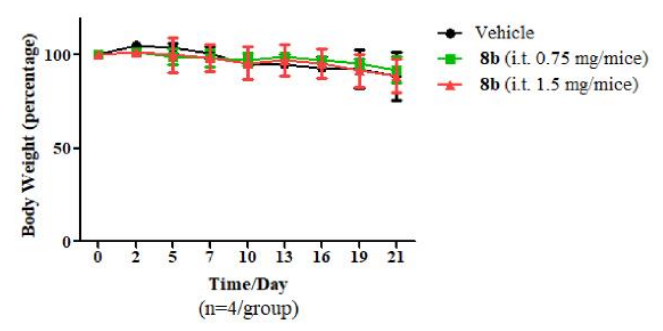

D

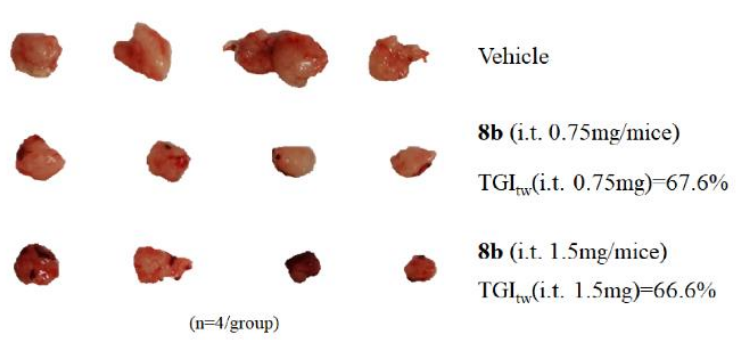

Figure S7. In vivo antitumor potency of compound $8 \mathbf{b}$ against $A 549$ xenografts models $(n=4)$ with intratumor administration. (A) Tumor volume and (B) Body weight measurements for $\mathbf{8} \mathbf{b}$ treated mice groups after 21 days. The data were presented as percentage compared to day 0 . (C) Comparison of the final tumor weights in each group after the 21 days treatment period of $\mathbf{8 b}$. (D) The picture of dissected A549 tumor tissues. ${ }^{*} p<0.05$ or ${ }^{* *} p<0.01$ compared with the control group. 
A

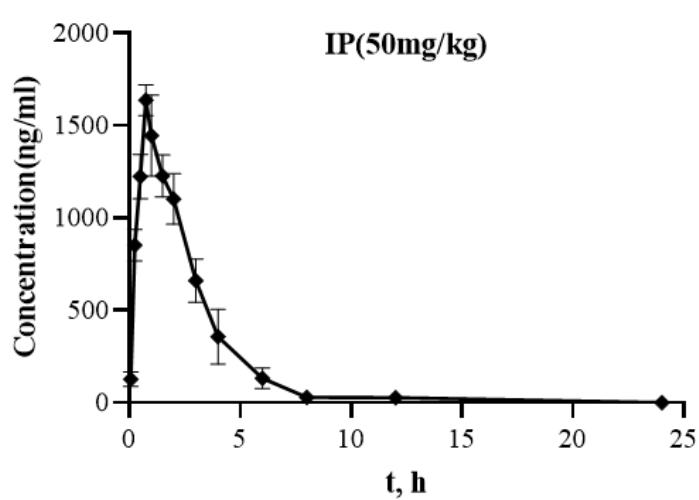

B

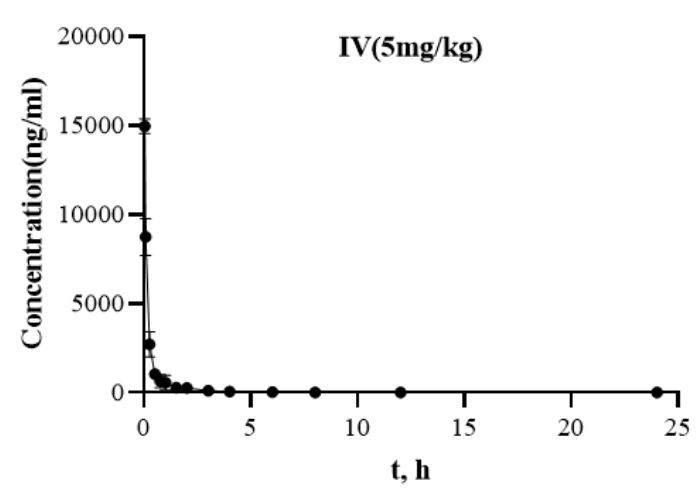

Figure S8. (A)Plasma concentration-time curve of $\mathbf{8 b}$ after intraperitoneal injection to SD rat; (B) Plasma concentration-time curve of $\mathbf{8} \mathbf{b}$ after intravenous administration. 
Table S1. The pharmacokinetic (PK) properties of $8 \mathbf{b}$ in Sprague-Dawley rats $(n=6)$

\begin{tabular}{lcc}
\hline Compound & \multicolumn{2}{c}{$\mathbf{8 b}$} \\
\hline Route & i.p. & i.v. \\
Dose $(\mathrm{mg} / \mathrm{kg})$ & 50 & 5 \\
$\mathrm{~T}_{1 / 2}(\mathrm{~h})$ & 2.81 & 3.79 \\
$\mathrm{~T}_{\max }(\mathrm{h})$ & 0.92 & 0.0333 \\
$\mathrm{C}_{\max }(\mathrm{ng} / \mathrm{mL})$ & 2211.03 & 14951.78 \\
$\mathrm{AUC}_{0-\mathrm{t}}\left(\mathrm{ng}{ }^{*} \mathrm{~h} / \mathrm{mL}\right)$ & 4677.72 & 3598.13 \\
$\mathrm{AUC} \mathrm{C}_{0-\text { inf }}\left(\mathrm{ng}{ }^{*} \mathrm{~h} / \mathrm{mL}\right)$ & 4683.29 & 3687.99 \\
$\mathrm{CL}(\mathrm{mL} / \mathrm{kg} / \mathrm{h}):$ & 12755.6 & 1585.72 \\
$\mathrm{~F}(\%)$ & 13 & - \\
\hline
\end{tabular}

Table S2. Amount of surviving animals in MTD experiment

\begin{tabular}{cccccc}
\hline Group & Day 1 & Day 2 & Day 3 & Day 4 & Day 5 \\
\hline Vehicle & 4 & 4 & 4 & 4 & 4 \\
$8 \mathrm{~b}(200 \mathrm{mg} / \mathrm{kg})$ & 4 & 2 & 2 & 1 & 0 \\
$8 \mathrm{~b}(100 \mathrm{mg} / \mathrm{kg})$ & 4 & 4 & 4 & 4 & 4 \\
\hline
\end{tabular}

${ }^{*}$ Compound was administered once daily (qd) intravenously (iv) for five consecutive days.

Table S3 Binding rate of rat plasma protein for $\mathbf{8 b}$

\begin{tabular}{ccccccc}
\hline \multirow{2}{*}{ Compound } & Concentration, $\mu \mathrm{g} / \mathrm{mL}$ & Sample & $D_{\mathrm{t}}, \mathrm{ng} / \mathrm{mL}$ & $D_{\mathrm{f}}, \mathrm{ng} / \mathrm{mL}$ & $\begin{array}{c}\text { Binding rate } \\
F_{u}, \%\end{array}$ & Average, \% \\
\hline \multirow{3}{*}{ 8b } & 1 & 1 & 513.1 & 87.3 & 83.0 & \\
& \multirow{2}{*}{15} & 2 & 406.9 & 83.1 & 79.6 & $76.9 \pm 6.4$ \\
& & 3 & 424.7 & 96.8 & 77.2 & \\
\hline
\end{tabular}

$F_{u}(\%)=\frac{D_{t}-D_{f}}{D_{t}} \times 100 \%$

$D_{t}$ is the total compound concentration in the plasma compartment and $D_{f}$ is the concentration of the compound in free form in the phosphate buffer compartment 


\section{${ }^{1} \mathrm{H}$ NMR Spectrum}

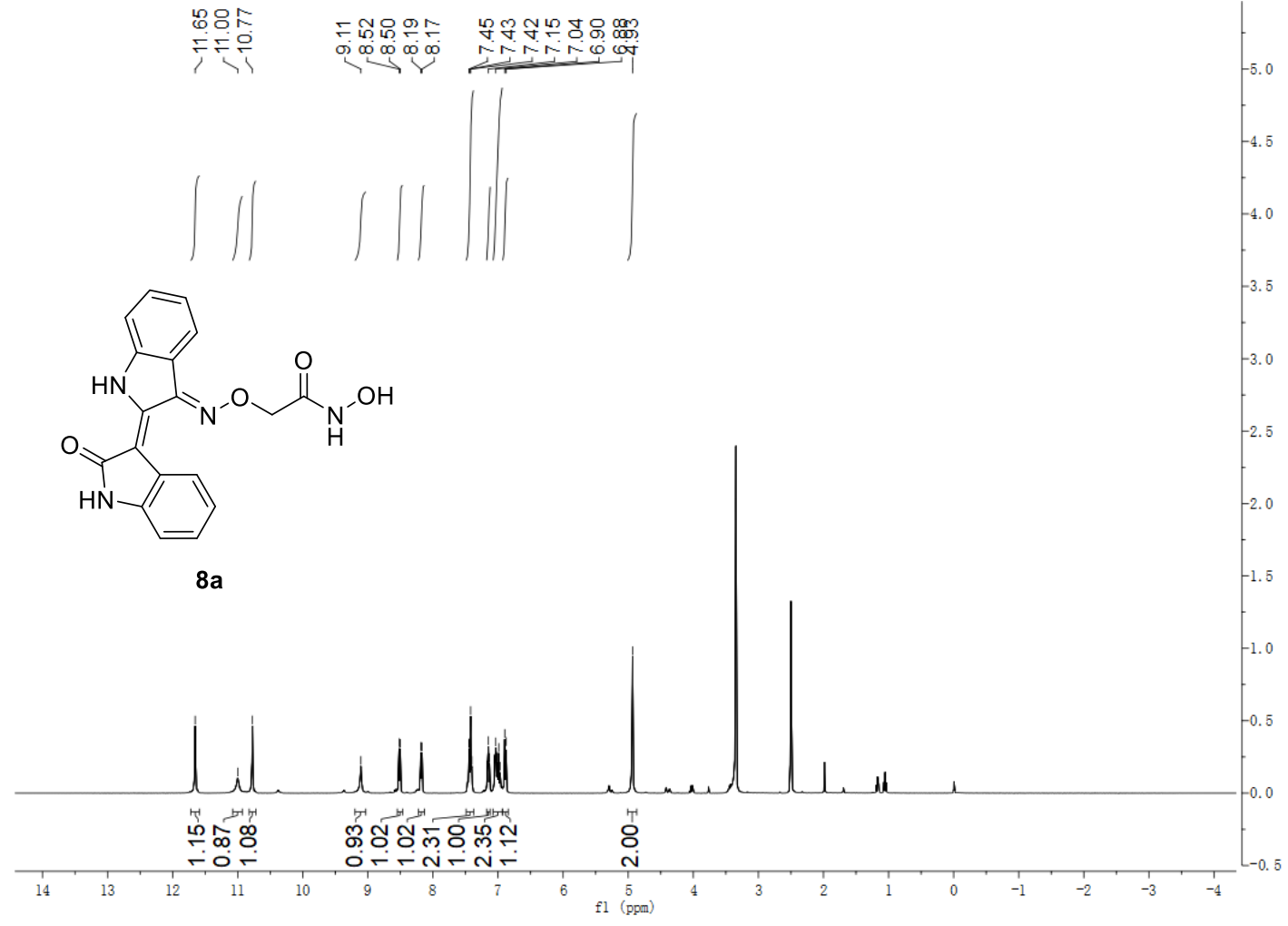

${ }^{13} \mathrm{C}$ NMR Spectrum

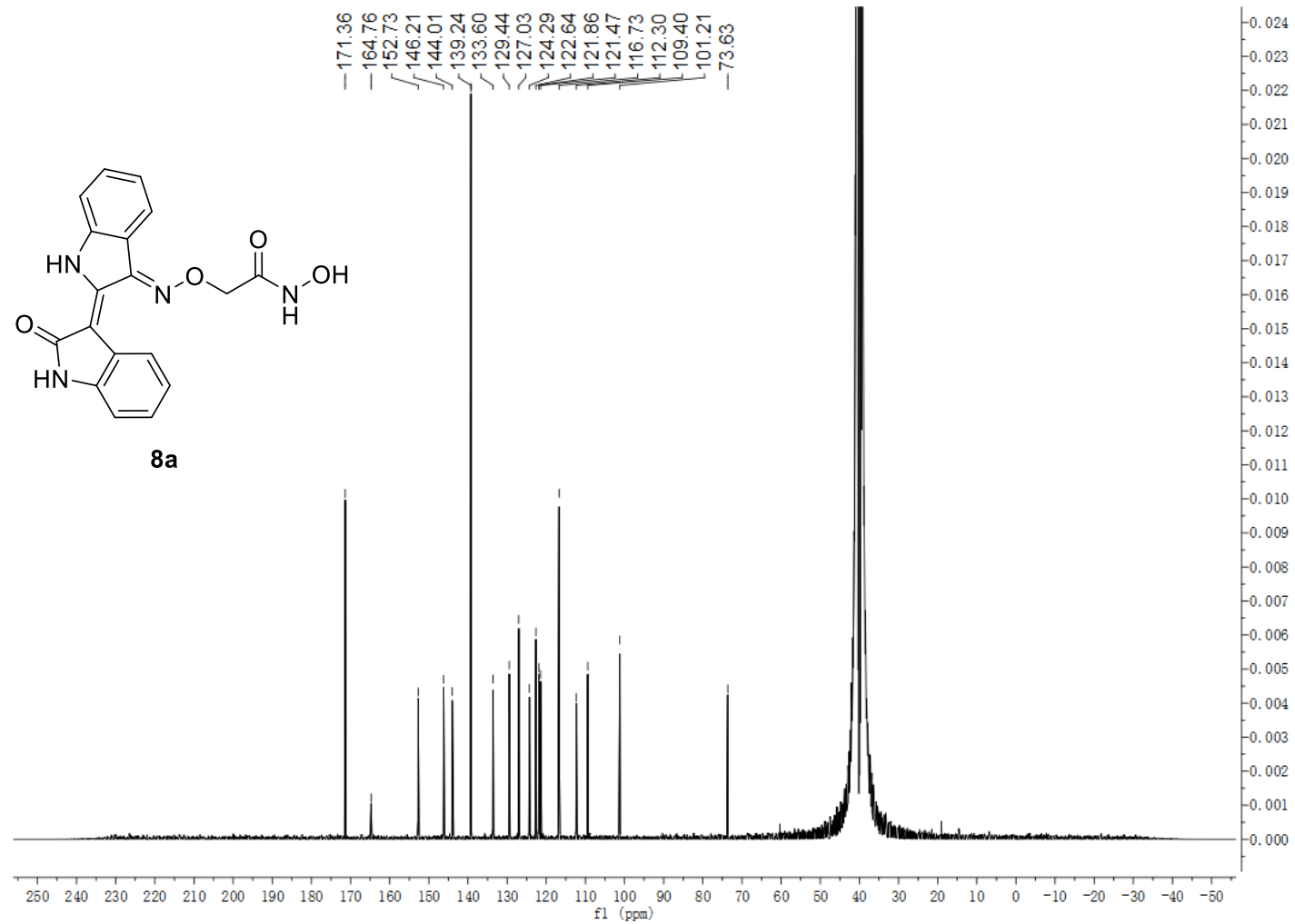




\section{${ }^{1} \mathrm{H}$ NMR Spectrum}

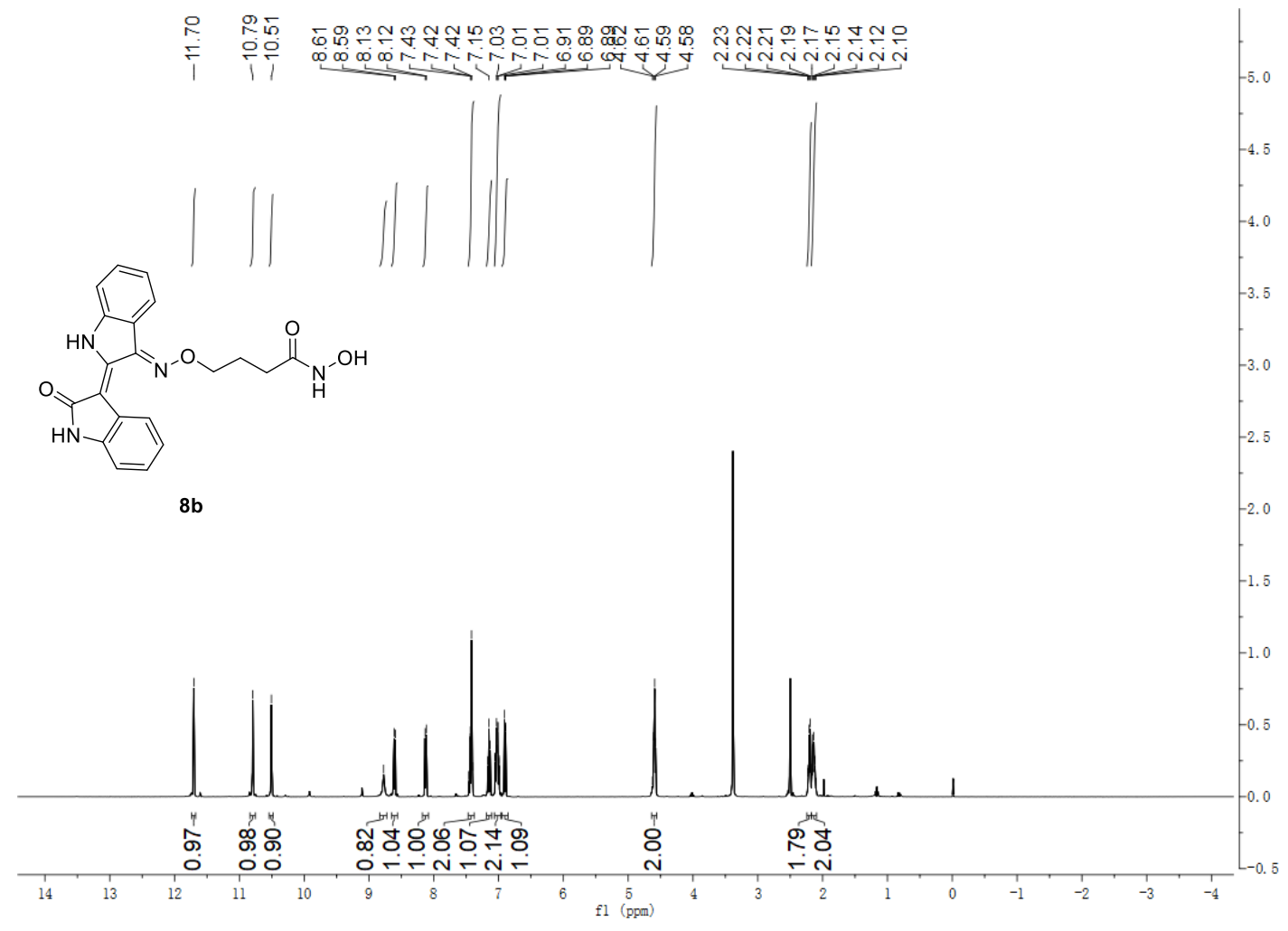

${ }^{13} \mathrm{C}$ NMR Spectrum

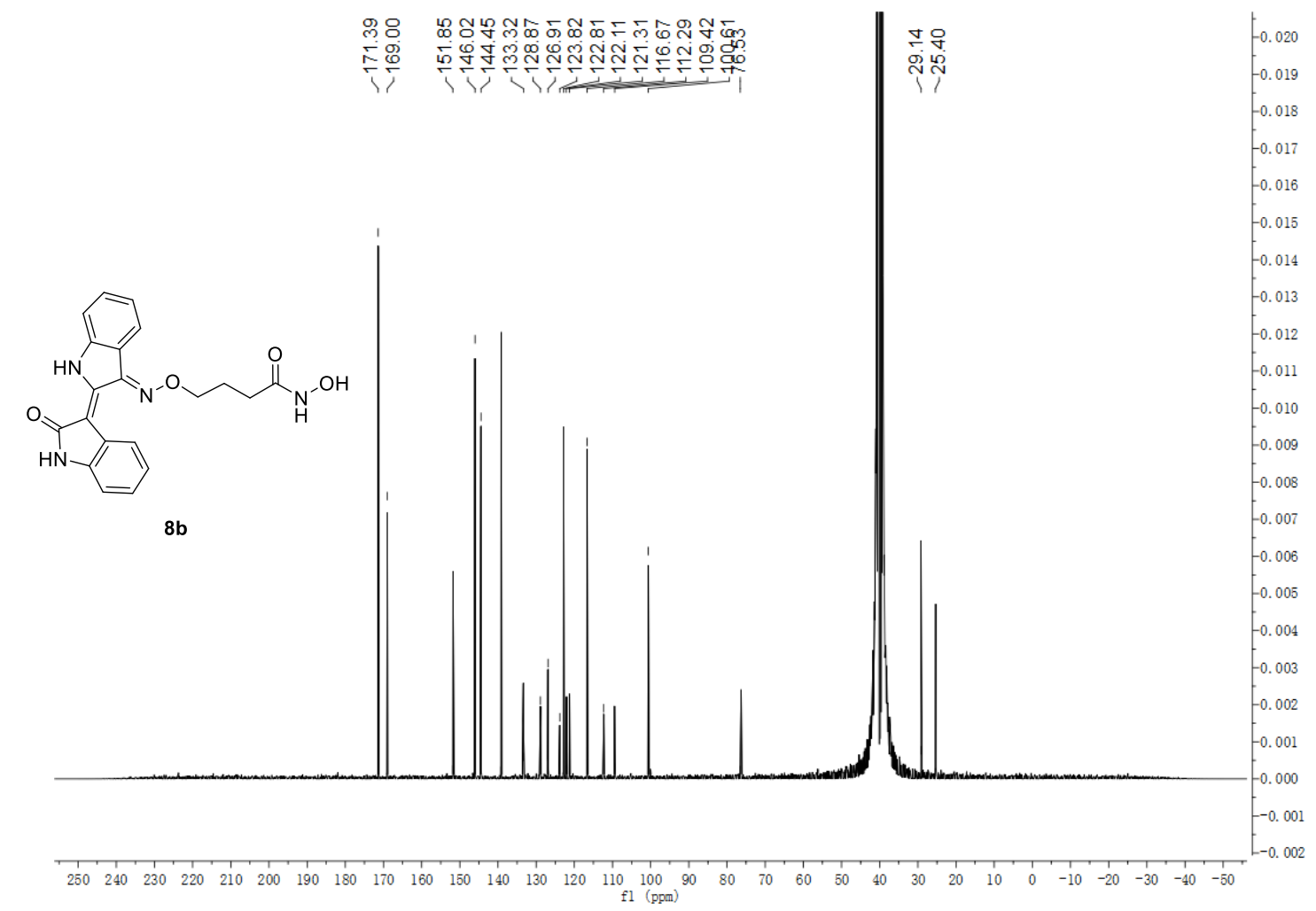




\section{${ }^{1}$ H NMR Spectrum}

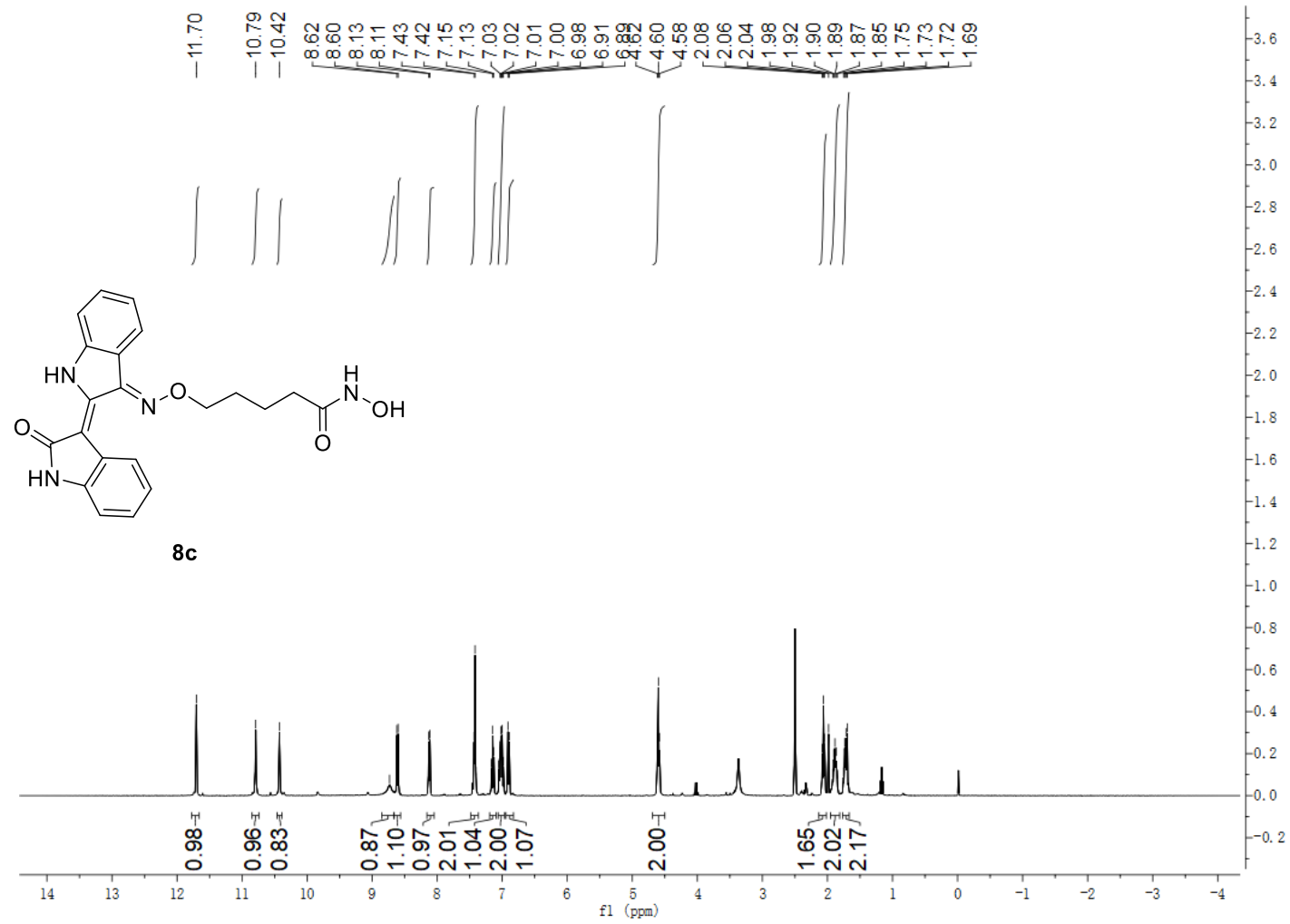

${ }^{13} \mathrm{C}$ NMR Spectrum

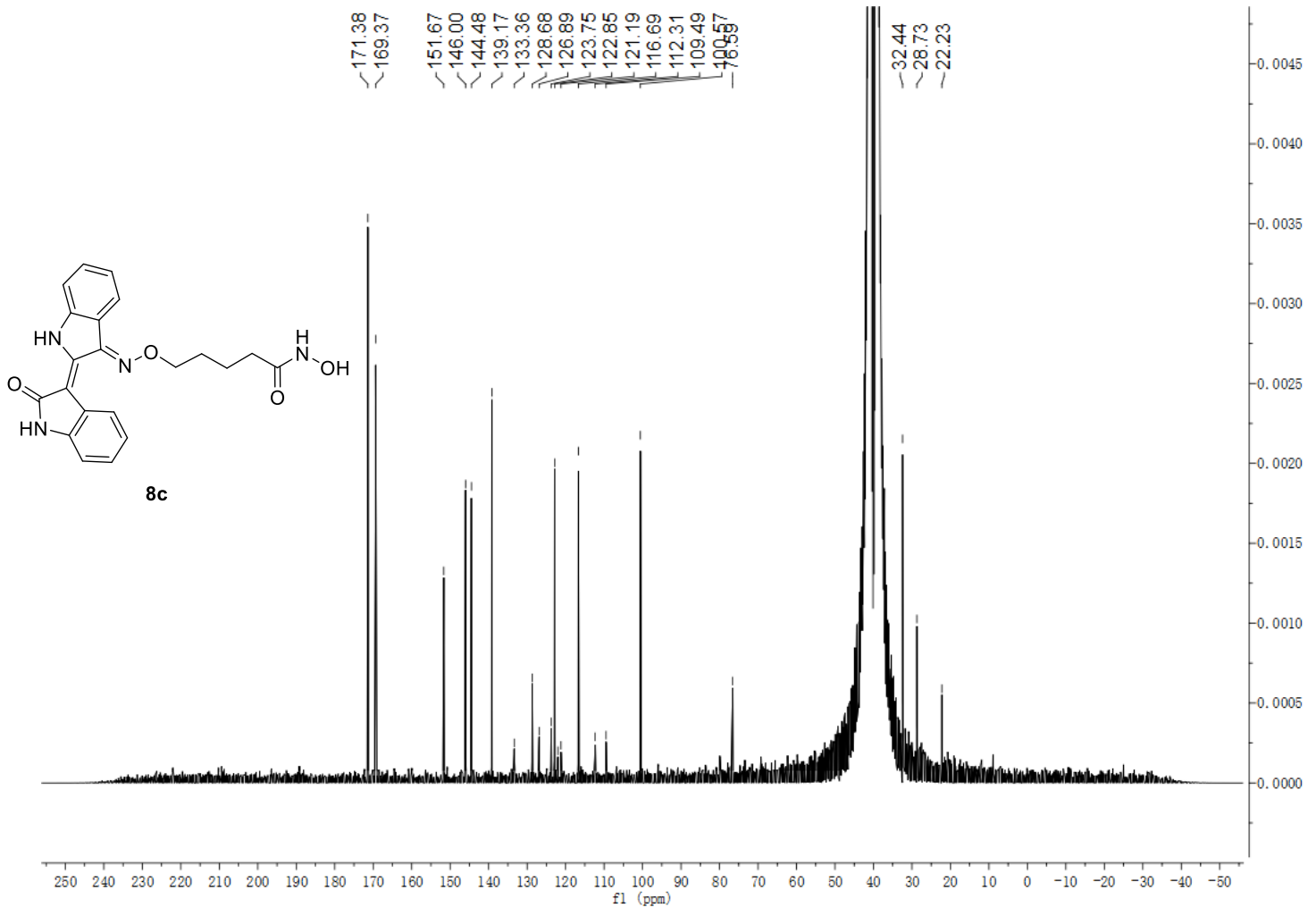


${ }^{1} \mathrm{H}$ NMR Spectrum

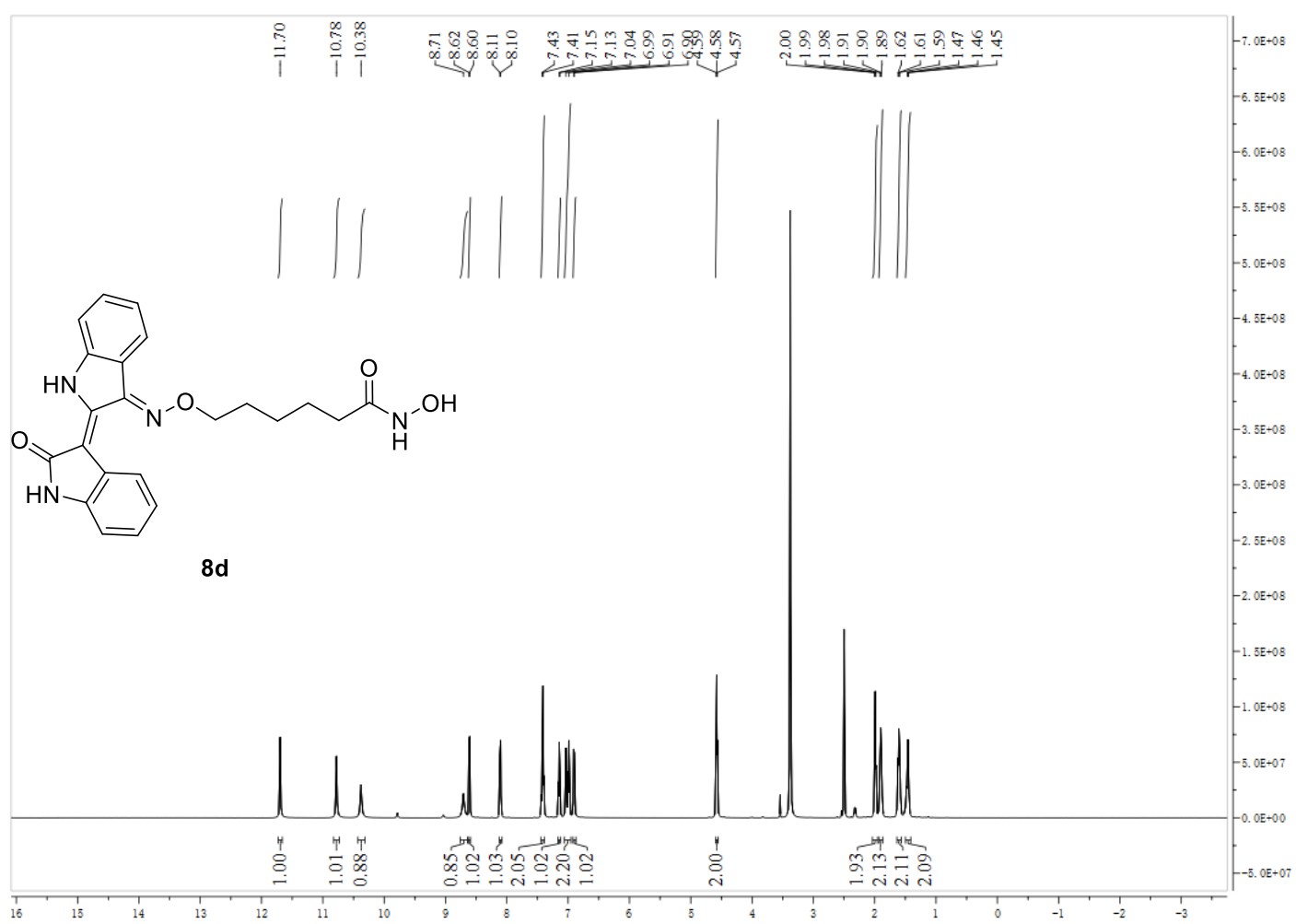

${ }^{13} \mathrm{C}$ NMR Spectrum

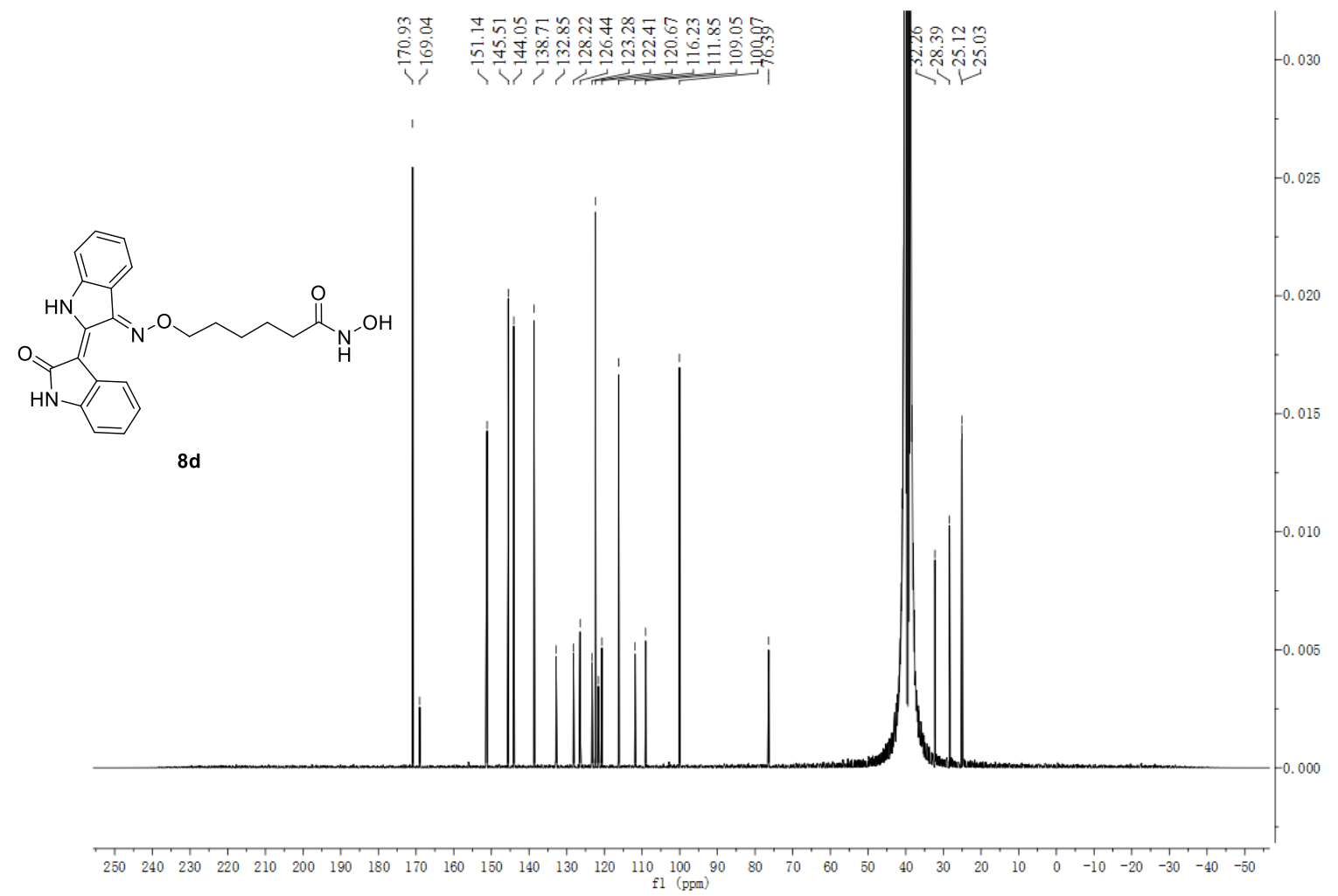




\section{${ }^{1}$ H NMR Spectrum}

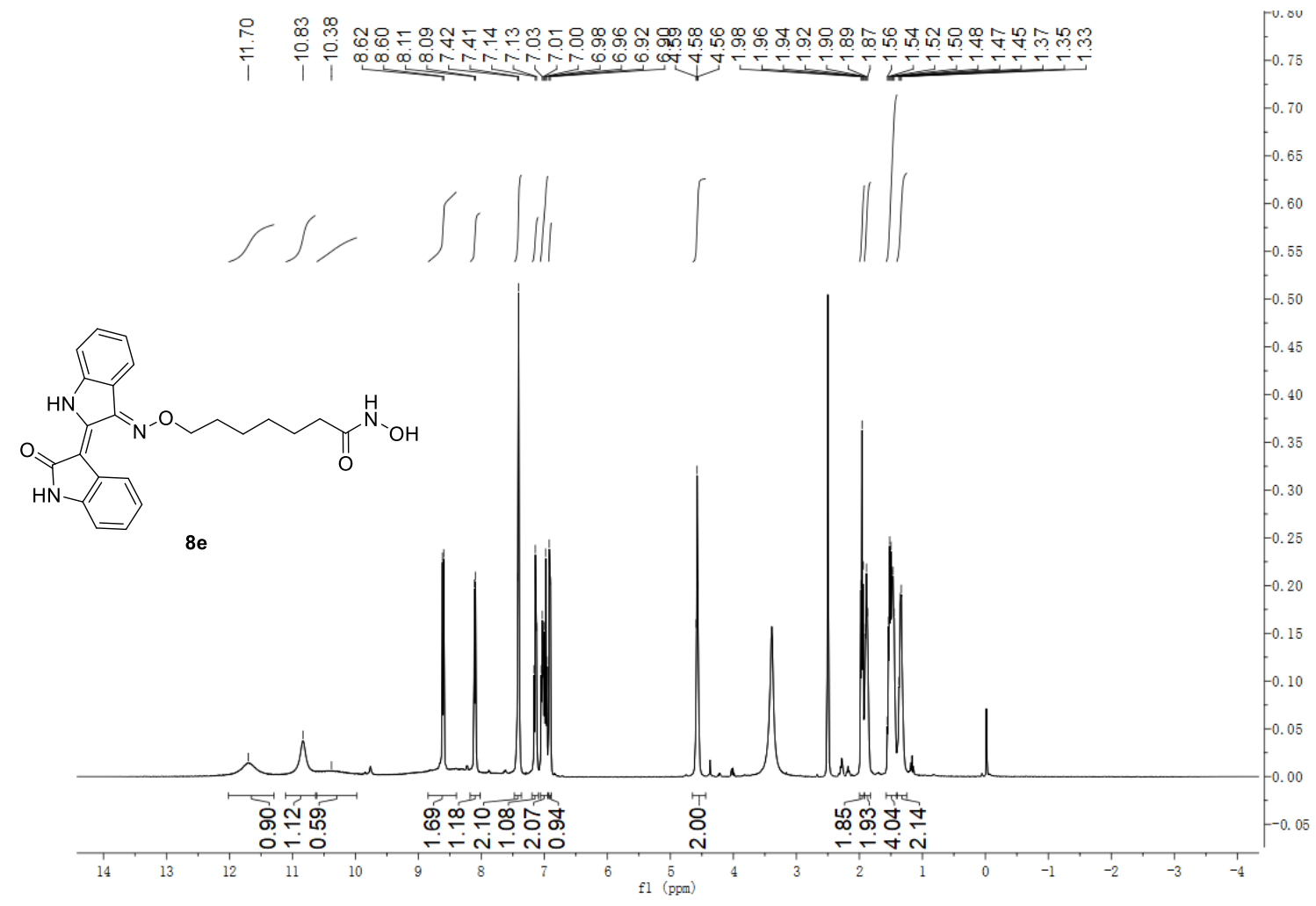

${ }^{13} \mathrm{C}$ NMR Spectrum

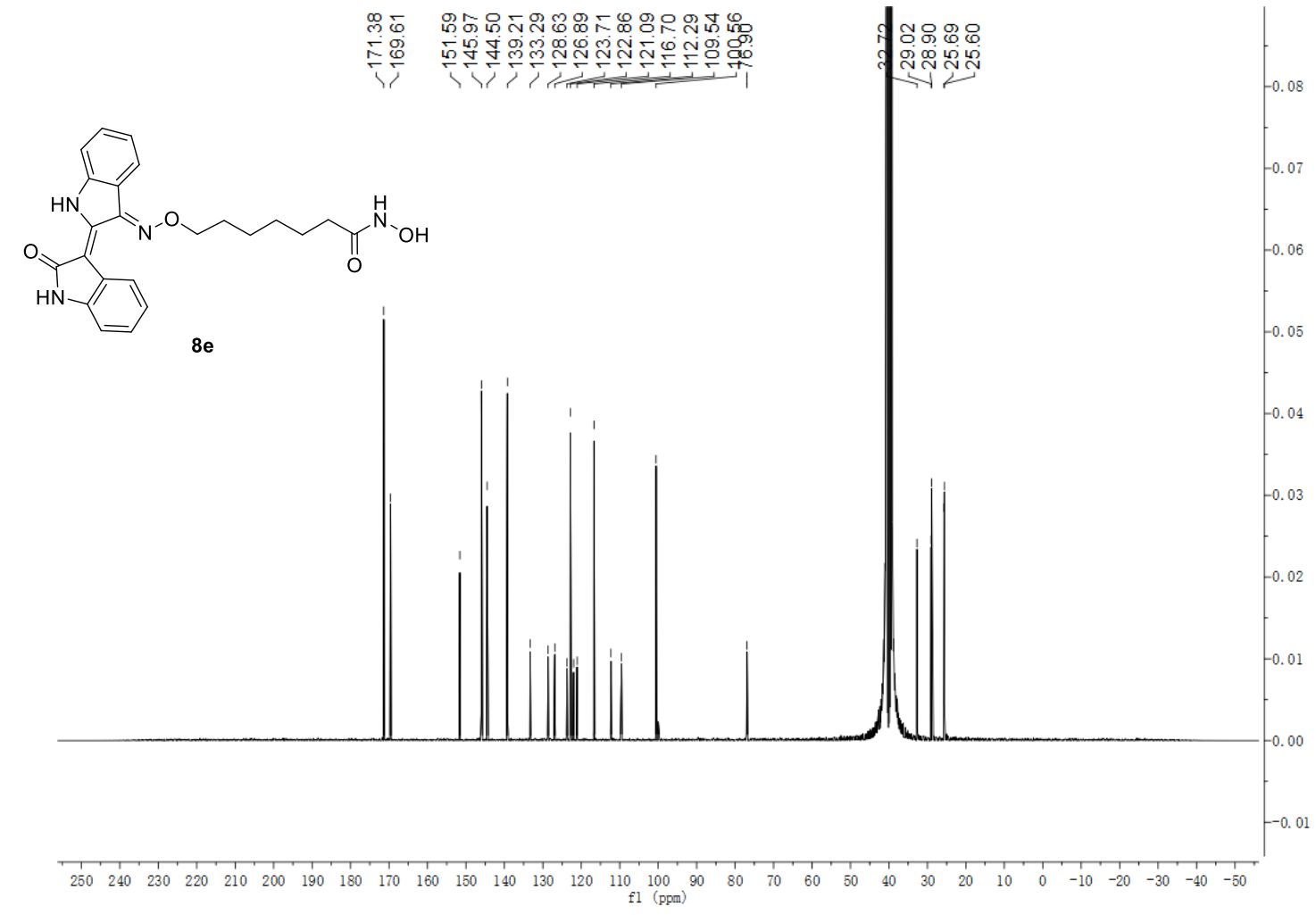




\section{${ }^{1} \mathrm{H}$ NMR Spectrum}

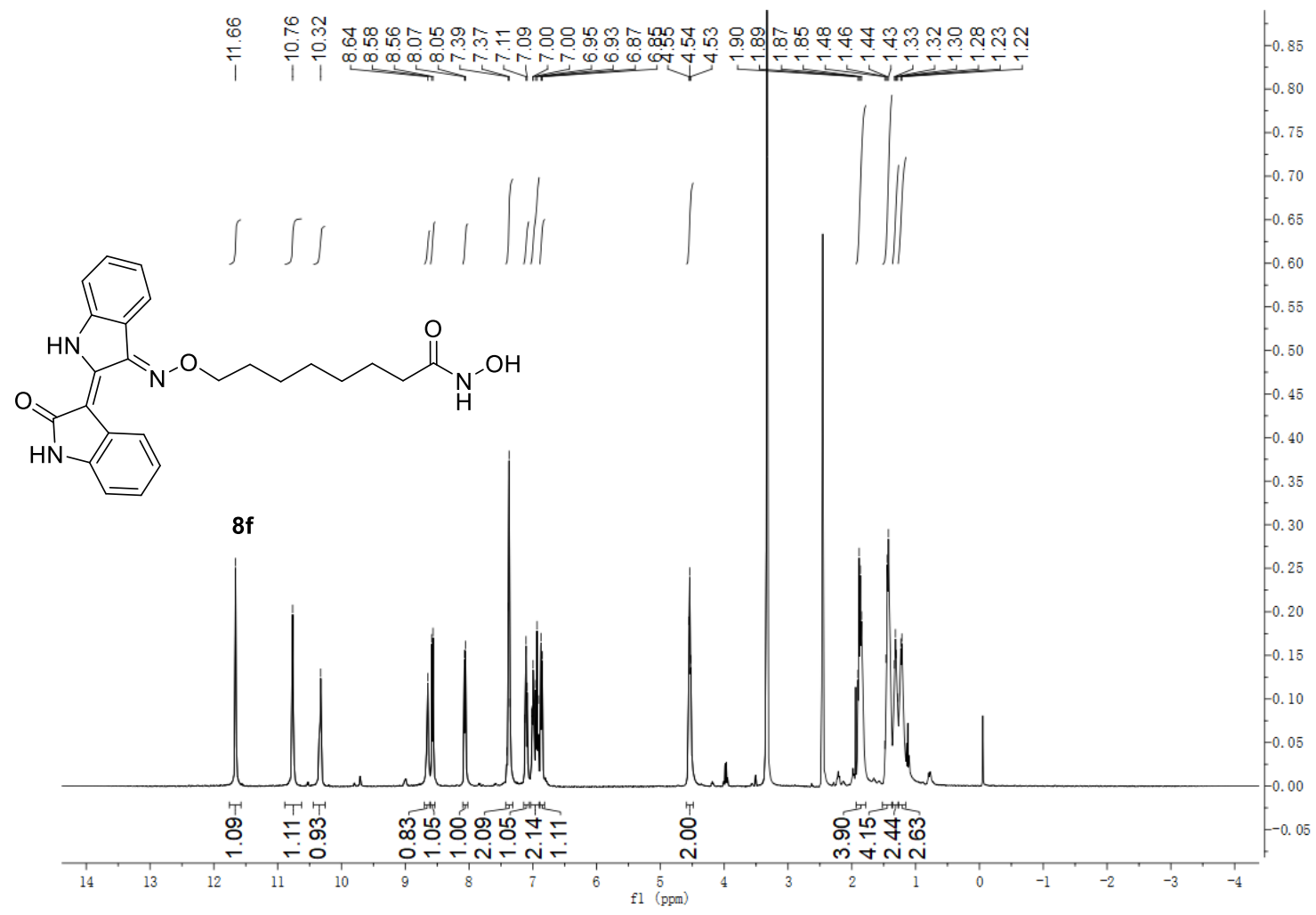

${ }^{13} \mathrm{C}$ NMR Spectrum

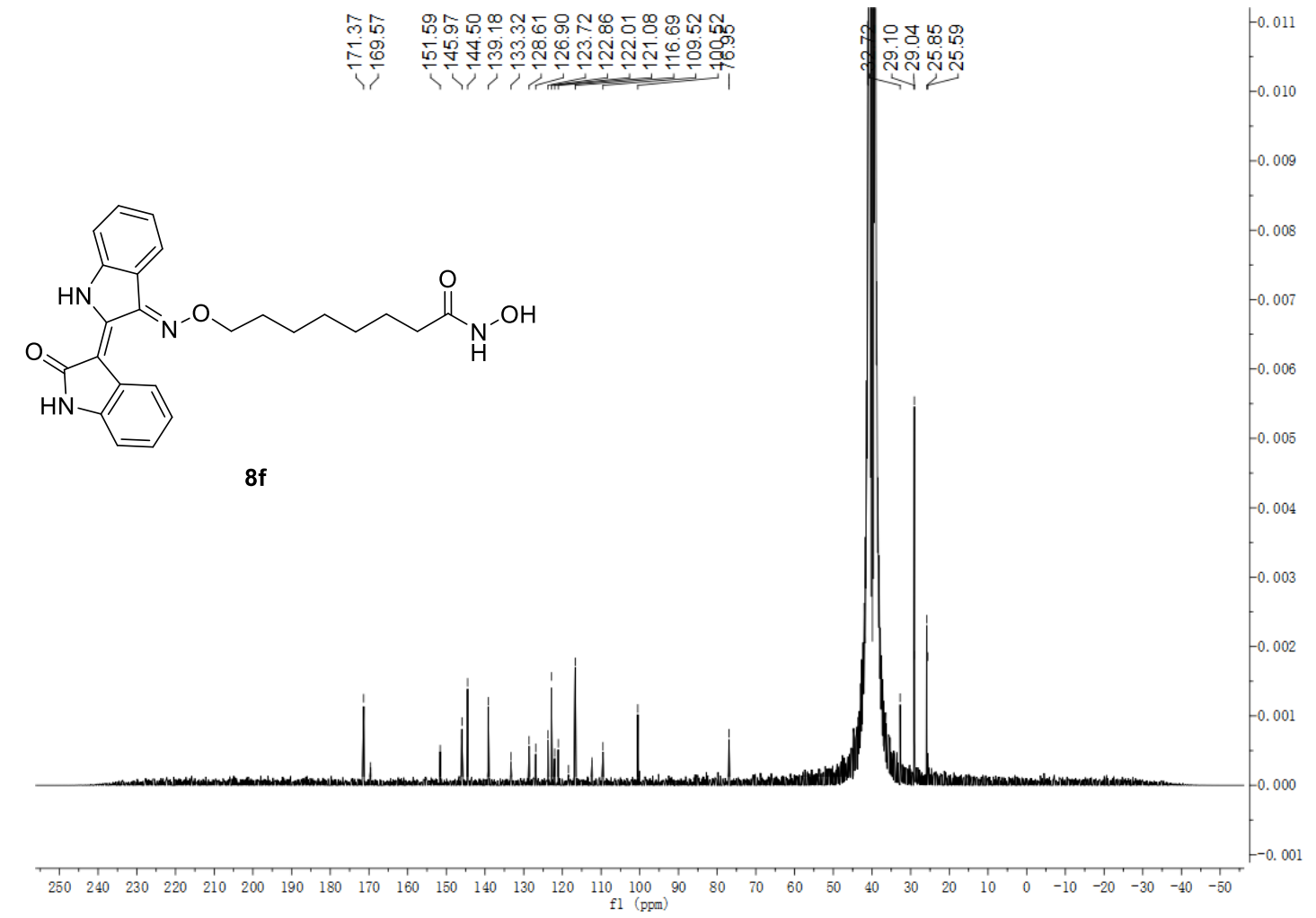




\section{${ }^{1} \mathrm{H}$ NMR Spectrum}

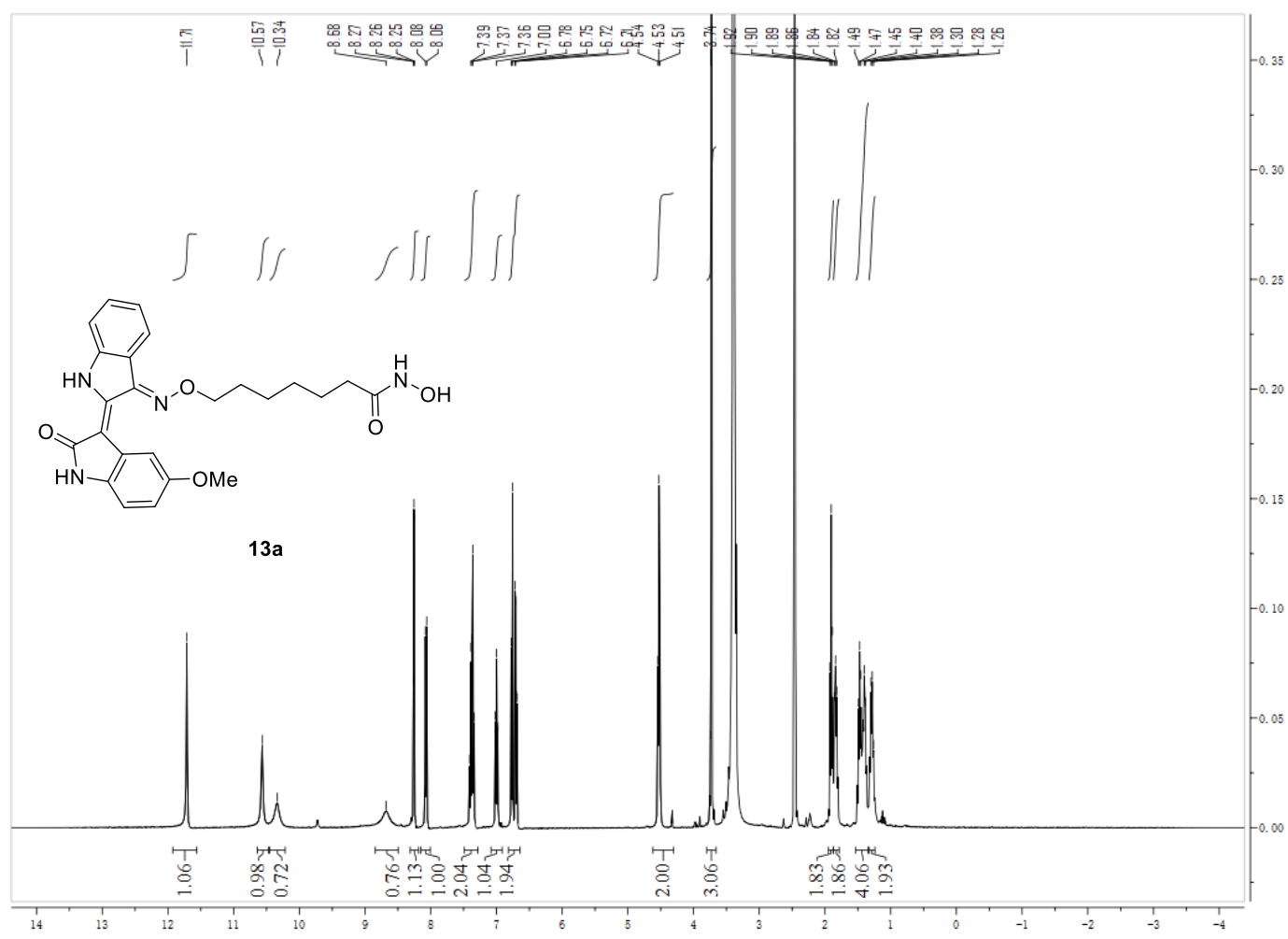

${ }^{13} \mathrm{C}$ NMR Spectrum

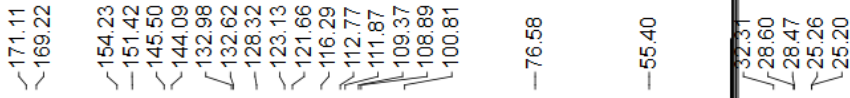

$-0.40$

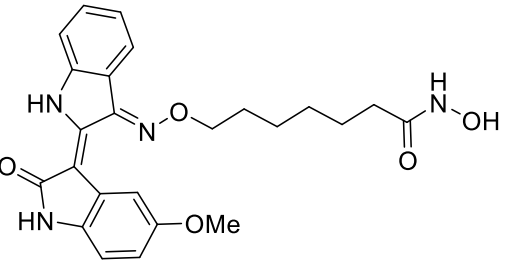

$13 a$ 
${ }^{1} \mathrm{H}$ NMR Spectrum

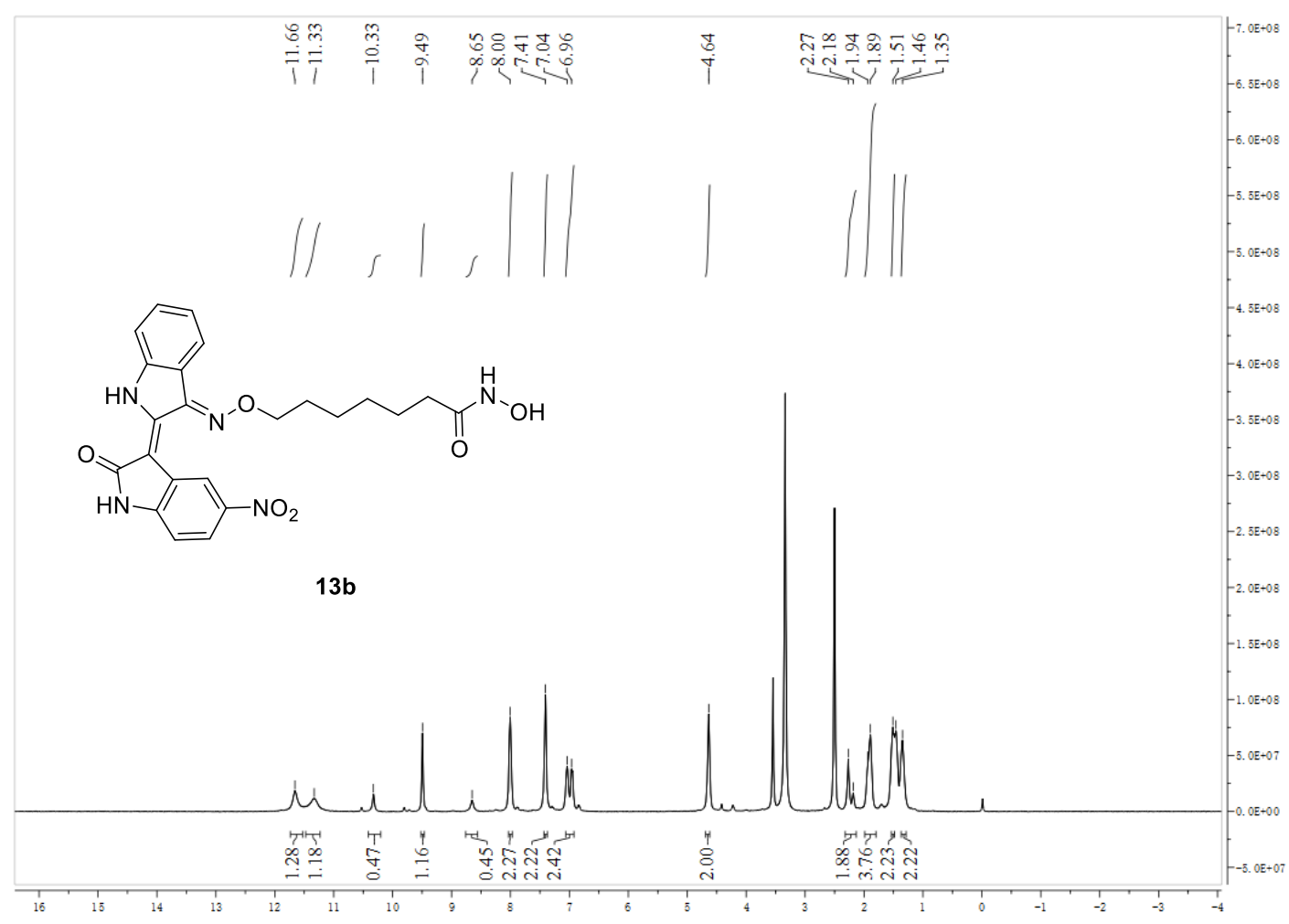

${ }^{13} \mathrm{C}$ NMR Spectrum

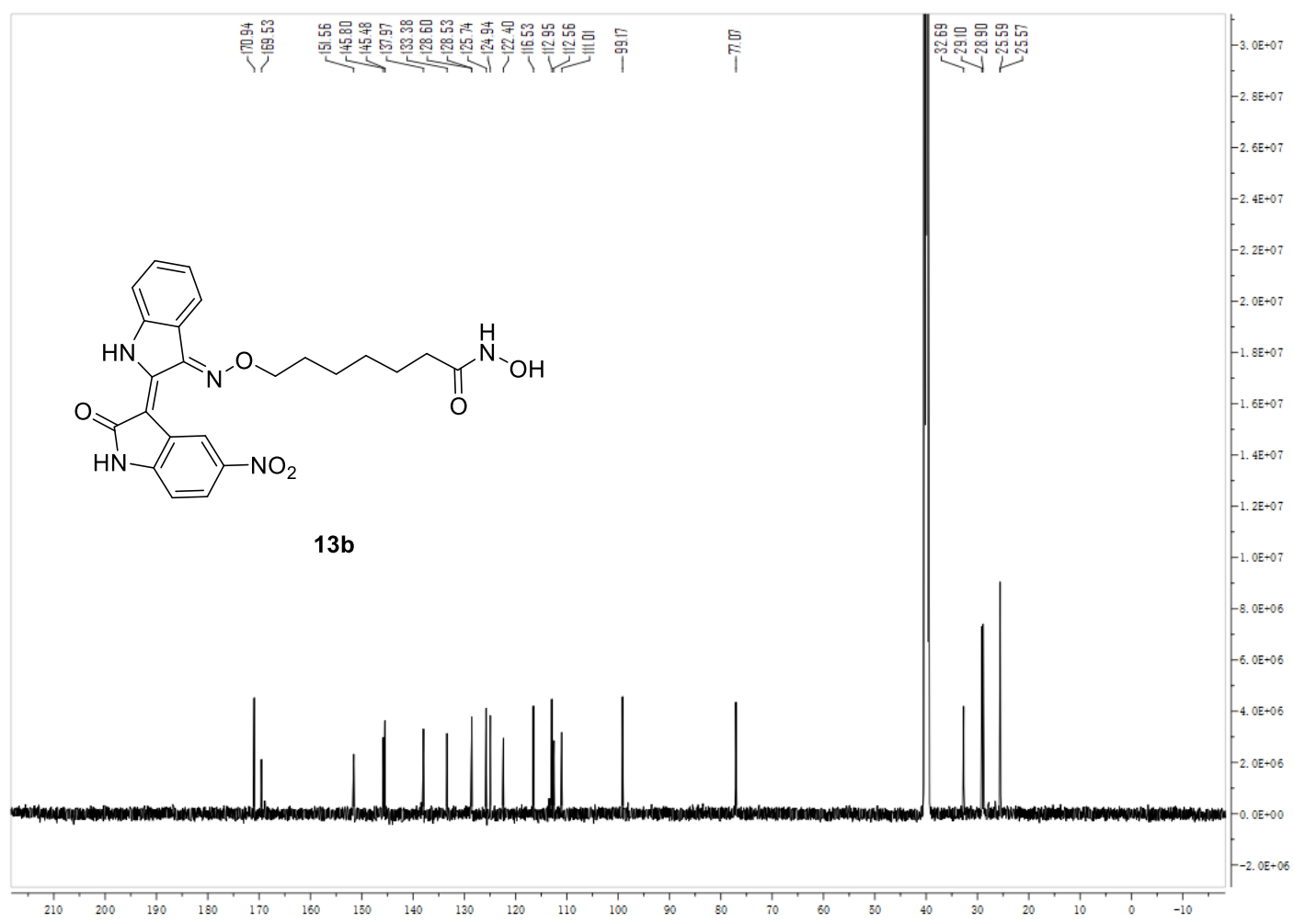




\section{${ }^{1} \mathrm{H}$ NMR Spectrum}

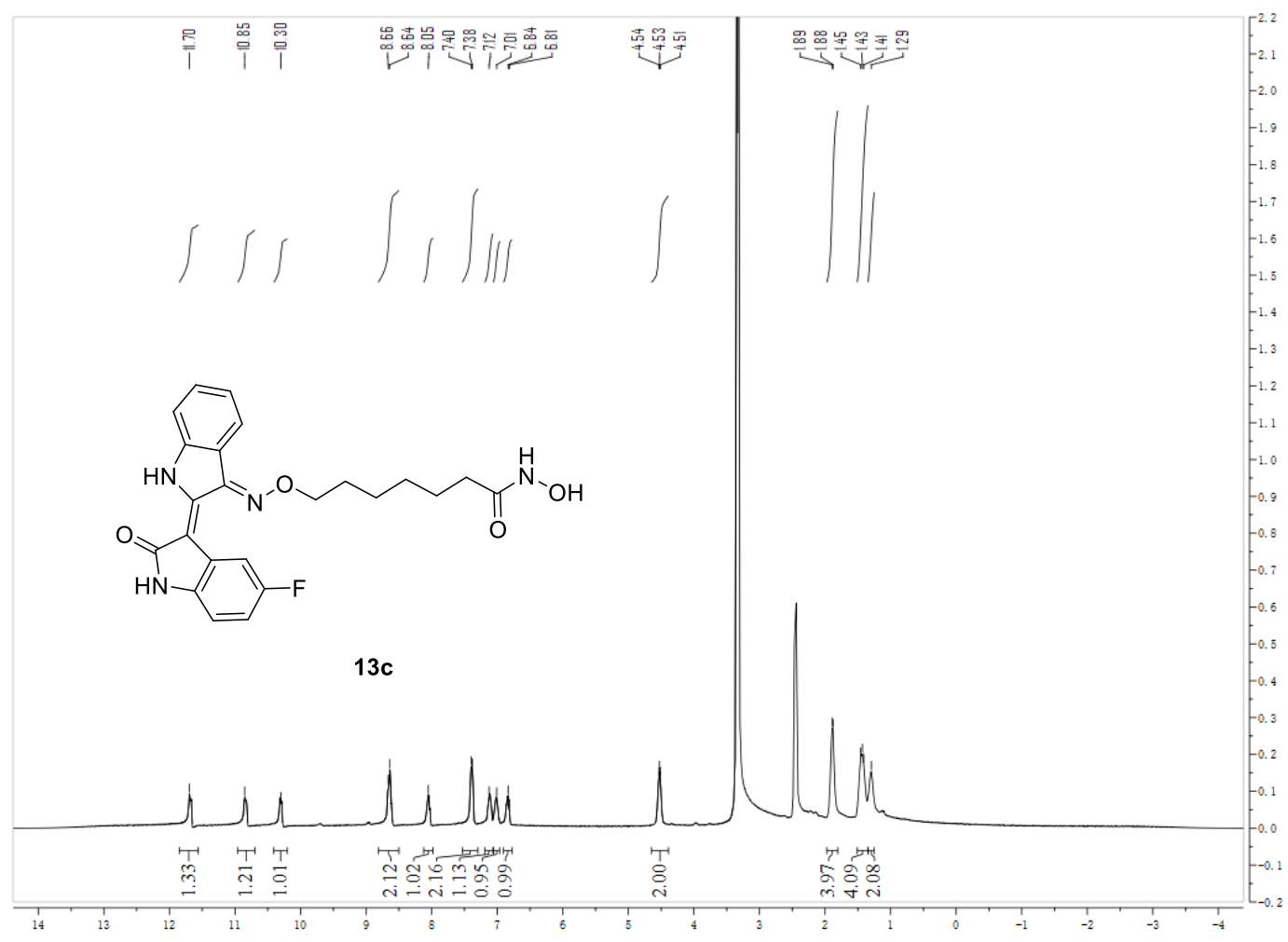

${ }^{13} \mathrm{C}$ NMR Spectrum

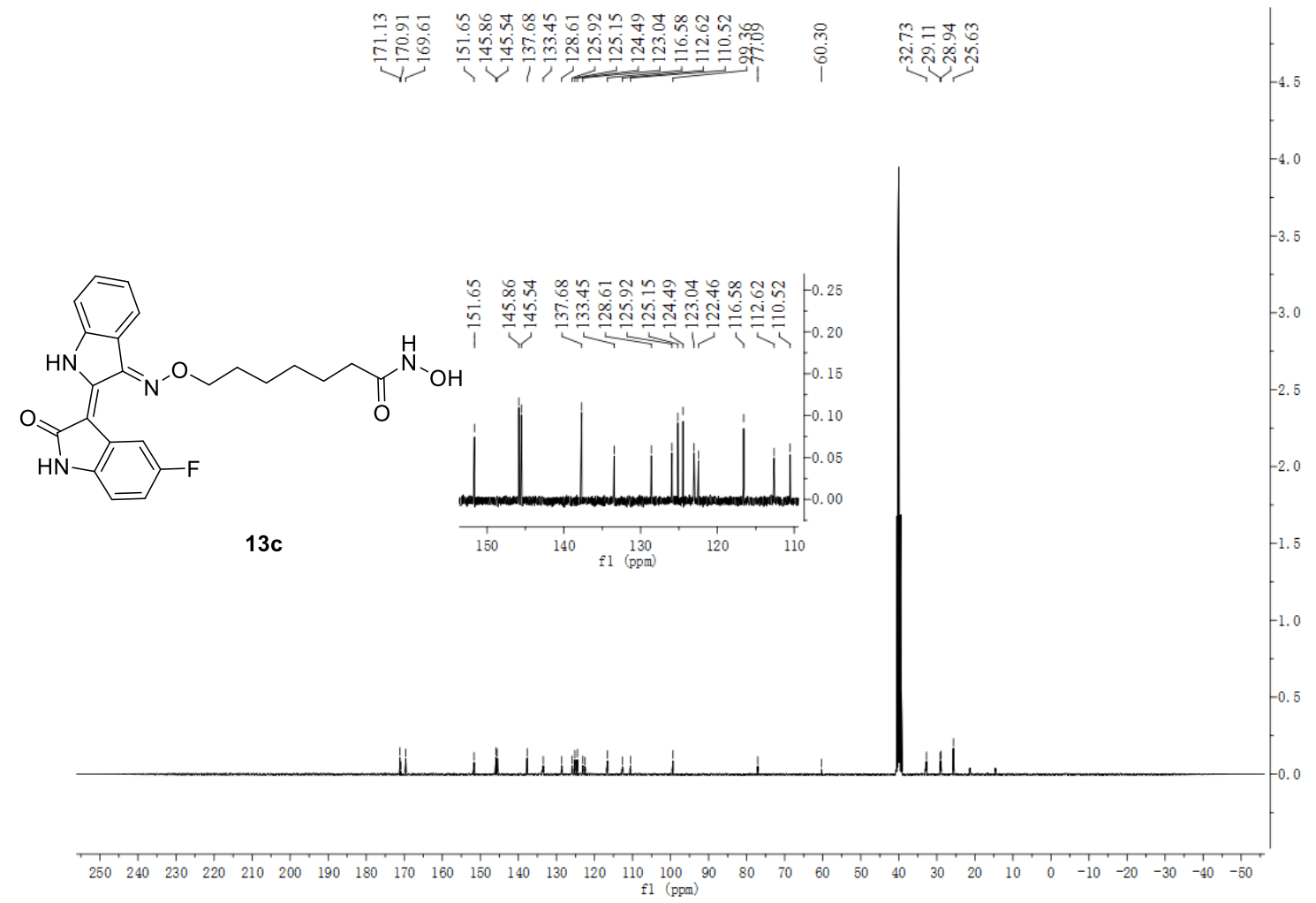


${ }^{1} \mathrm{H}$ NMR Spectrum

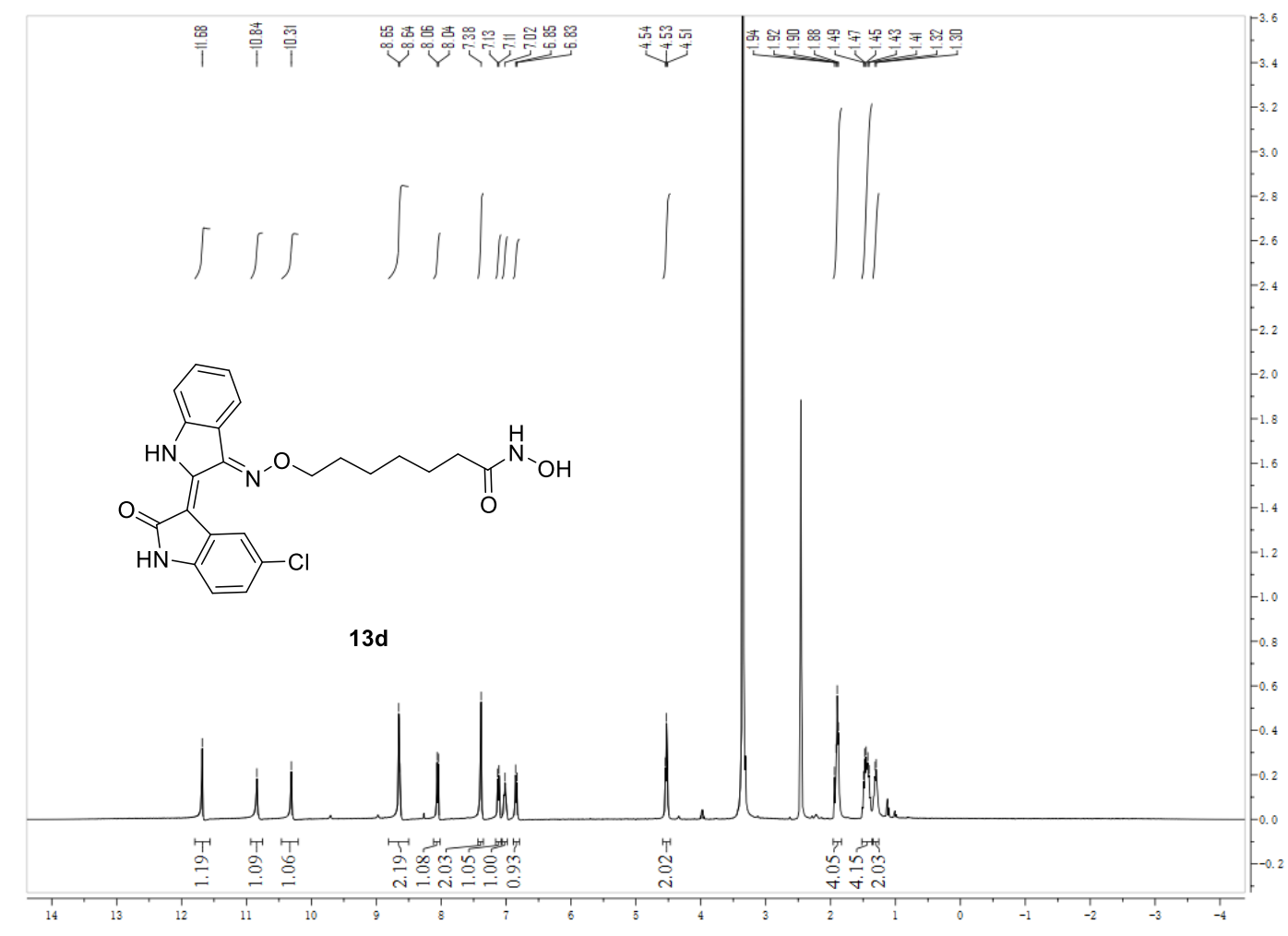

${ }^{13} \mathrm{C}$ NMR Spectrum

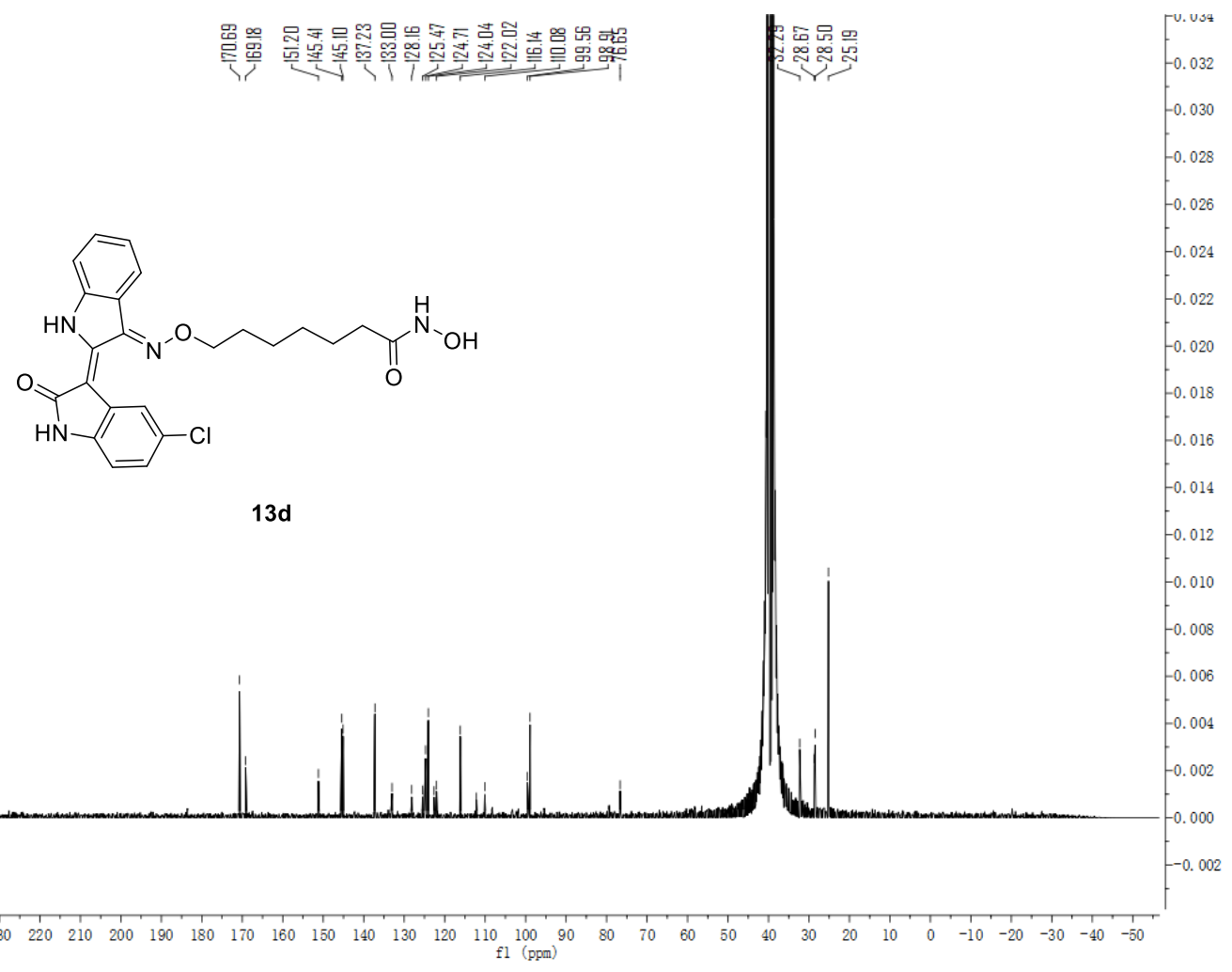


${ }^{1} \mathrm{H}$ NMR Spectrum

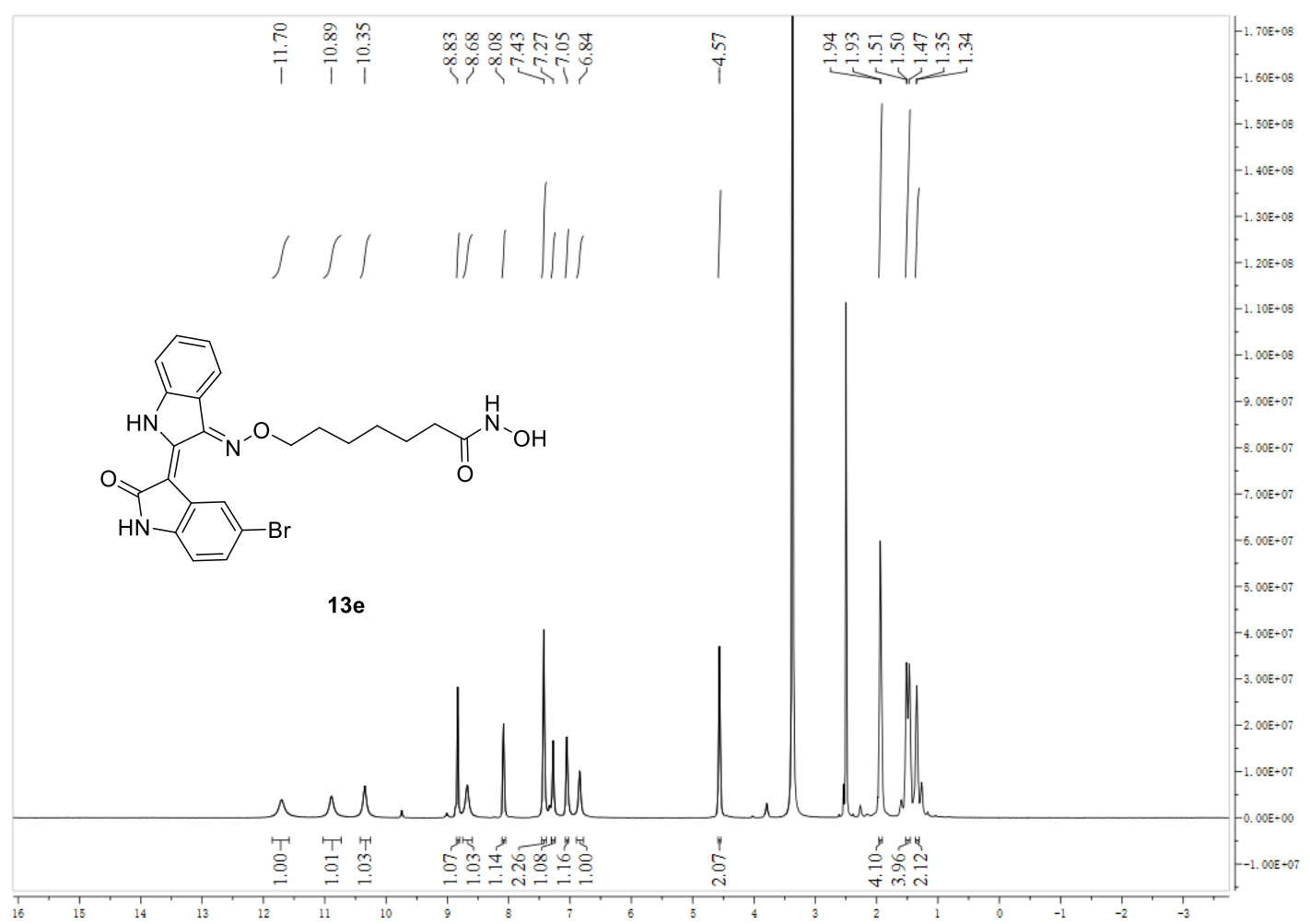

${ }^{13} \mathrm{C}$ NMR Spectrum

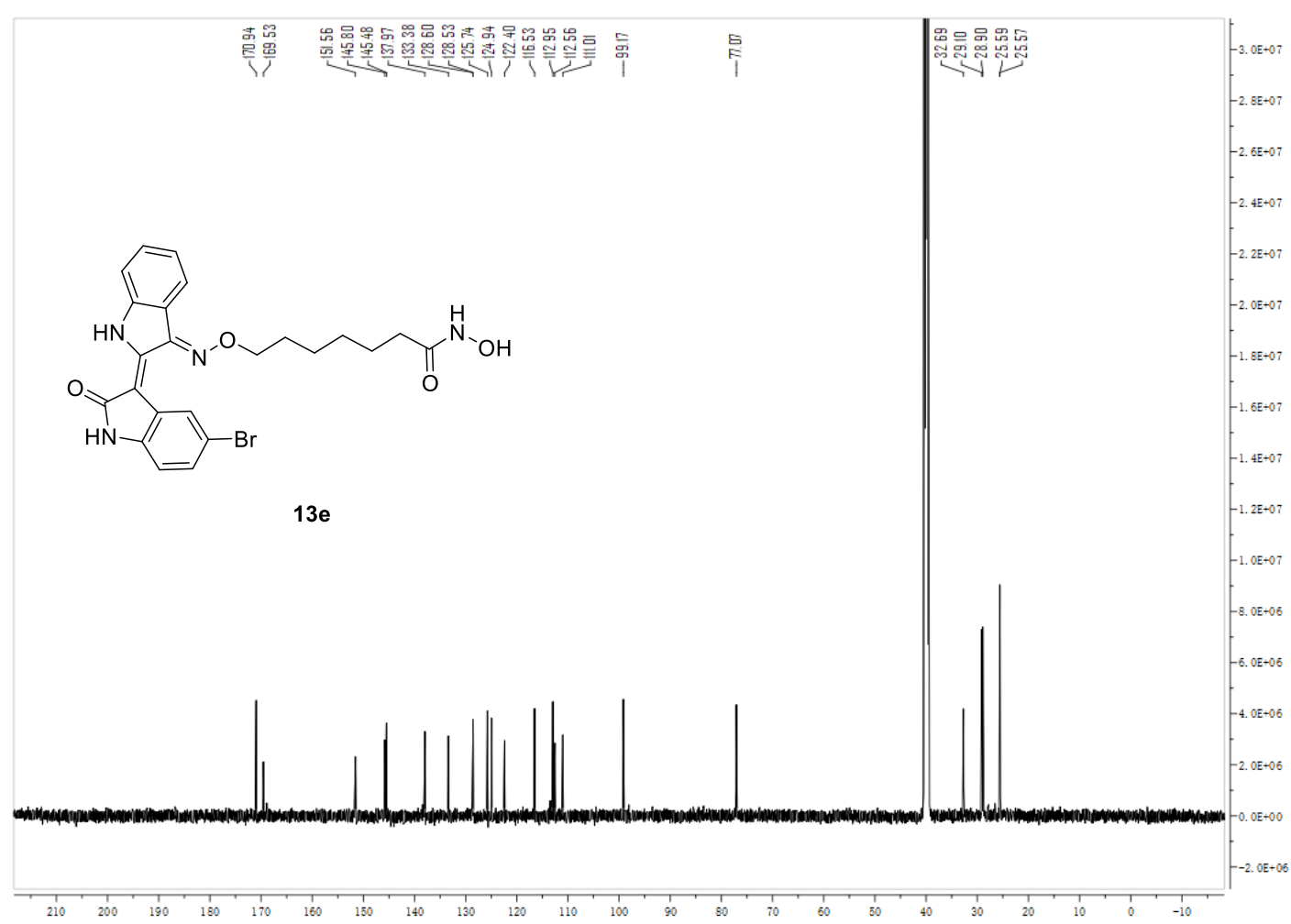


${ }^{1} \mathrm{H}$ NMR Spectrum

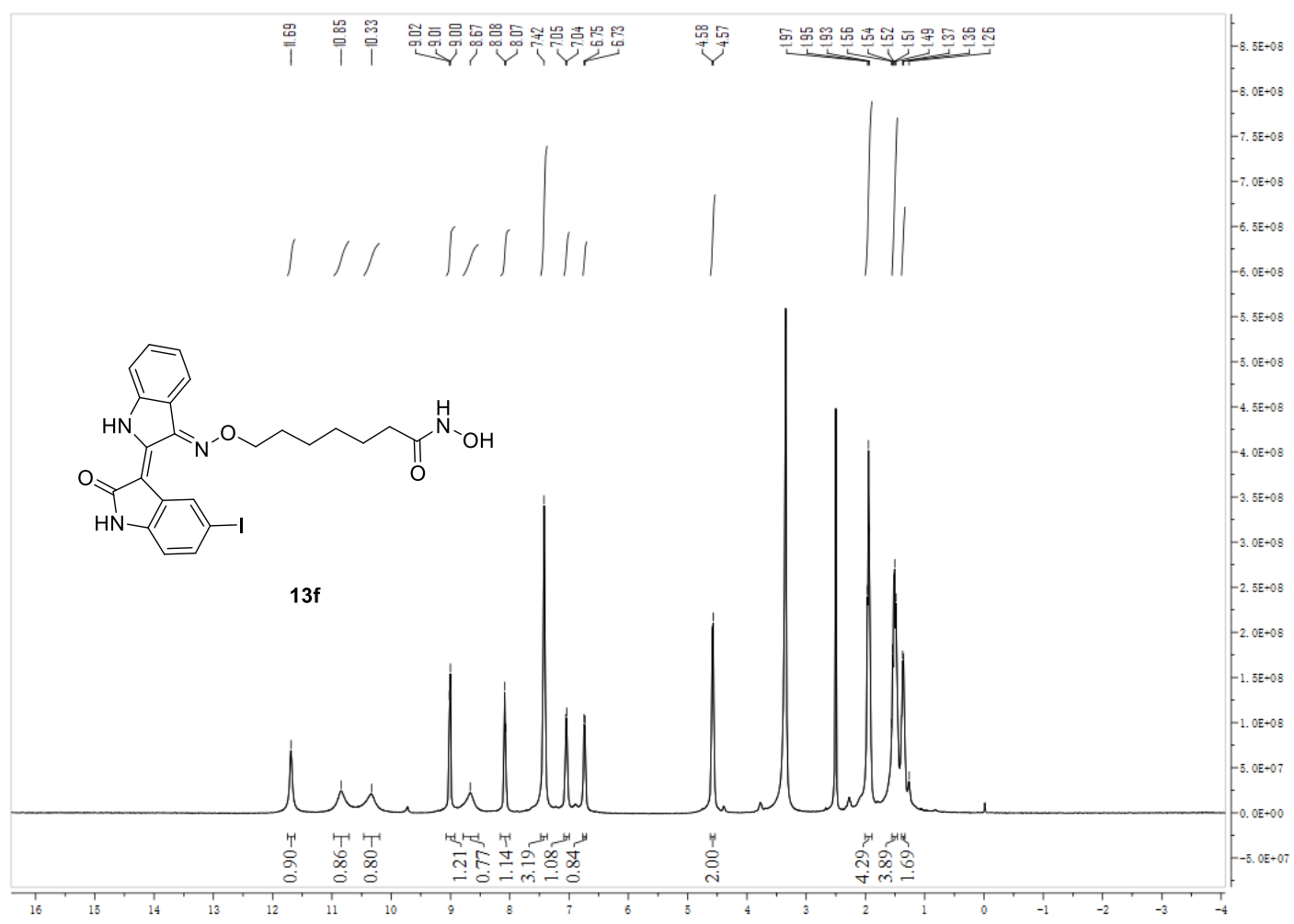

${ }^{13} \mathrm{C}$ NMR Spectrum

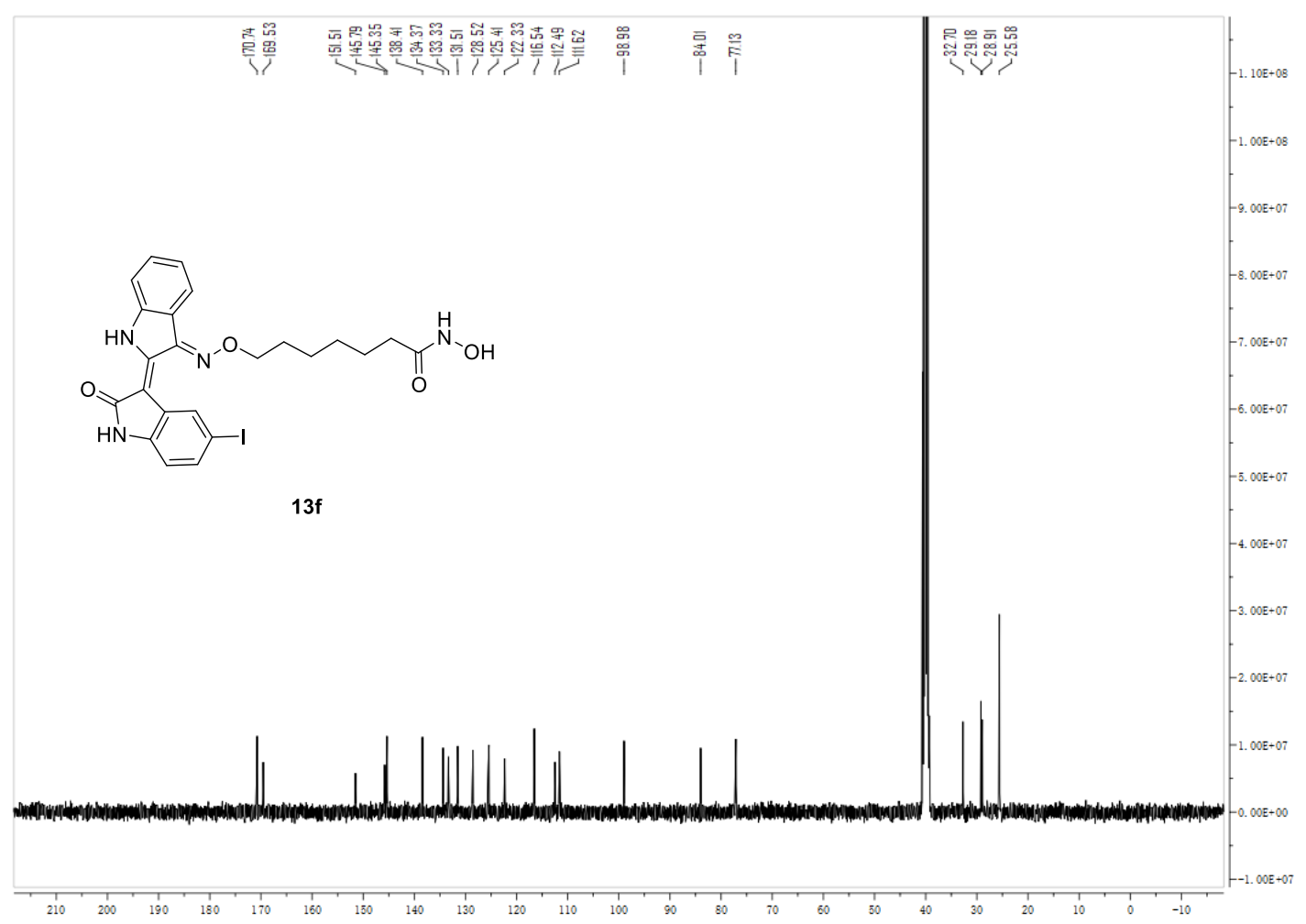




\section{${ }^{1} \mathrm{H}$ NMR Spectrum}

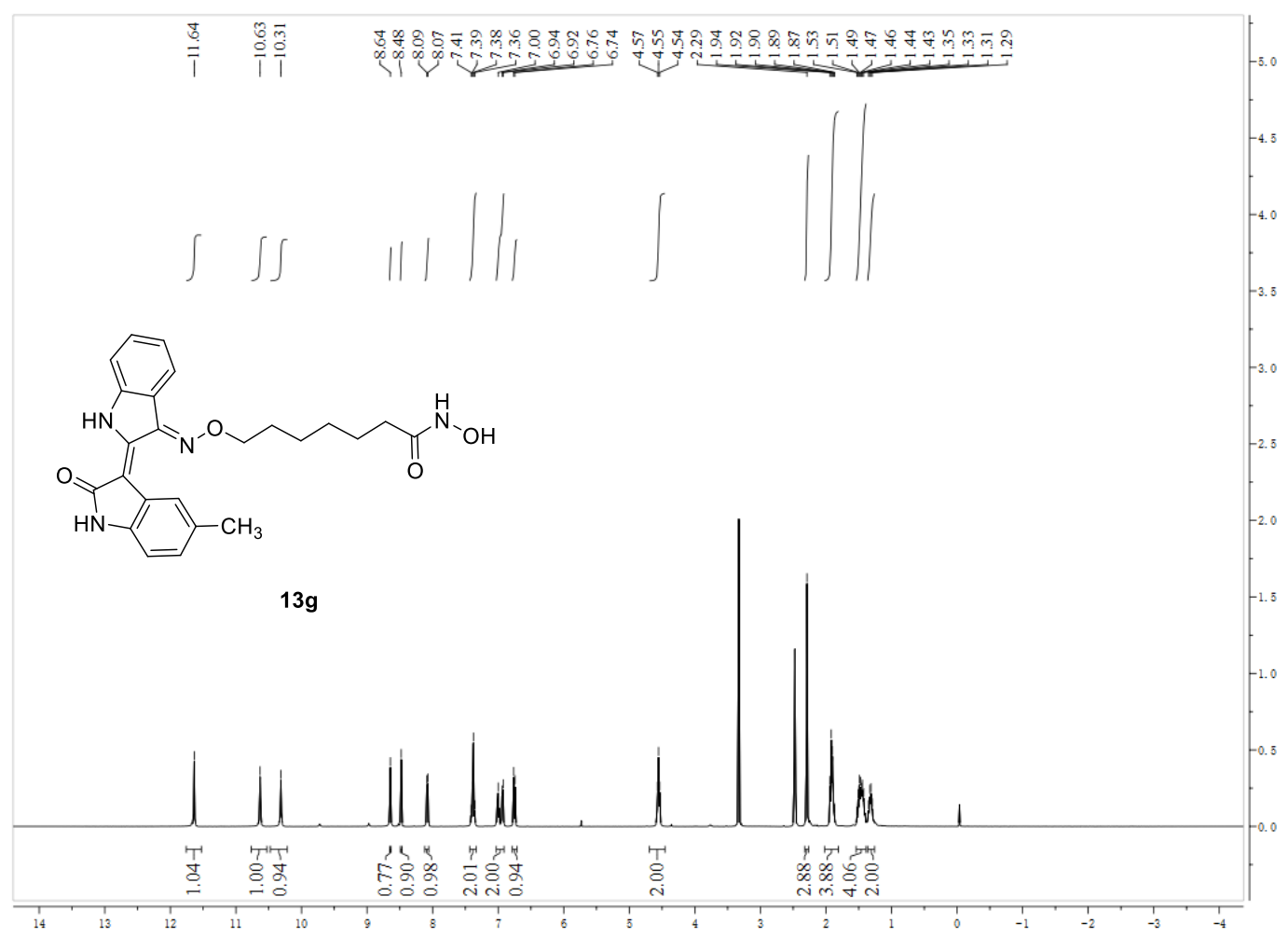

${ }^{13} \mathrm{C}$ NMR Spectrum

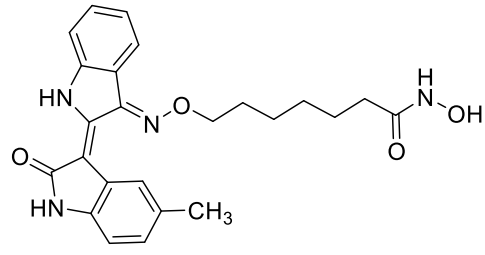

$13 \mathrm{~g}$

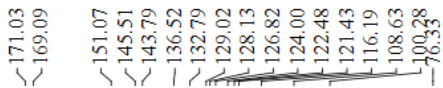
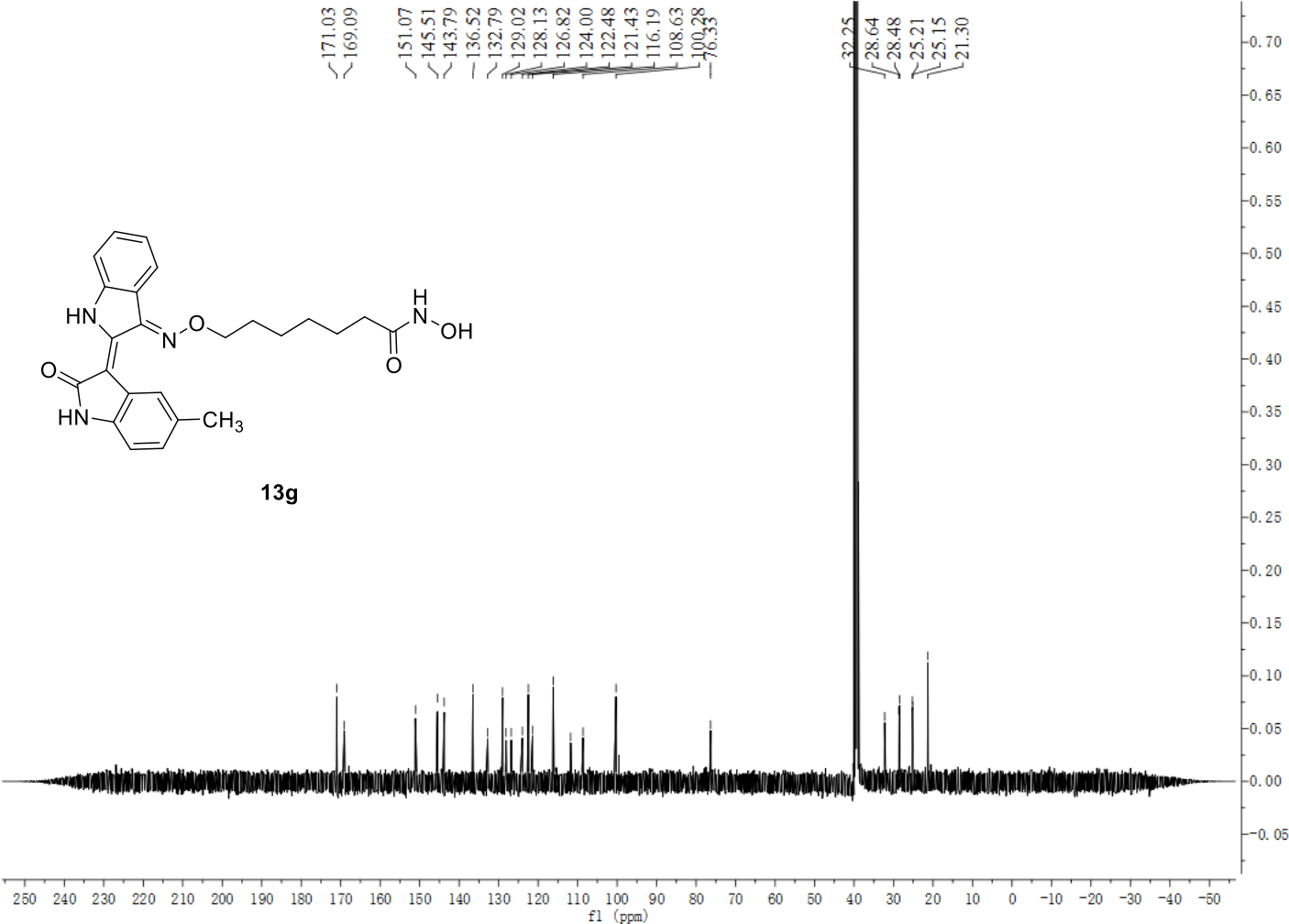
${ }^{1} \mathrm{H}$ NMR Spectrum

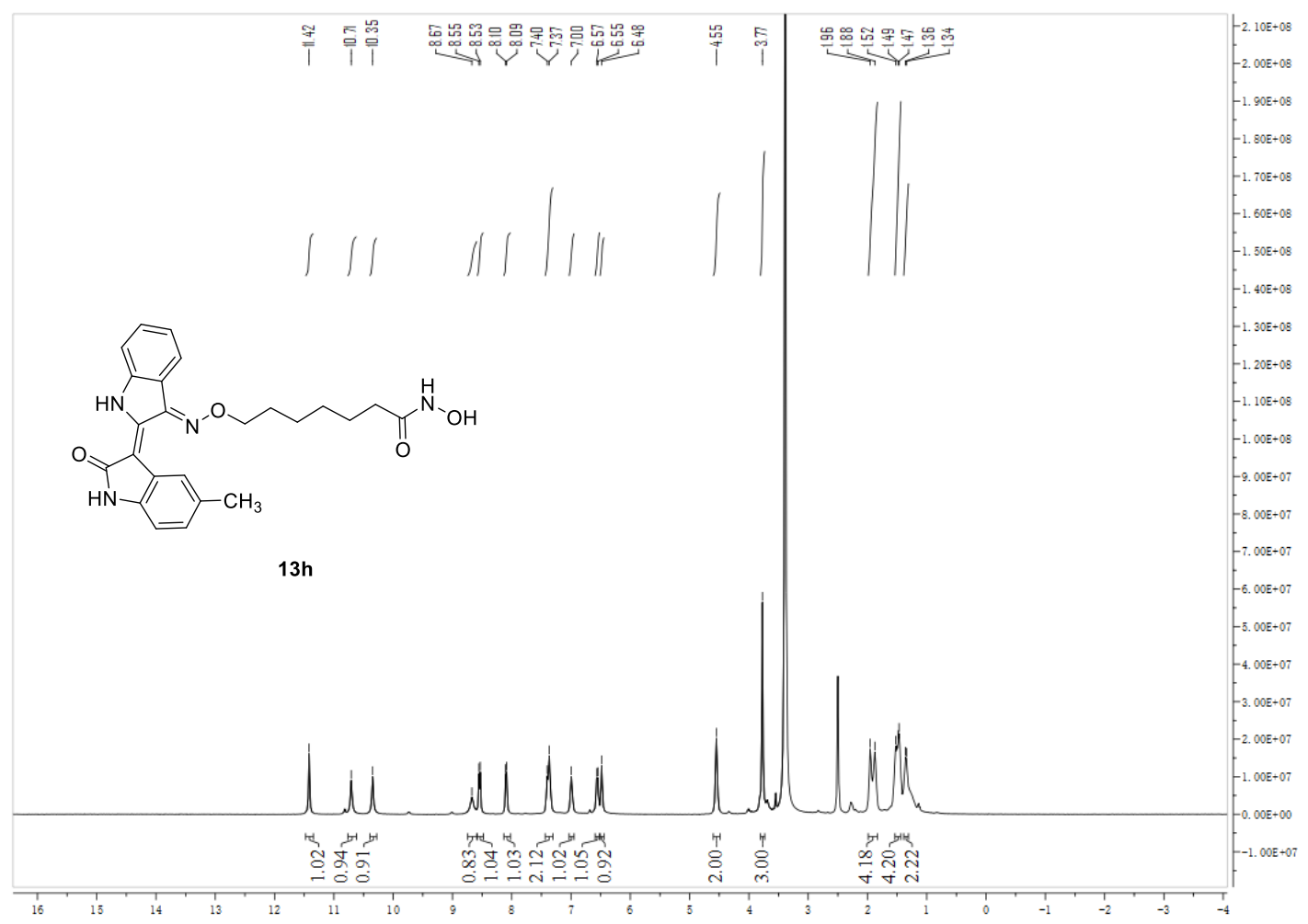

${ }^{13} \mathrm{C}$ NMR Spectrum

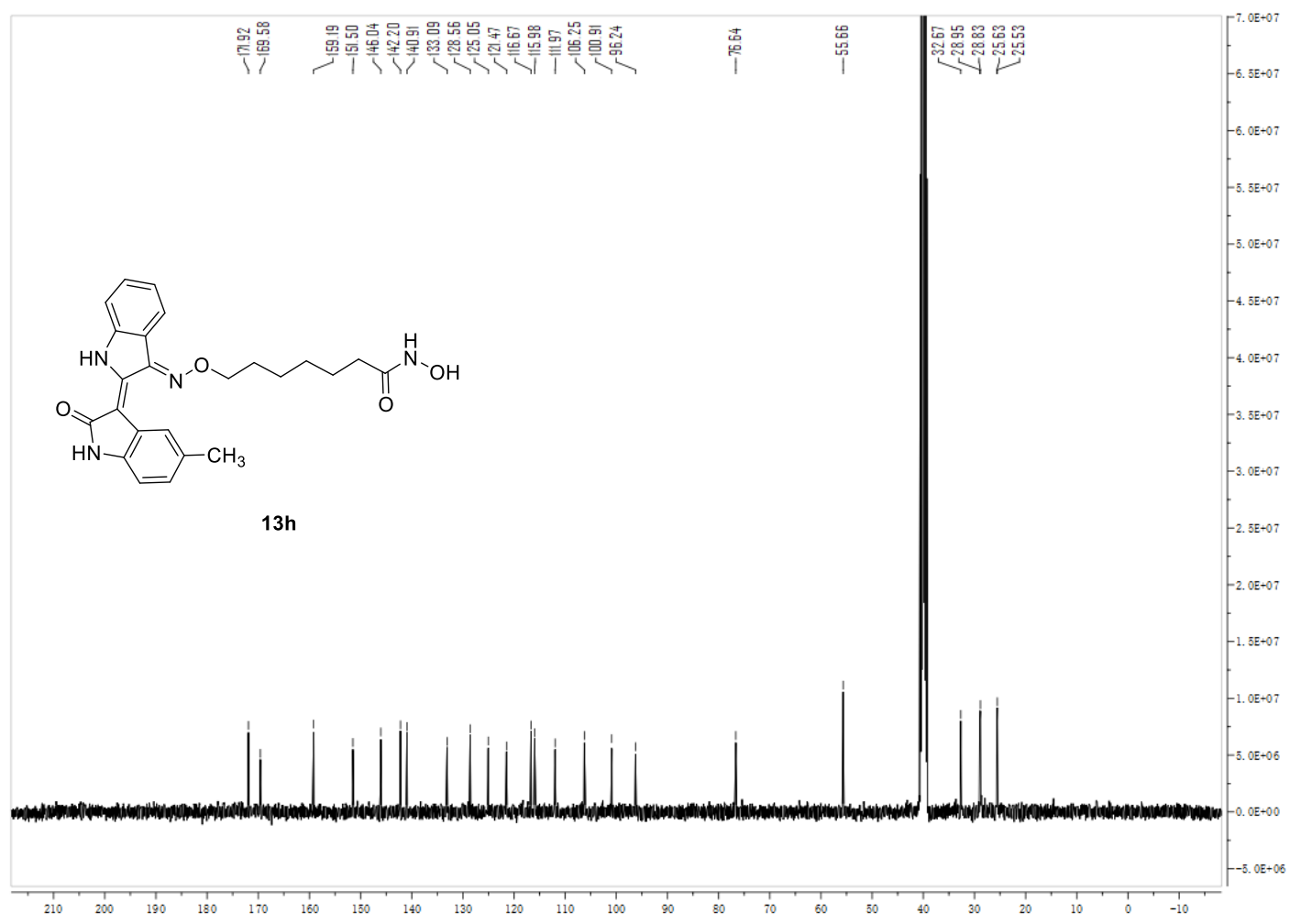


${ }^{1} \mathrm{H}$ NMR Spectrum

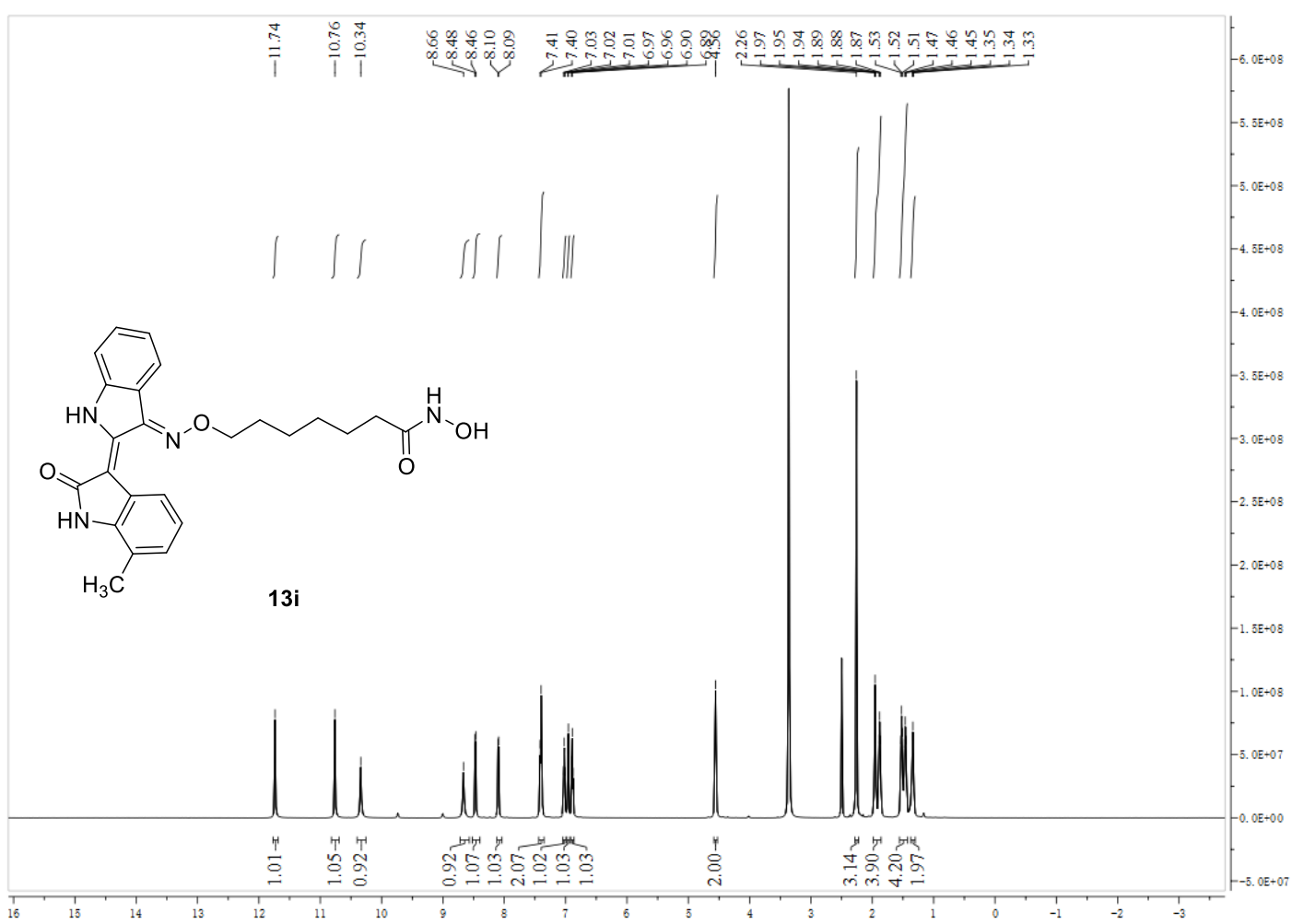

${ }^{13} \mathrm{C}$ NMR Spectrum

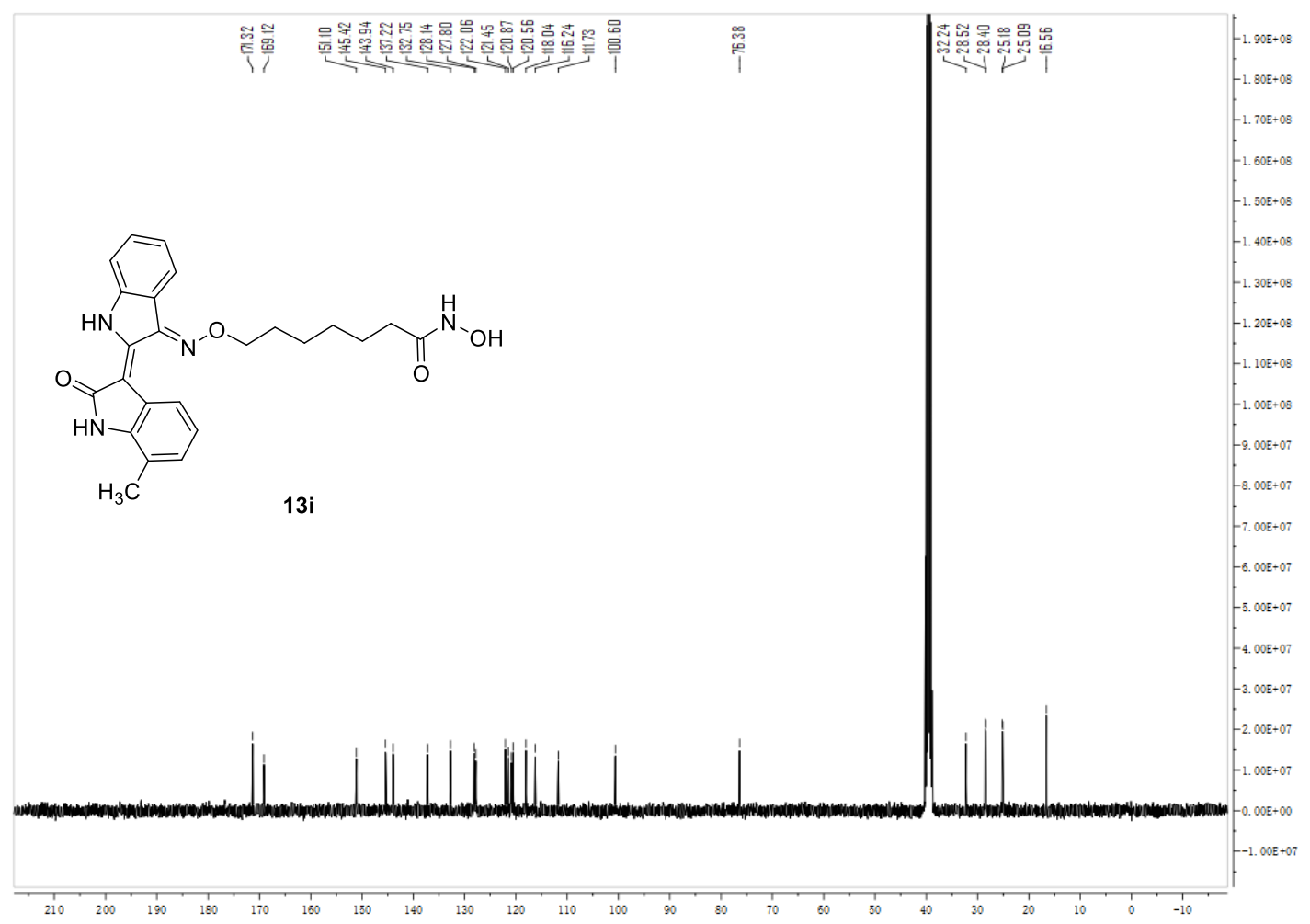


${ }^{1} \mathrm{H}$ NMR Spectrum

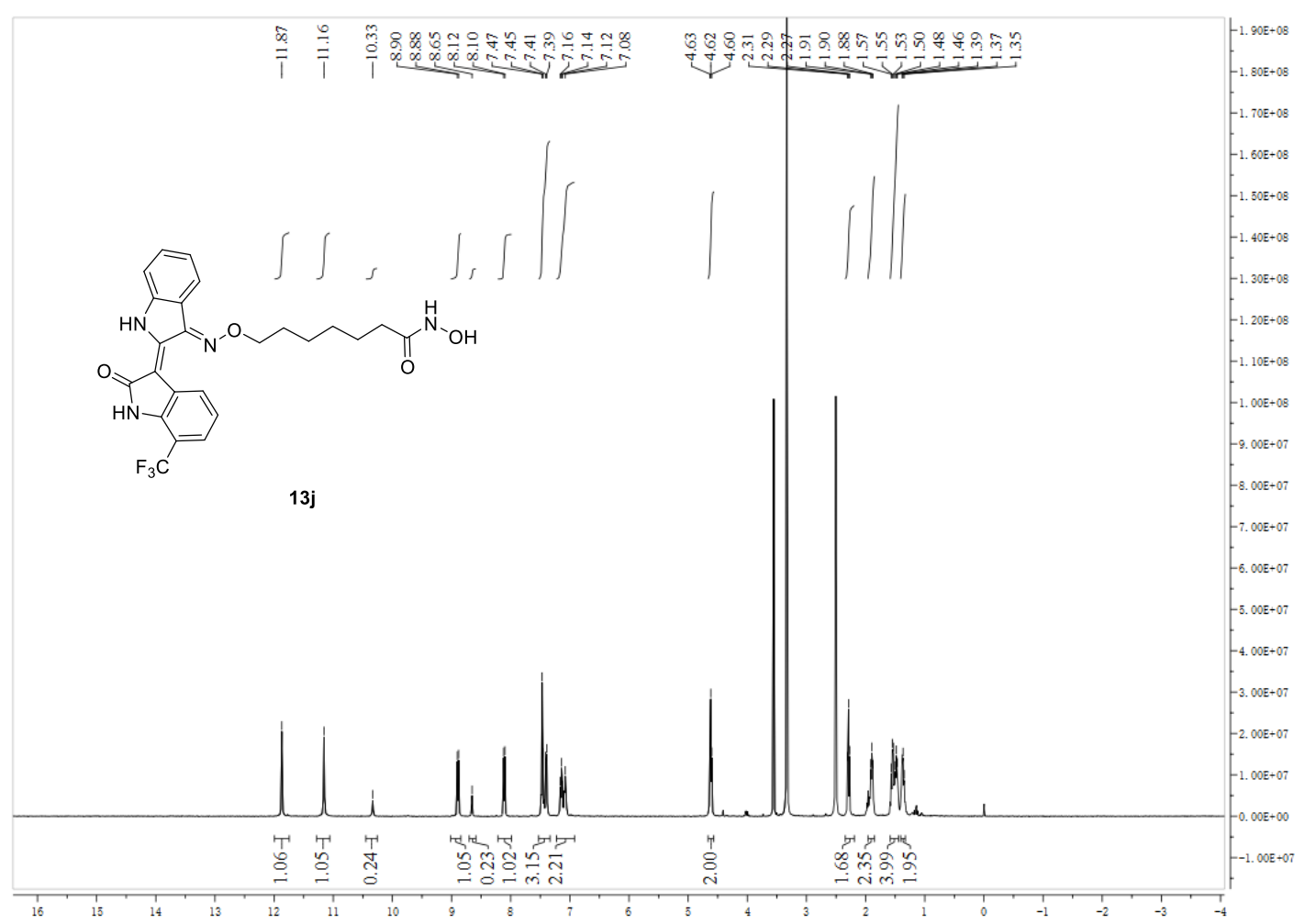

${ }^{13} \mathrm{C}$ NMR Spectrum

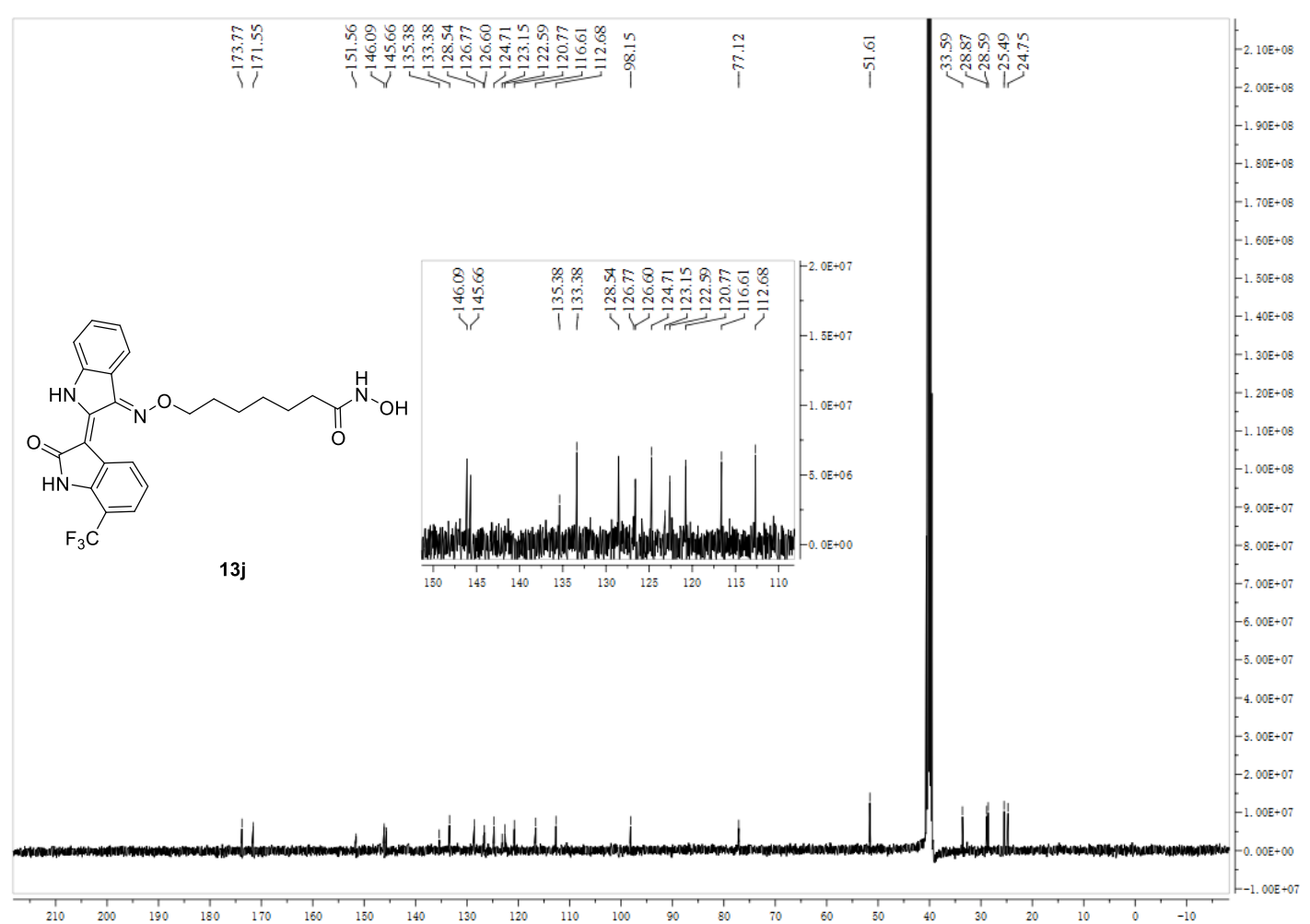




\section{${ }^{1} \mathrm{H}$ NMR Spectrum}

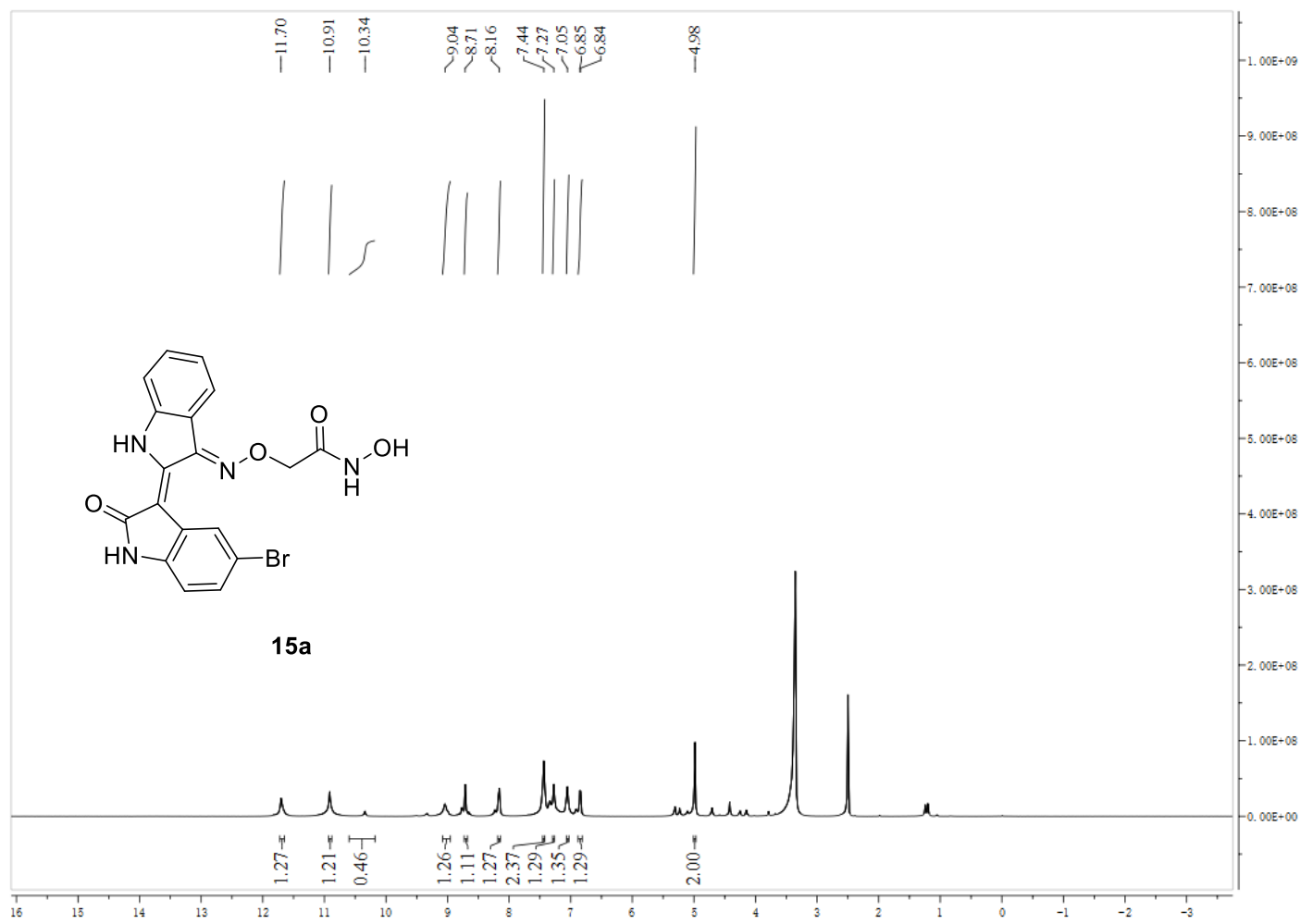

${ }^{13} \mathrm{C}$ NMR Spectrum

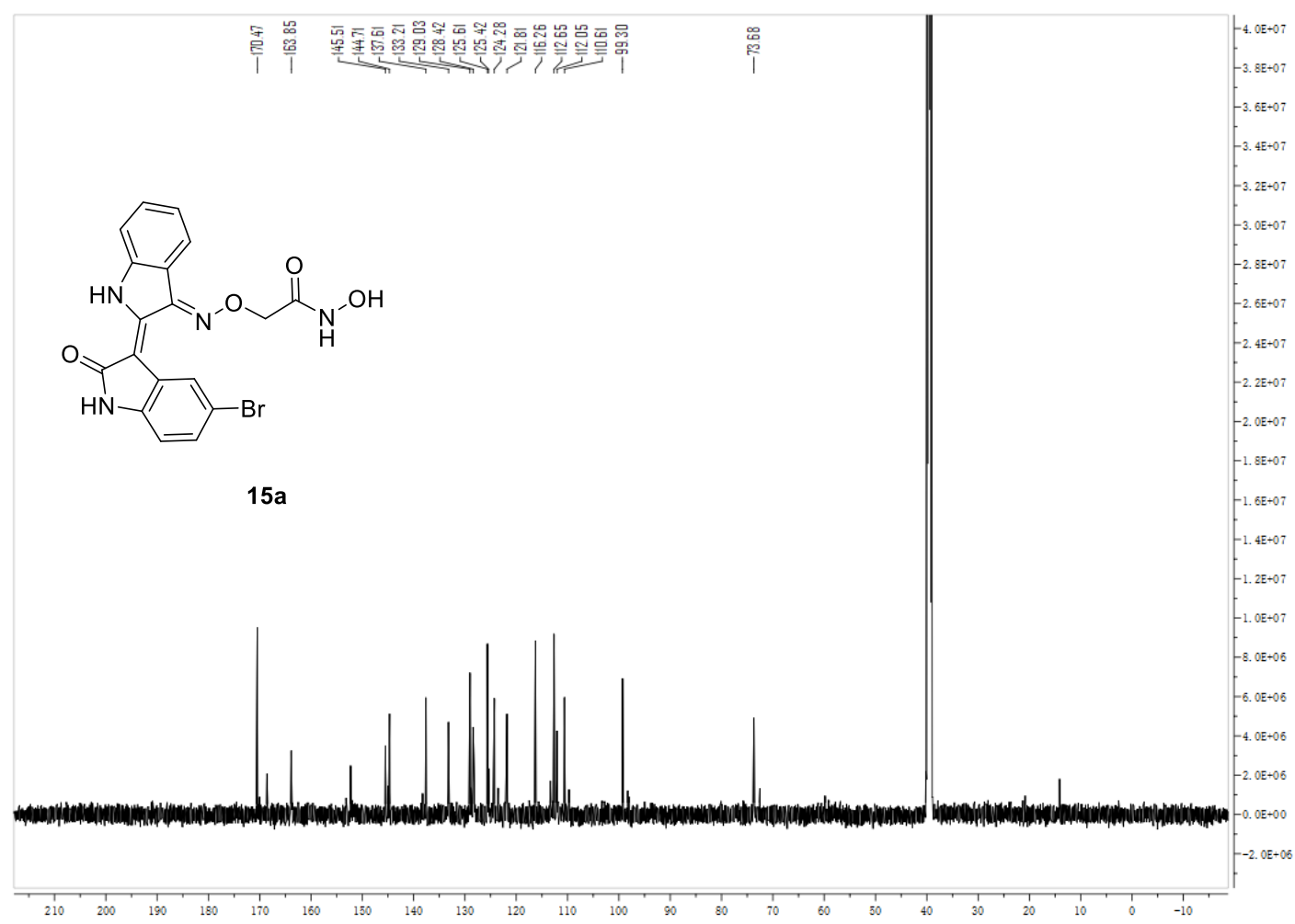


${ }^{1} \mathrm{H}$ NMR Spectrum

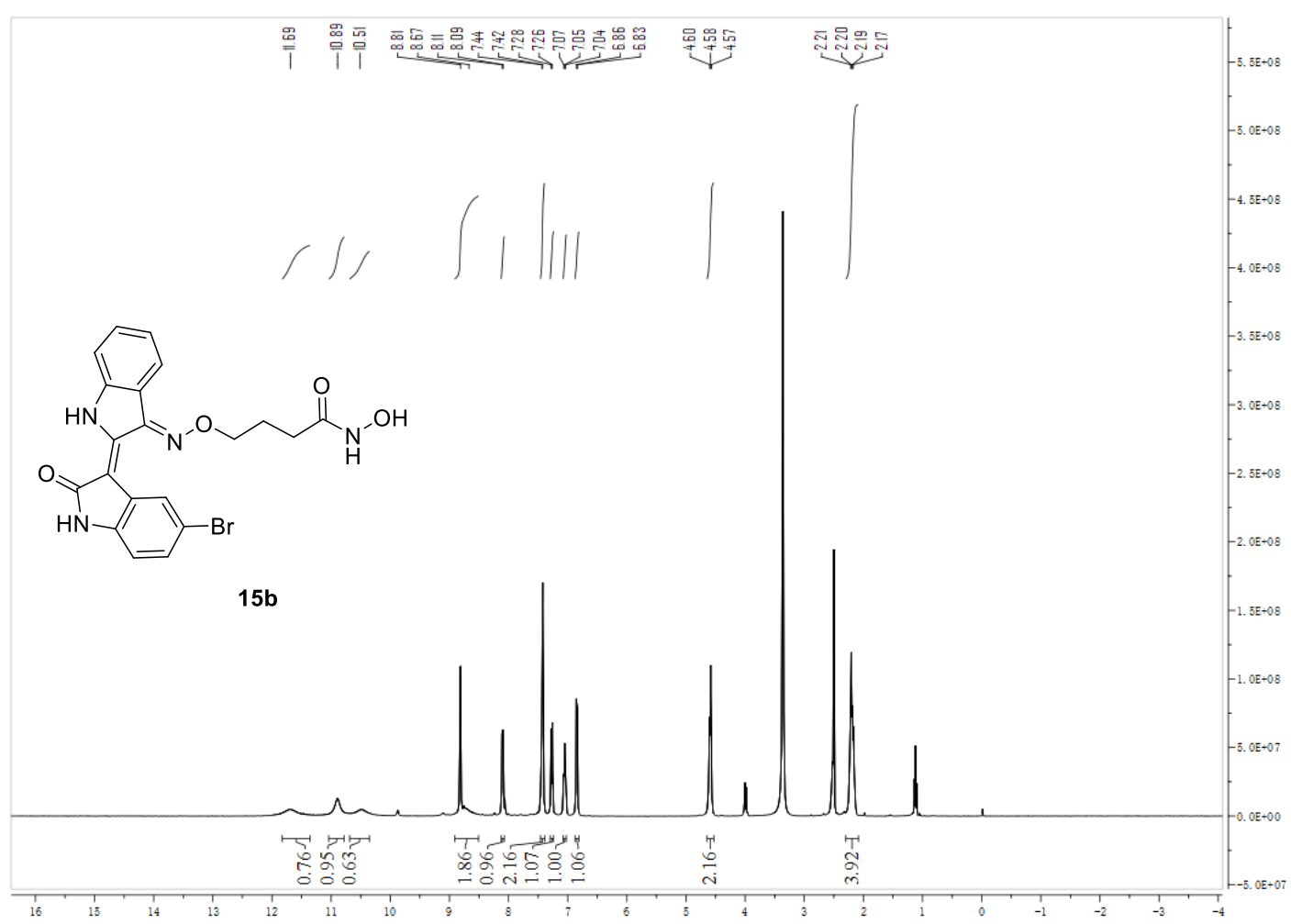

${ }^{13} \mathrm{C}$ NMR Spectrum

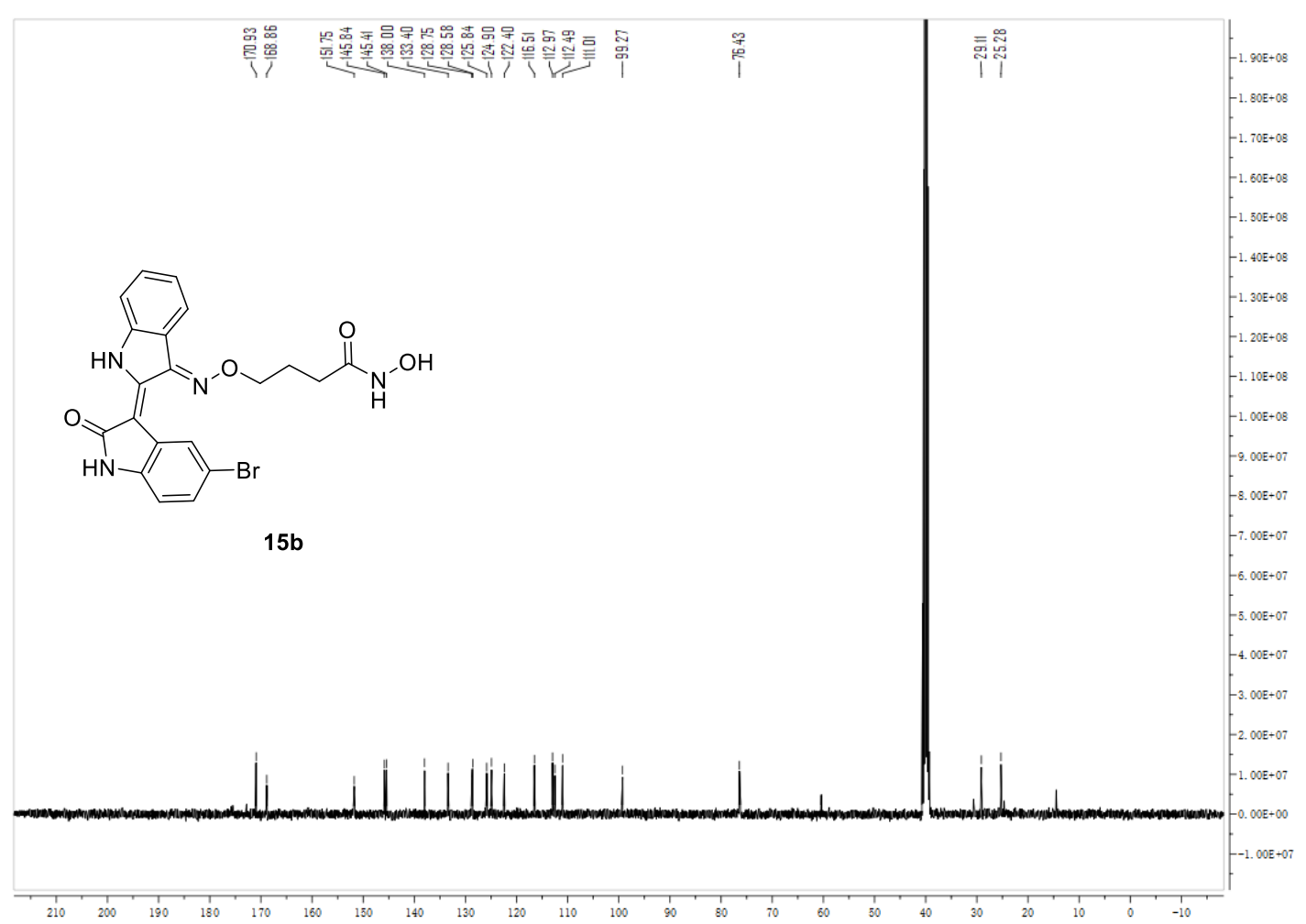




\section{${ }^{1} \mathrm{H}$ NMR Spectrum}

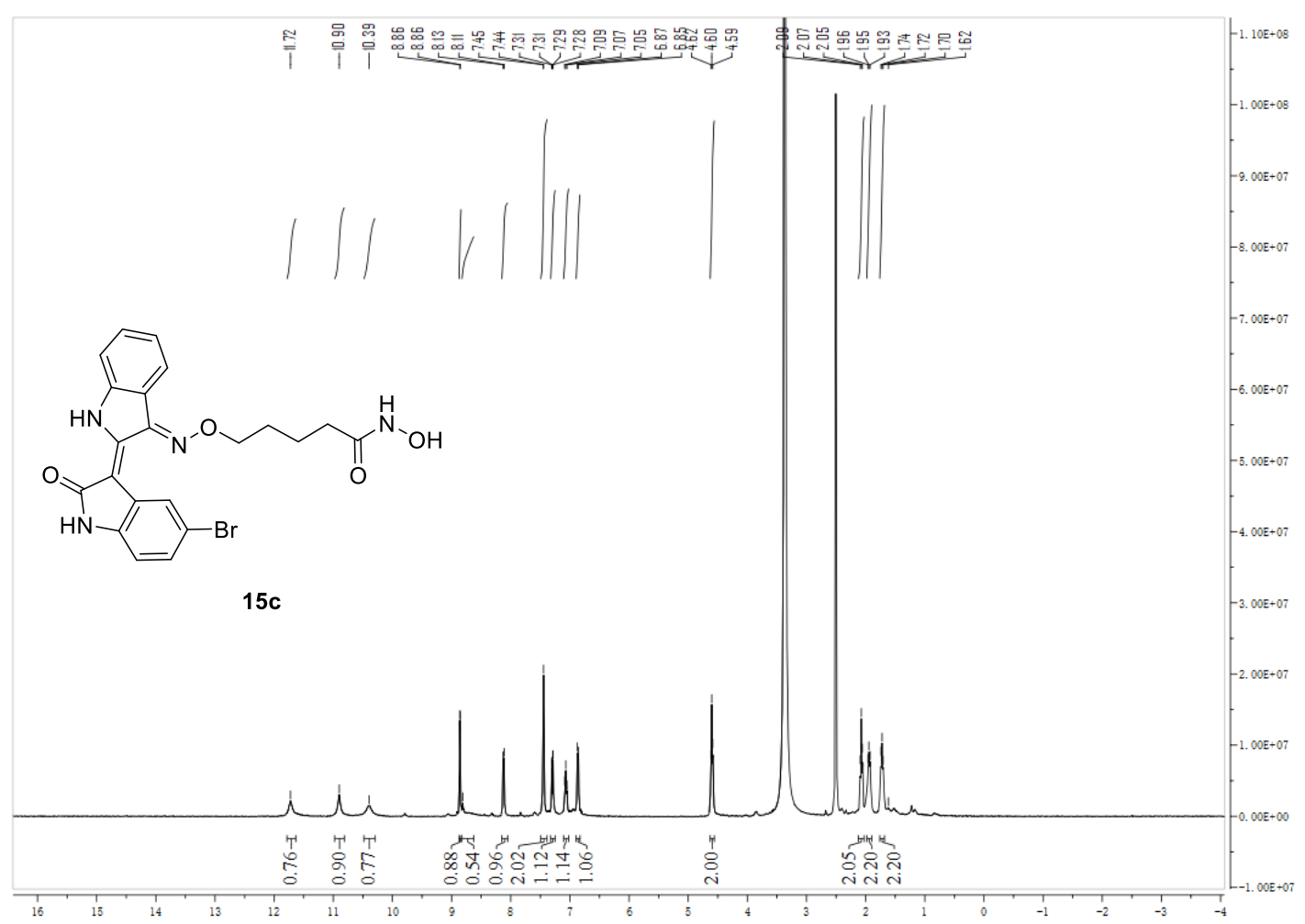

${ }^{13} \mathrm{C}$ NMR Spectrum

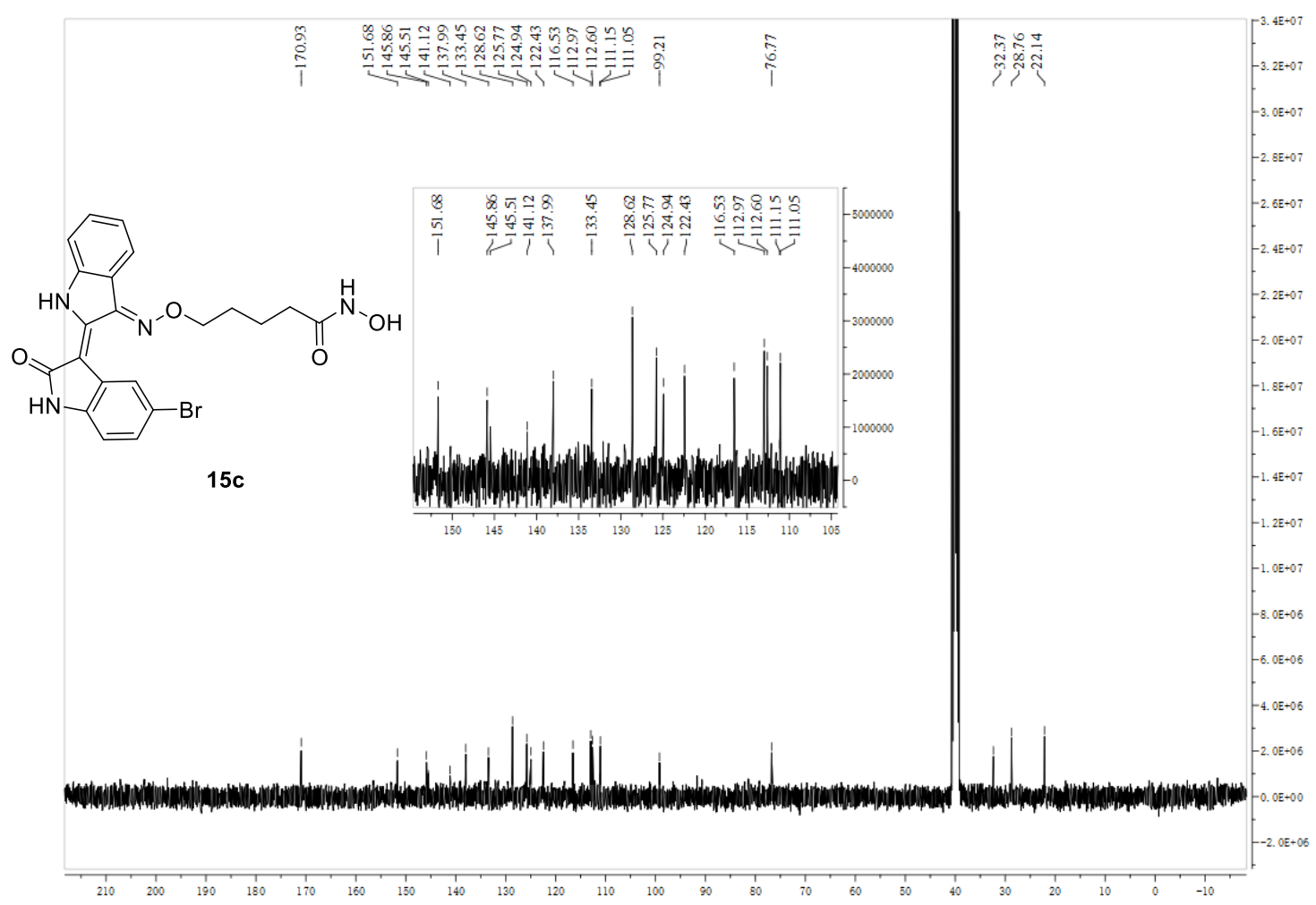


${ }^{1} \mathrm{H}$ NMR Spectrum

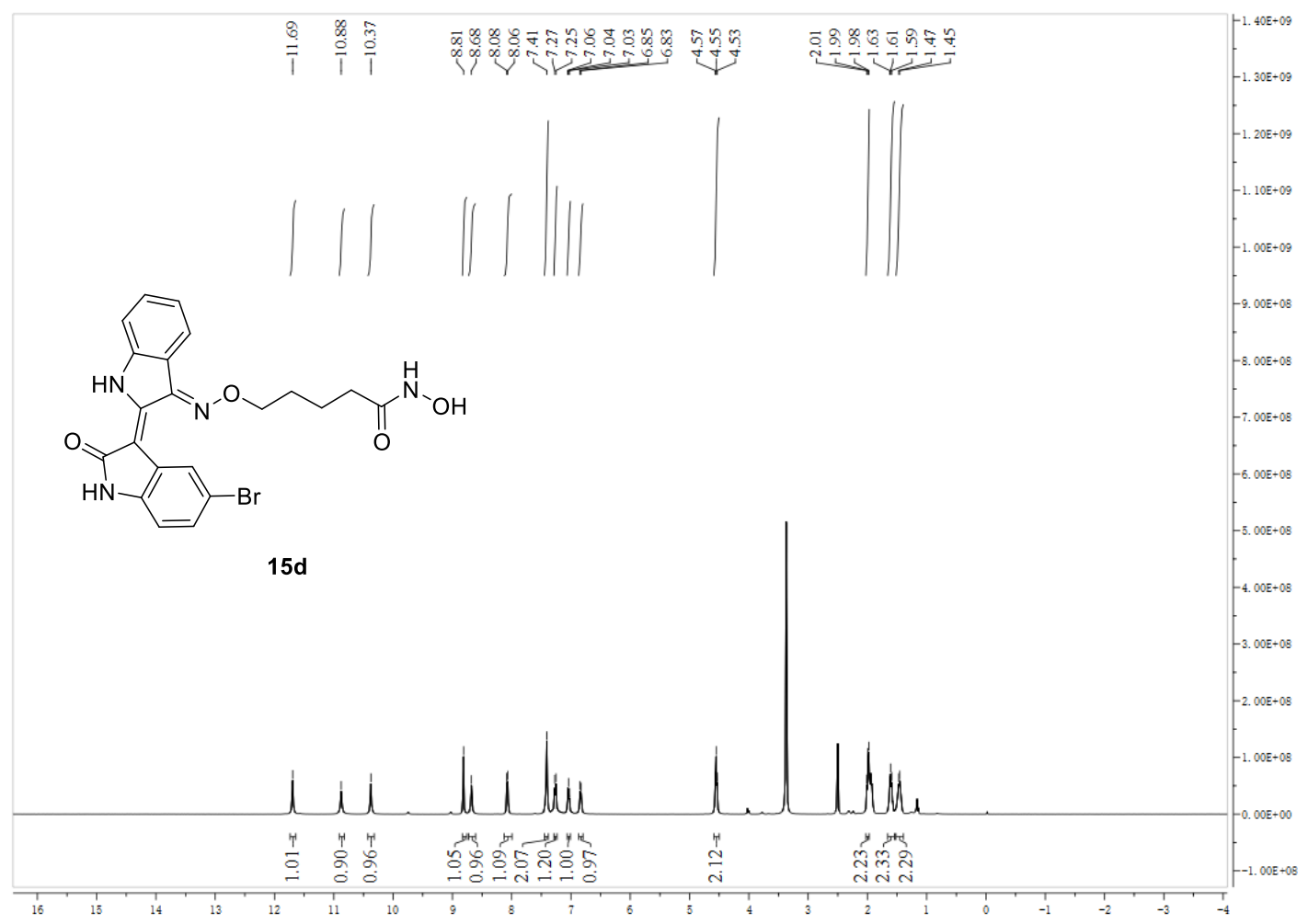

${ }^{13} \mathrm{C}$ NMR Spectrum

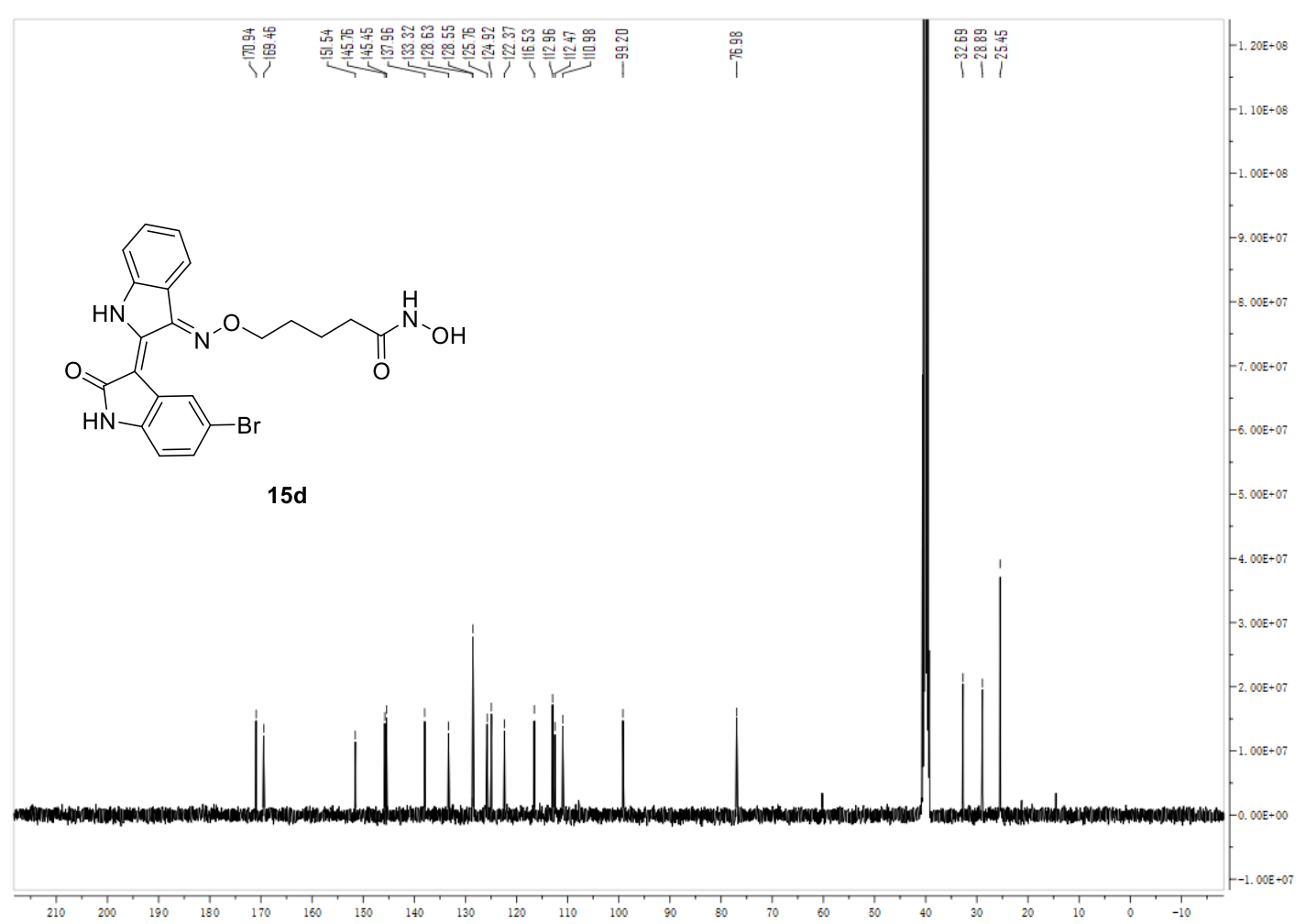




\section{${ }^{1} \mathrm{H}$ NMR Spectrum}

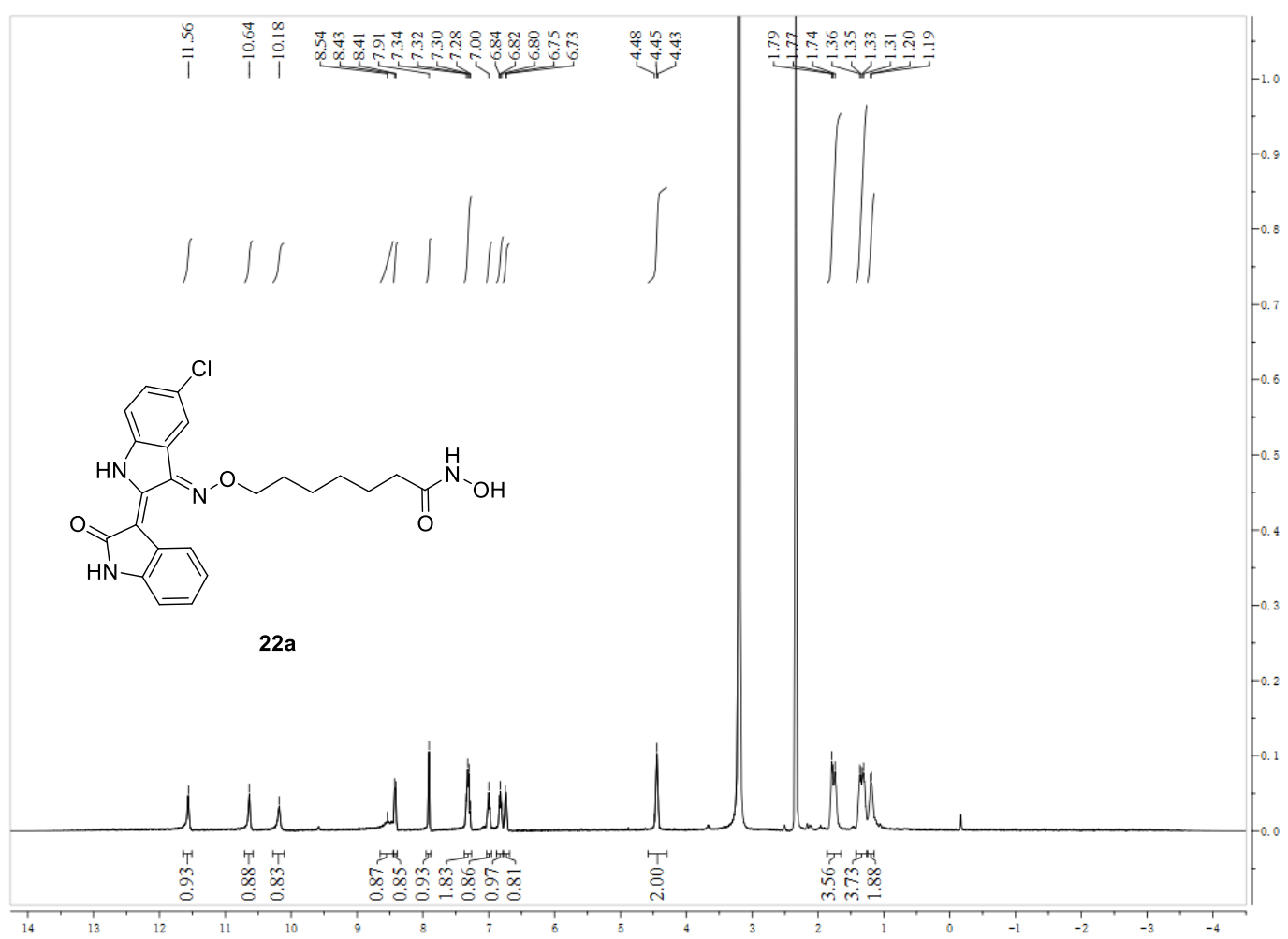

${ }^{13} \mathrm{C}$ NMR Spectrum

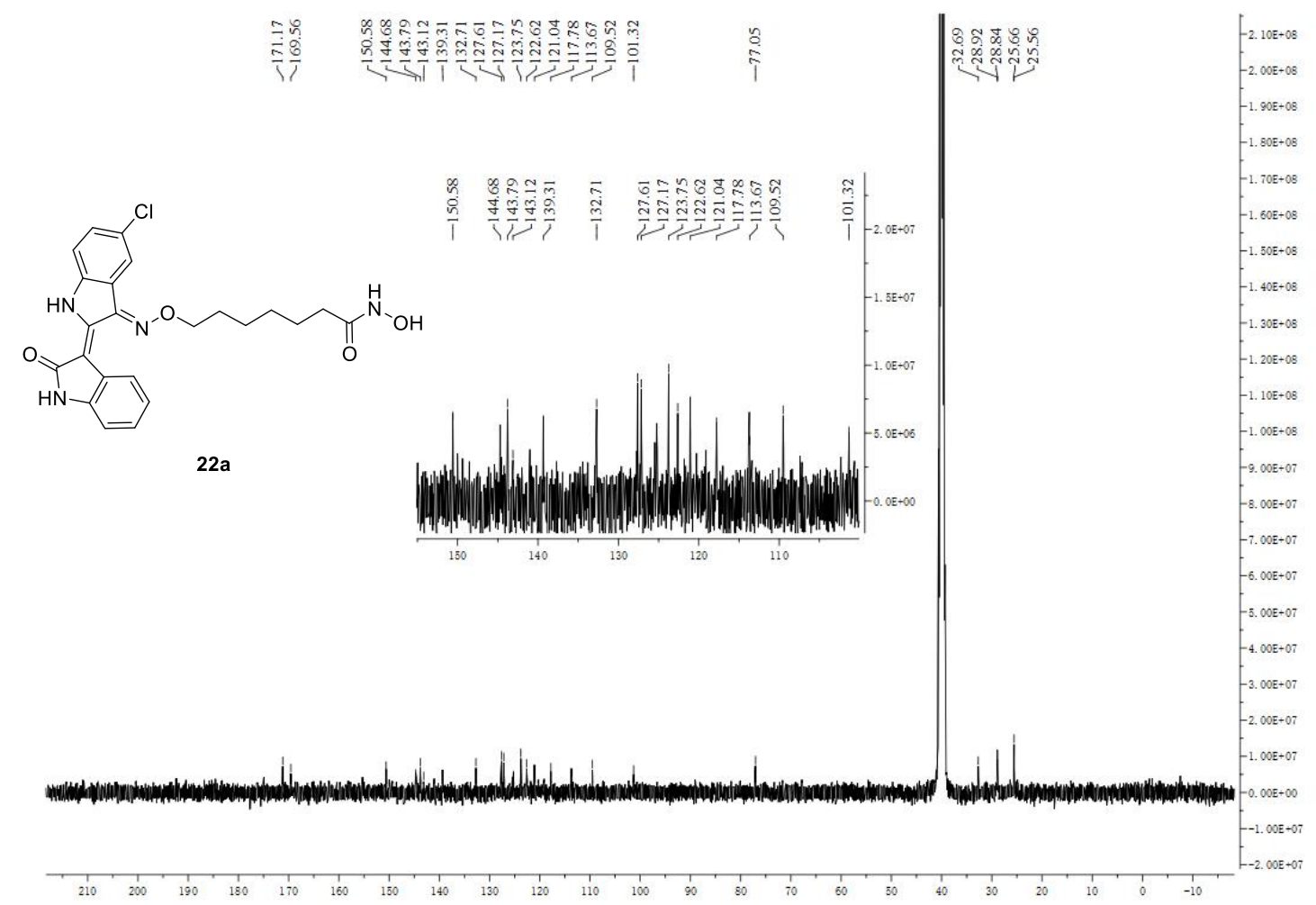




\section{${ }^{1} \mathrm{H}$ NMR Spectrum}

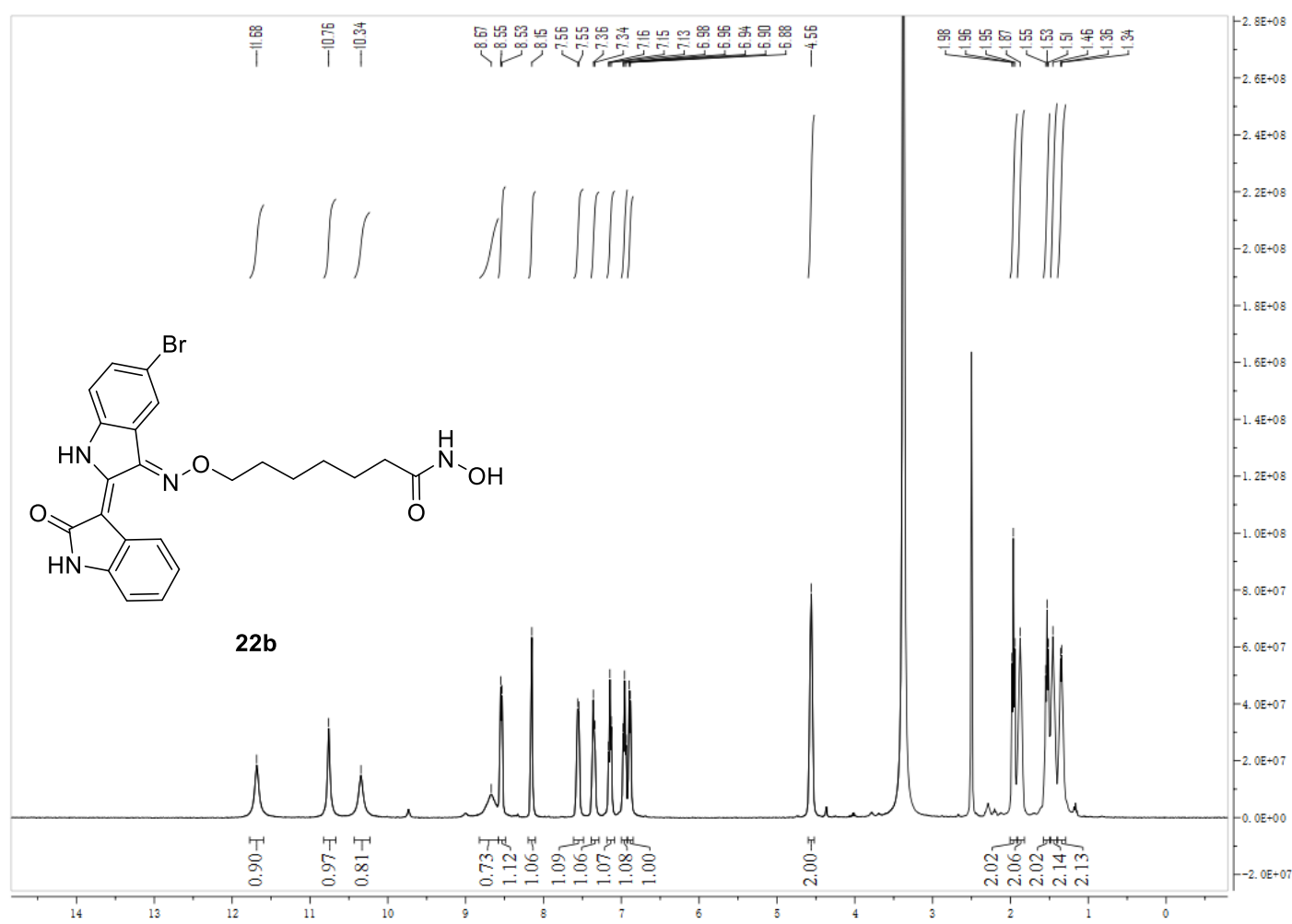

${ }^{13} \mathrm{C}$ NMR Spectrum

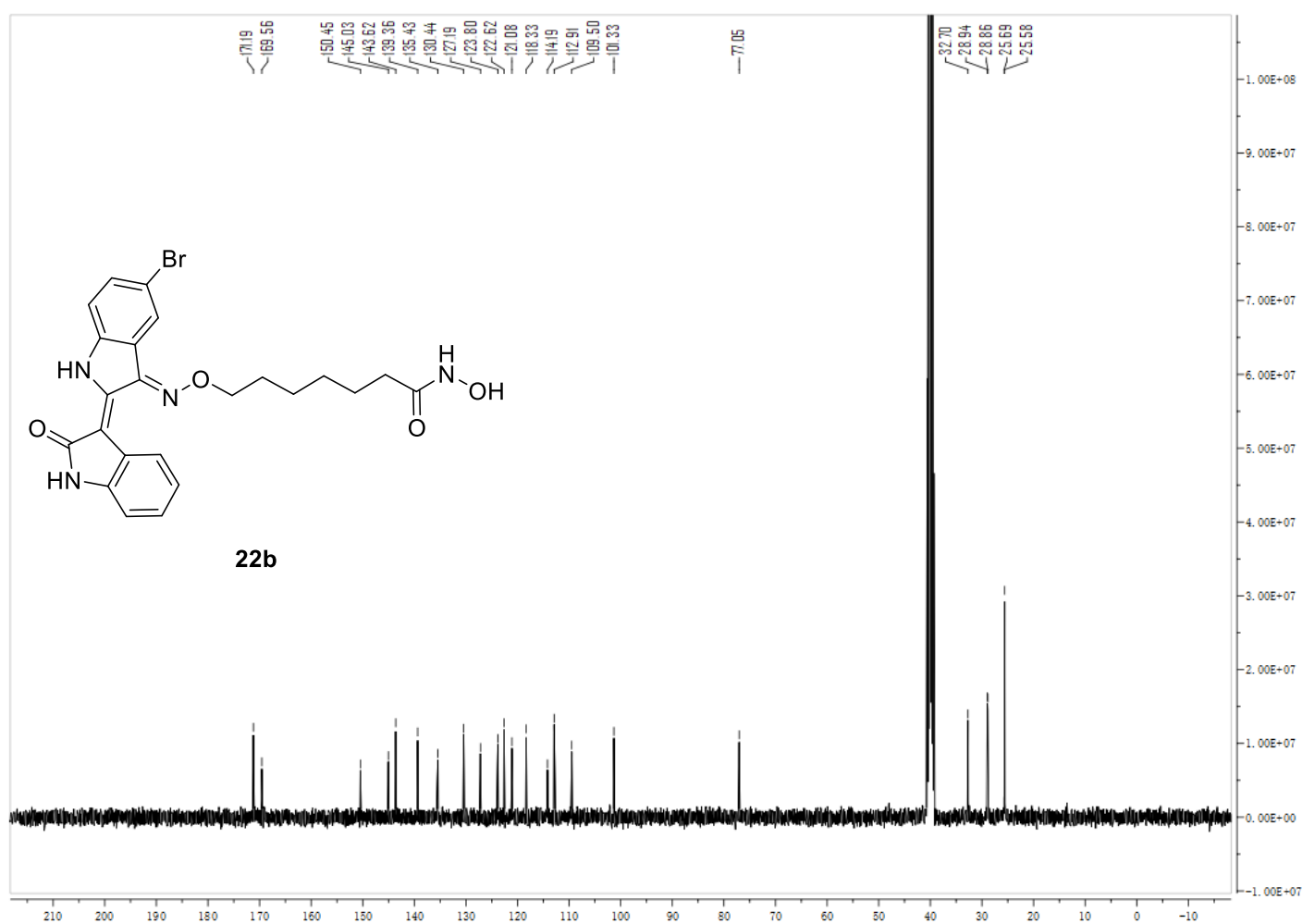


${ }^{1} \mathrm{H}$ NMR Spectrum

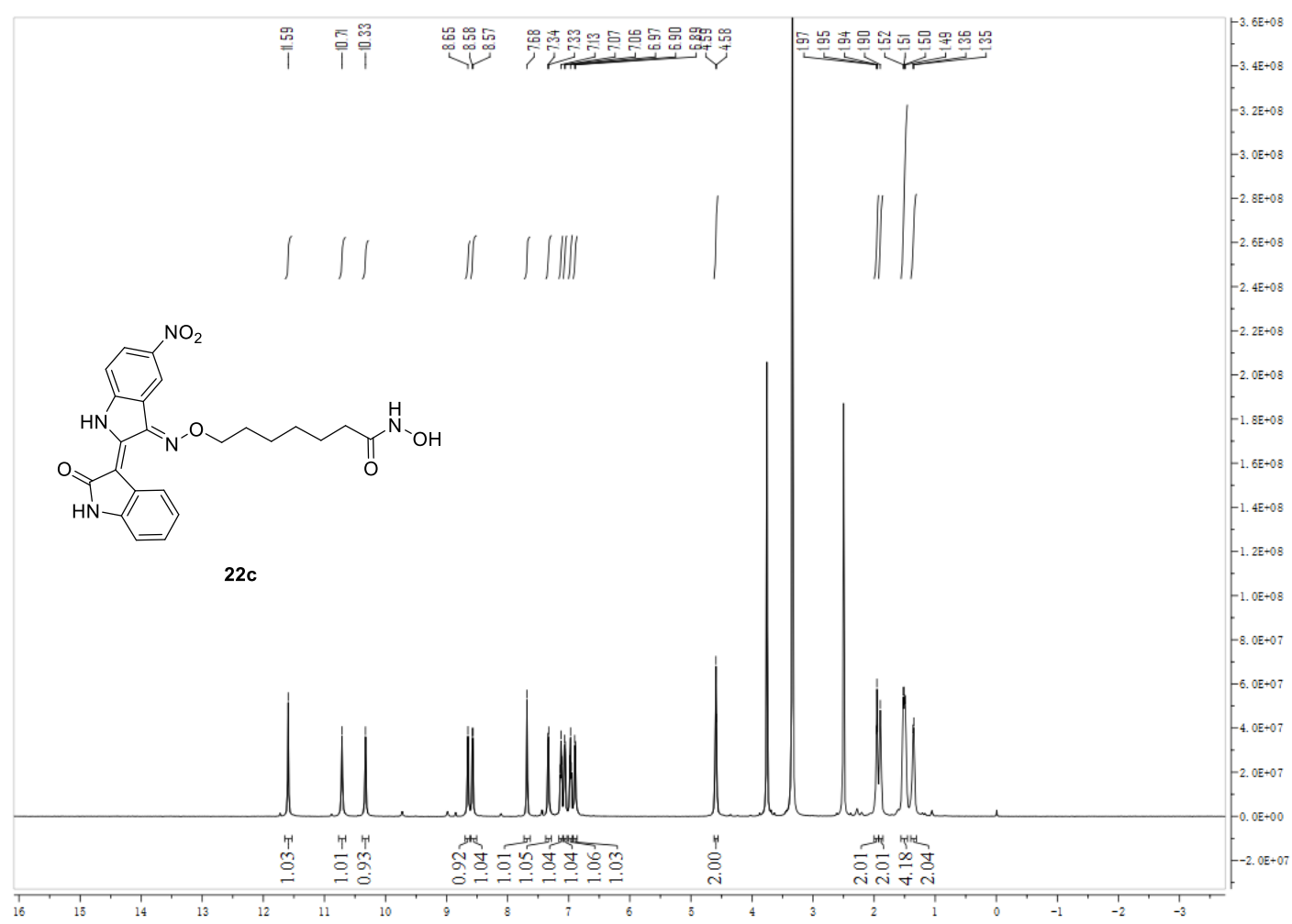

${ }^{13} \mathrm{C}$ NMR Spectrum

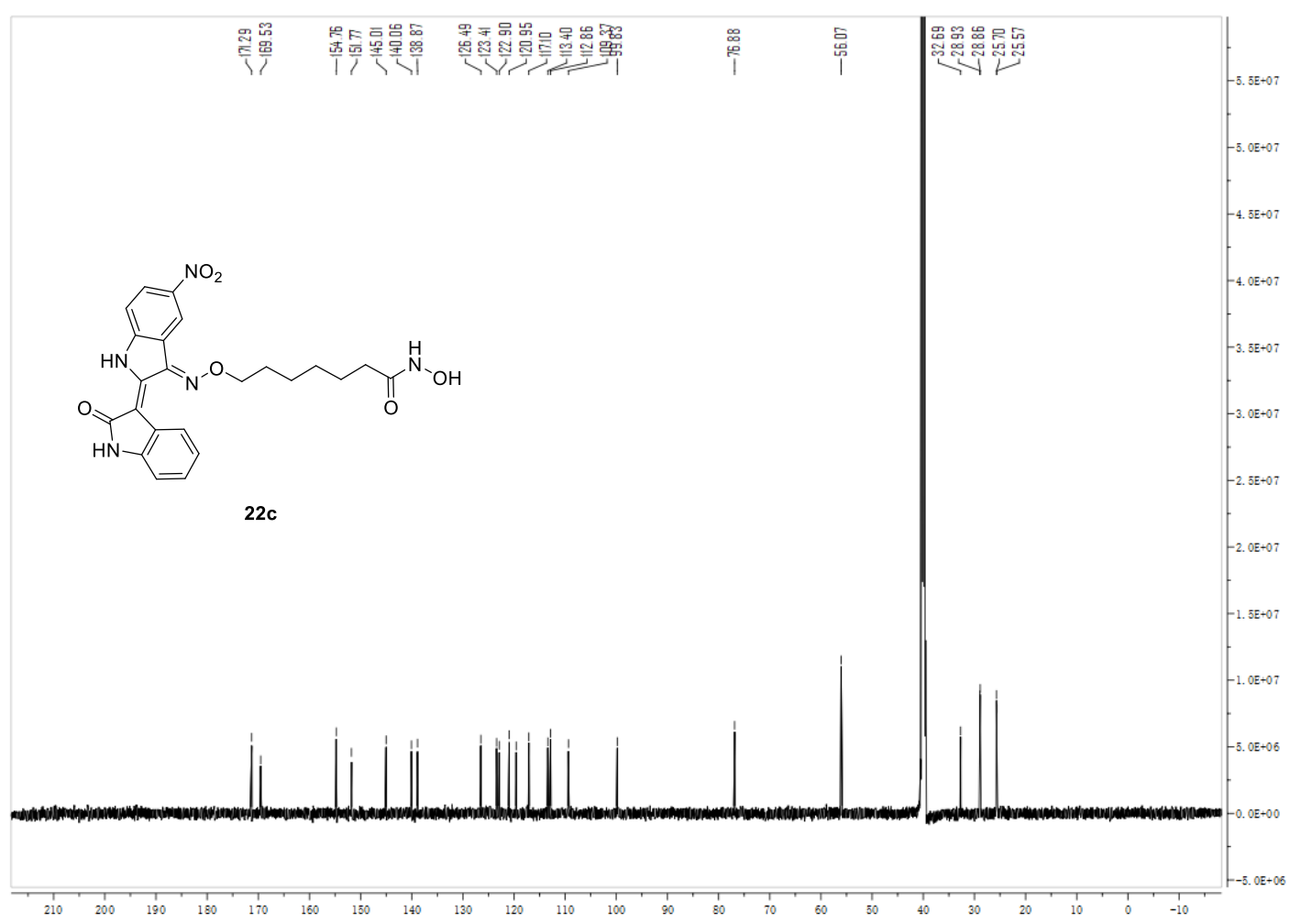




\section{${ }^{1} \mathrm{H}$ NMR Spectrum}

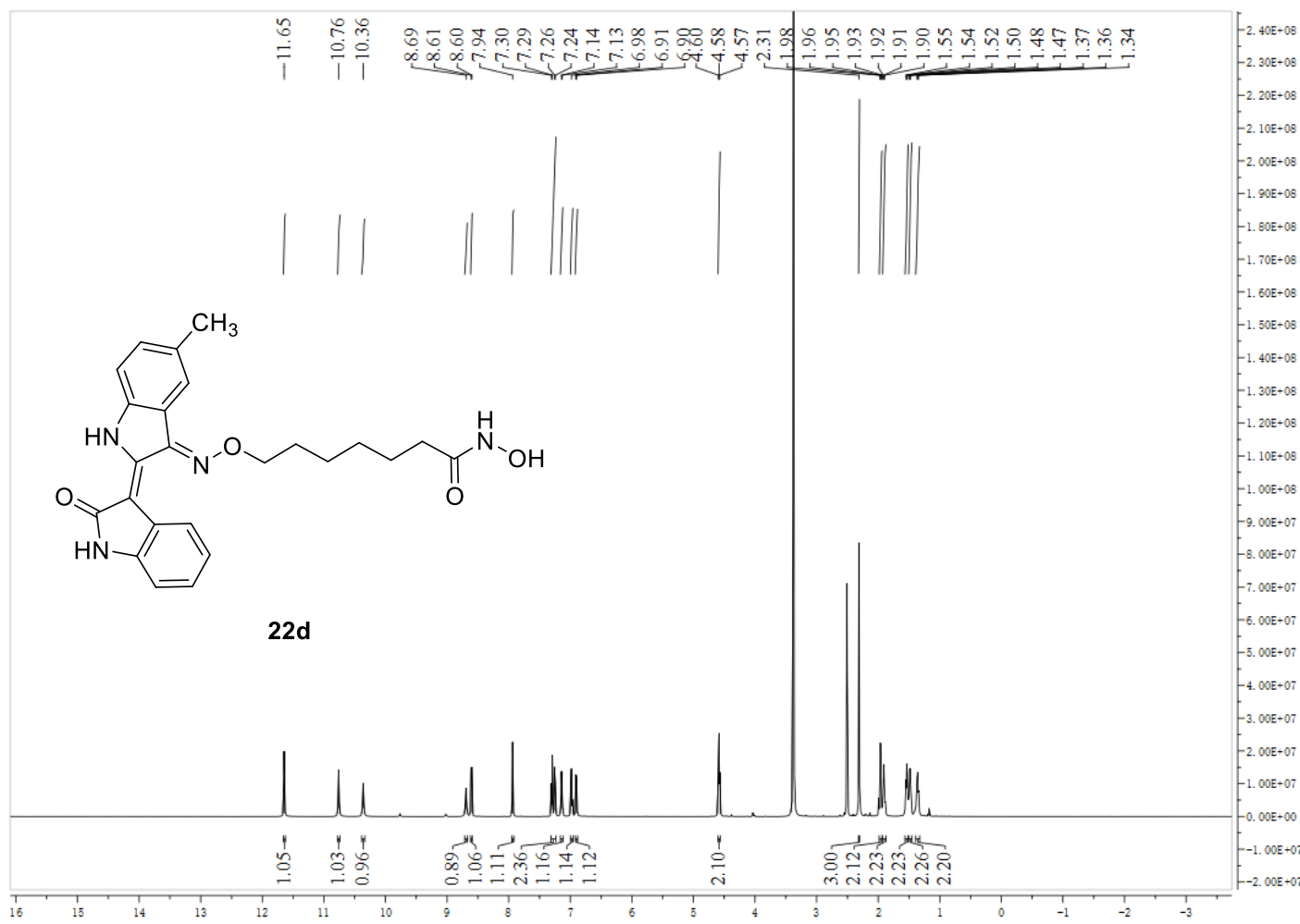

${ }^{13} \mathrm{C}$ NMR Spectrum

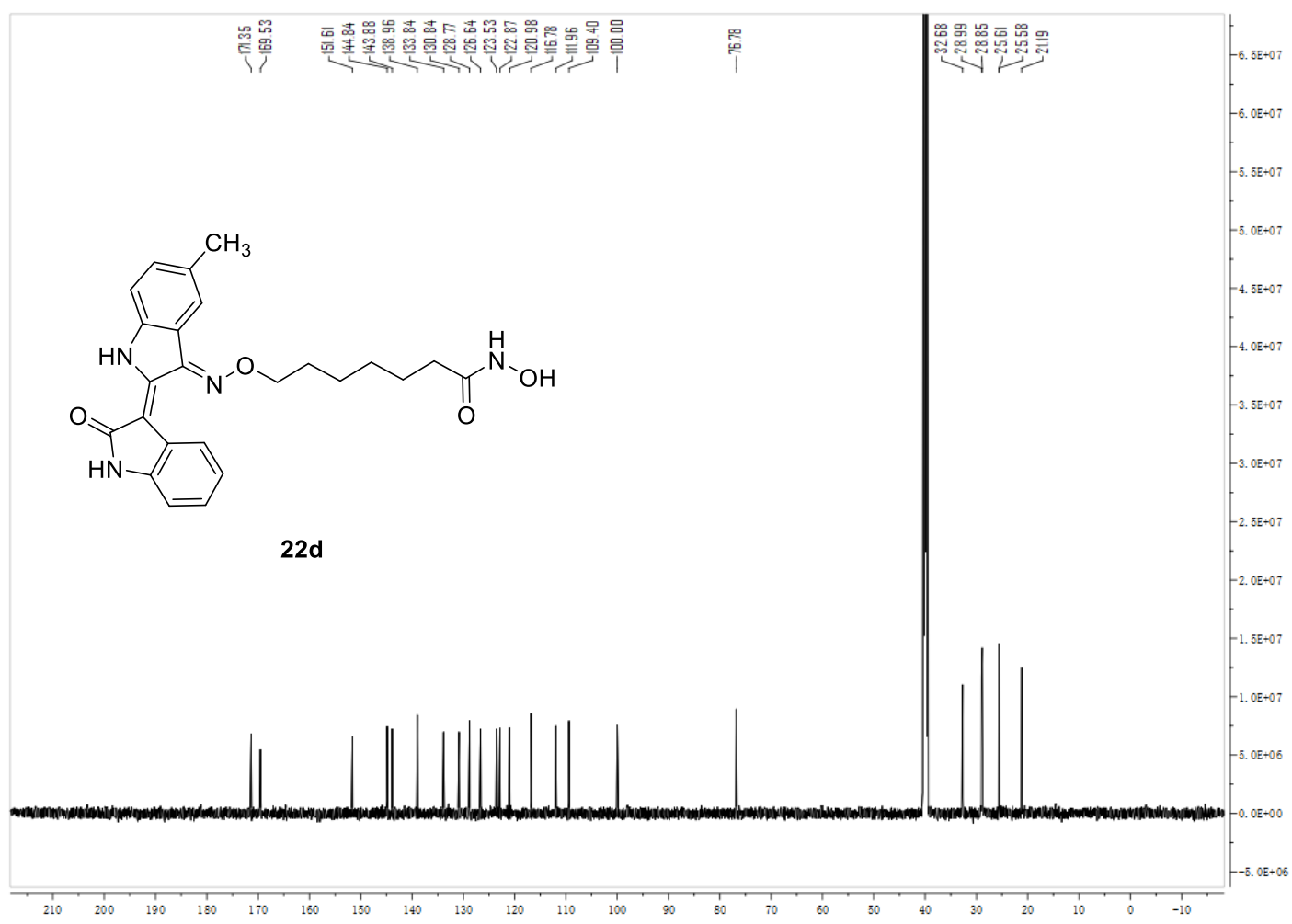


${ }^{1} \mathrm{H}$ NMR Spectrum

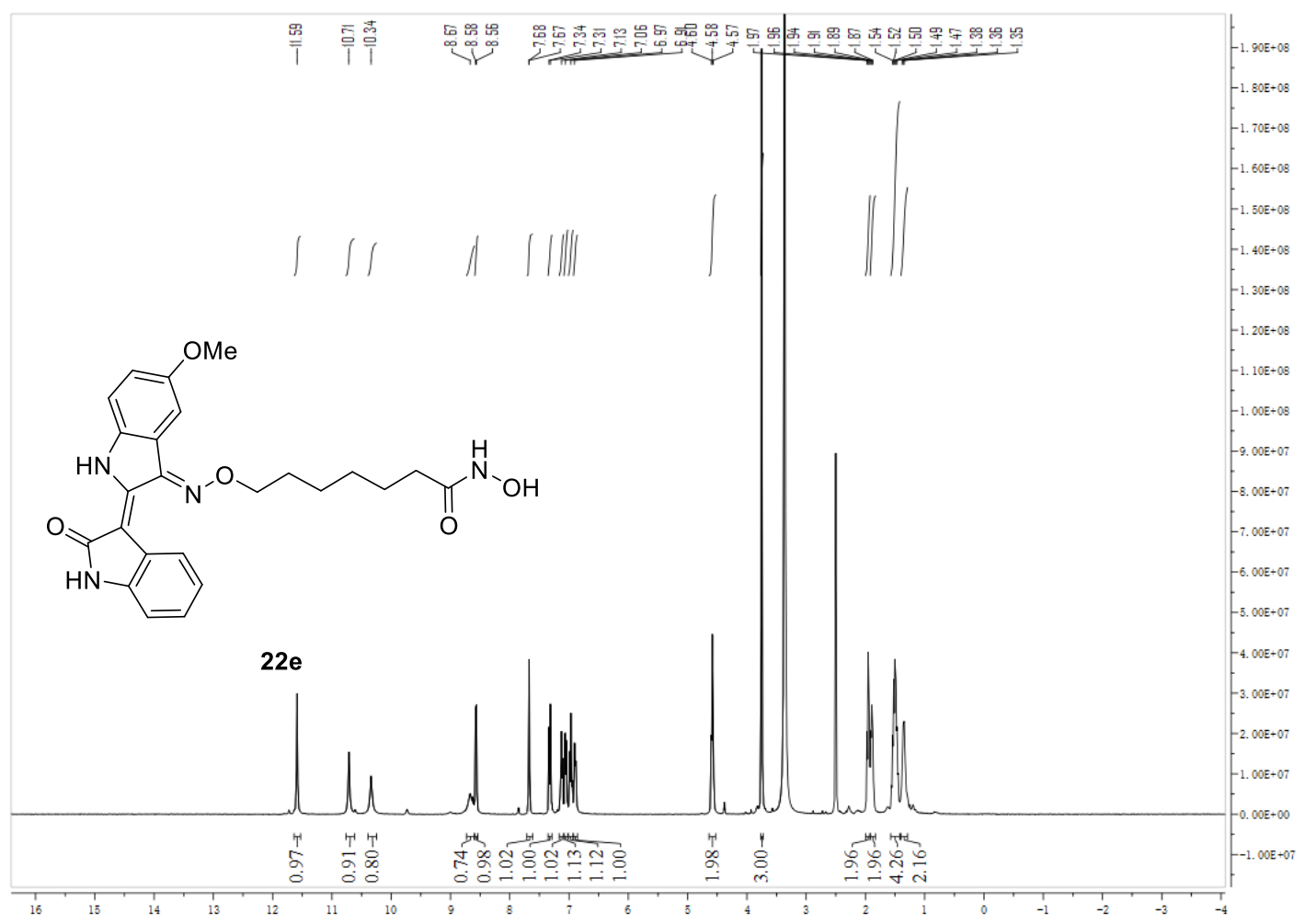

${ }^{13} \mathrm{C}$ NMR Spectrum

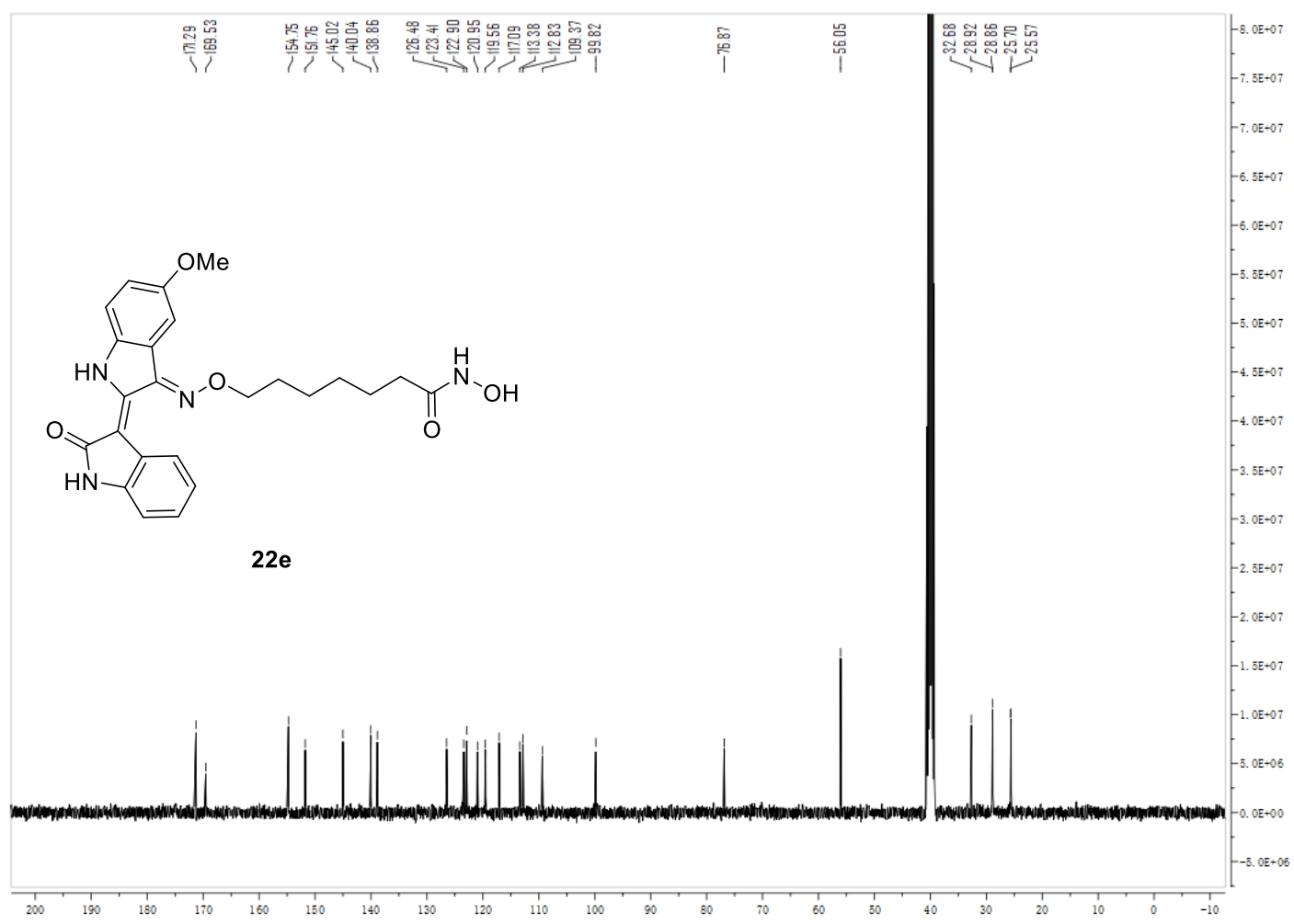




\section{${ }^{1} \mathrm{H}$ NMR Spectrum}

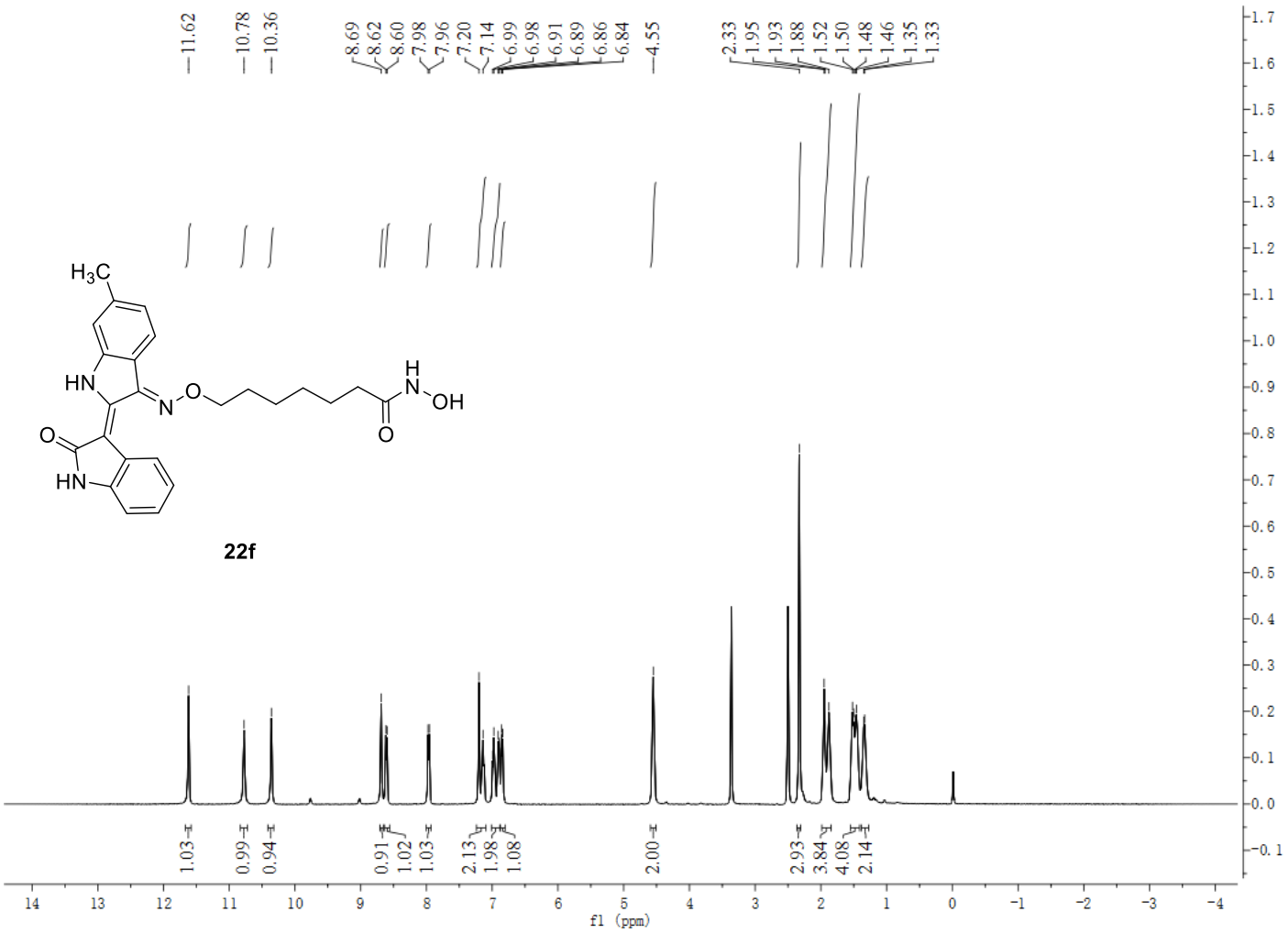

${ }^{13} \mathrm{C}$ NMR Spectrum

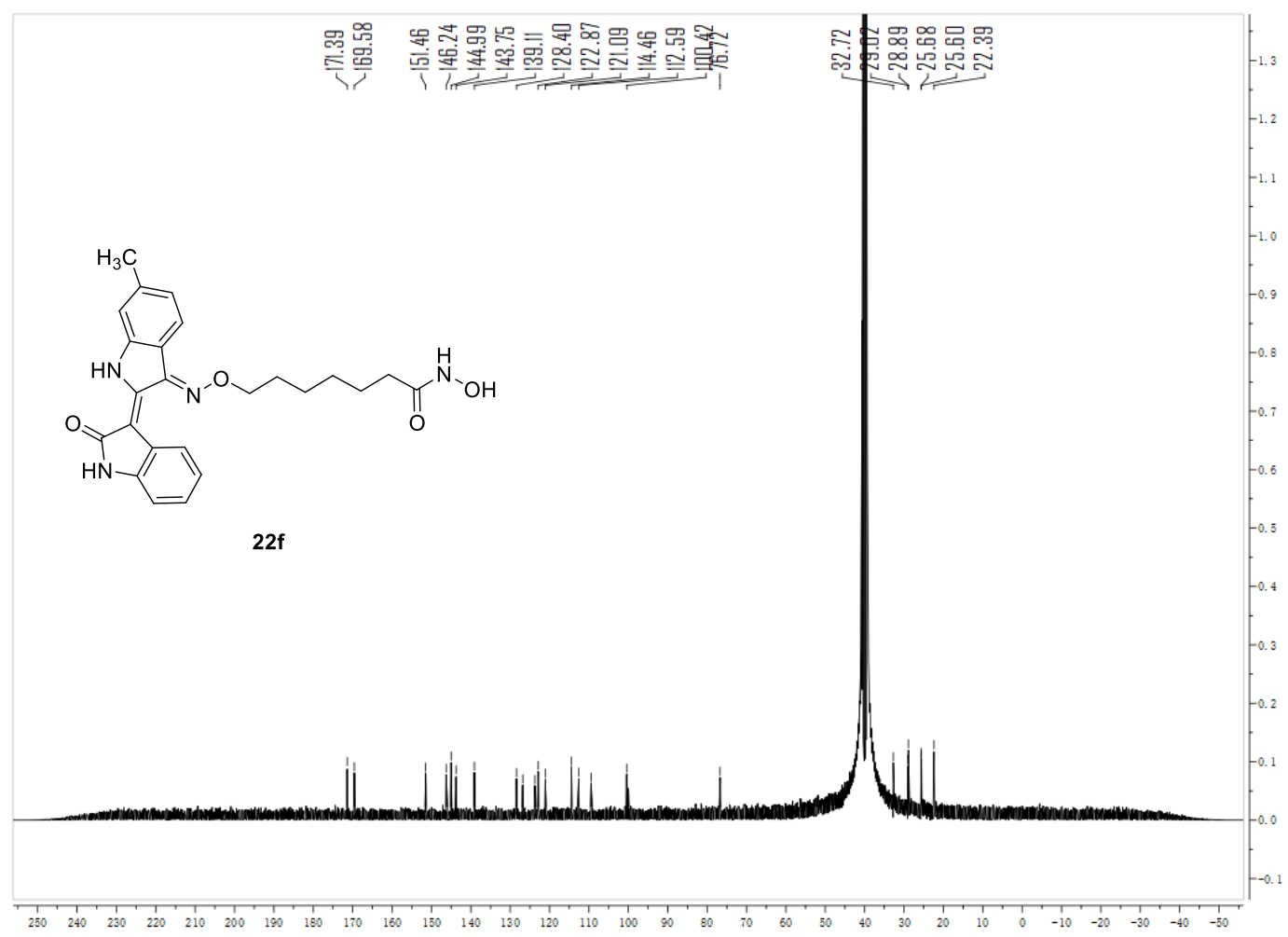




\section{${ }^{1} \mathrm{H}$ NMR Spectrum}

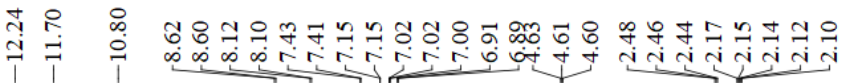
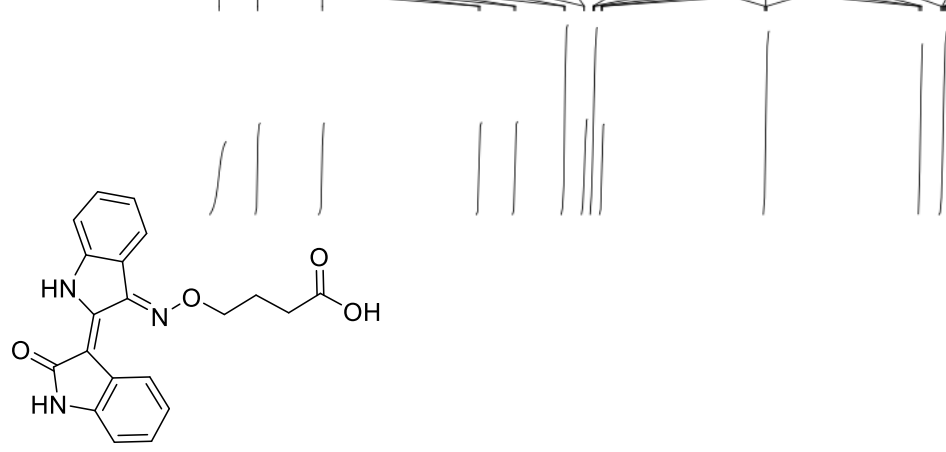

8b-N

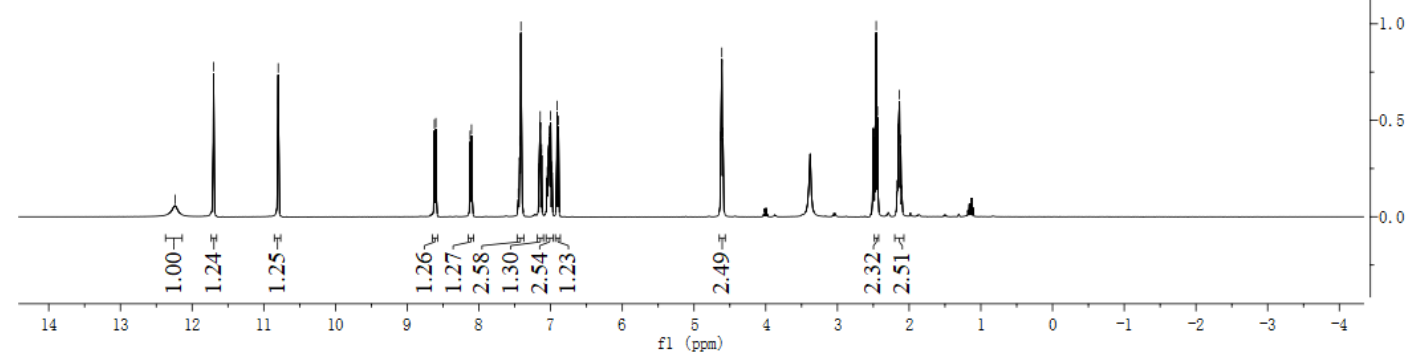

${ }^{13} \mathrm{C}$ NMR Spectrum

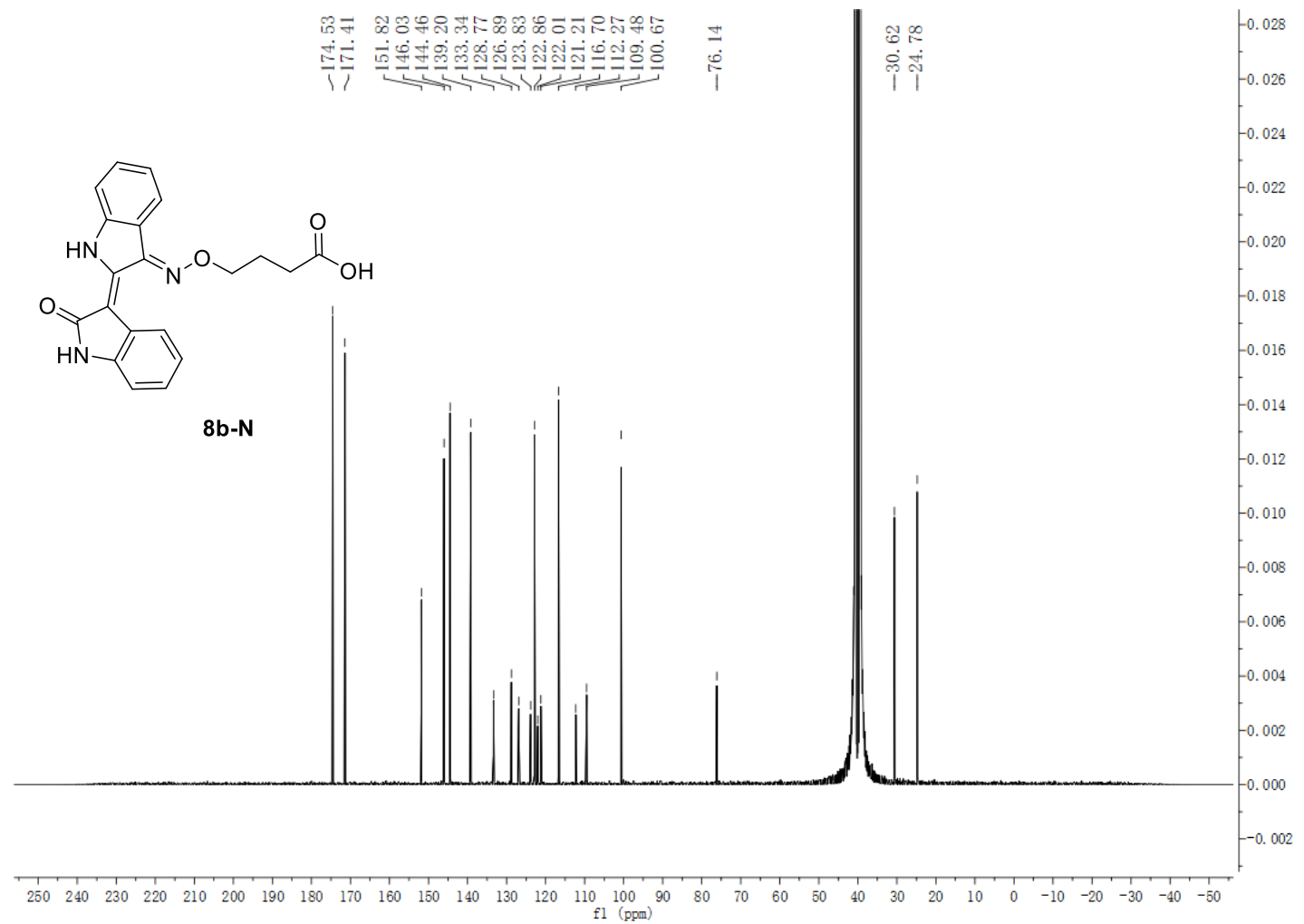




\section{${ }^{1} \mathrm{H}$ NMR Spectrum}

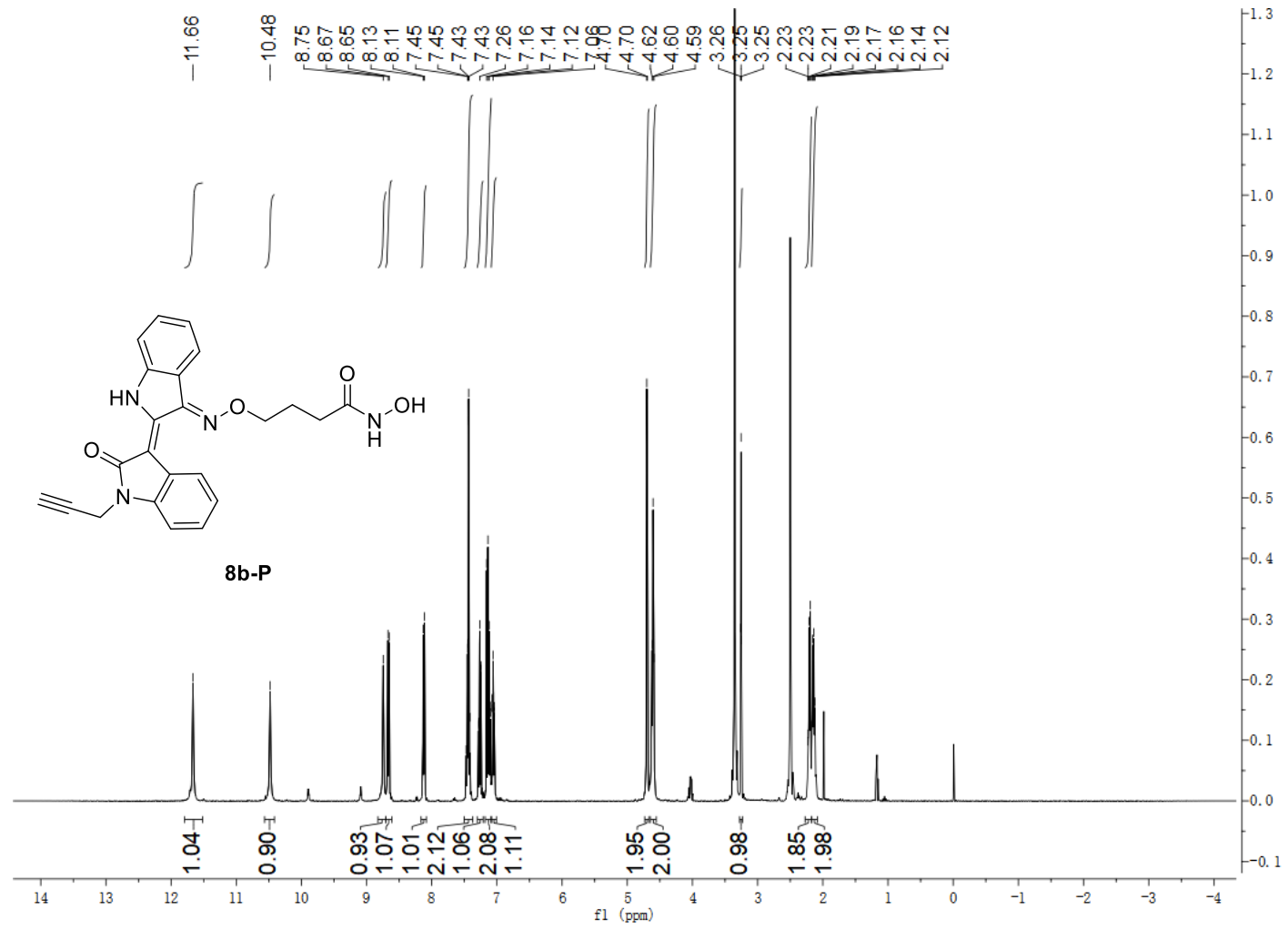

${ }^{13} \mathrm{C}$ NMR Spectrum

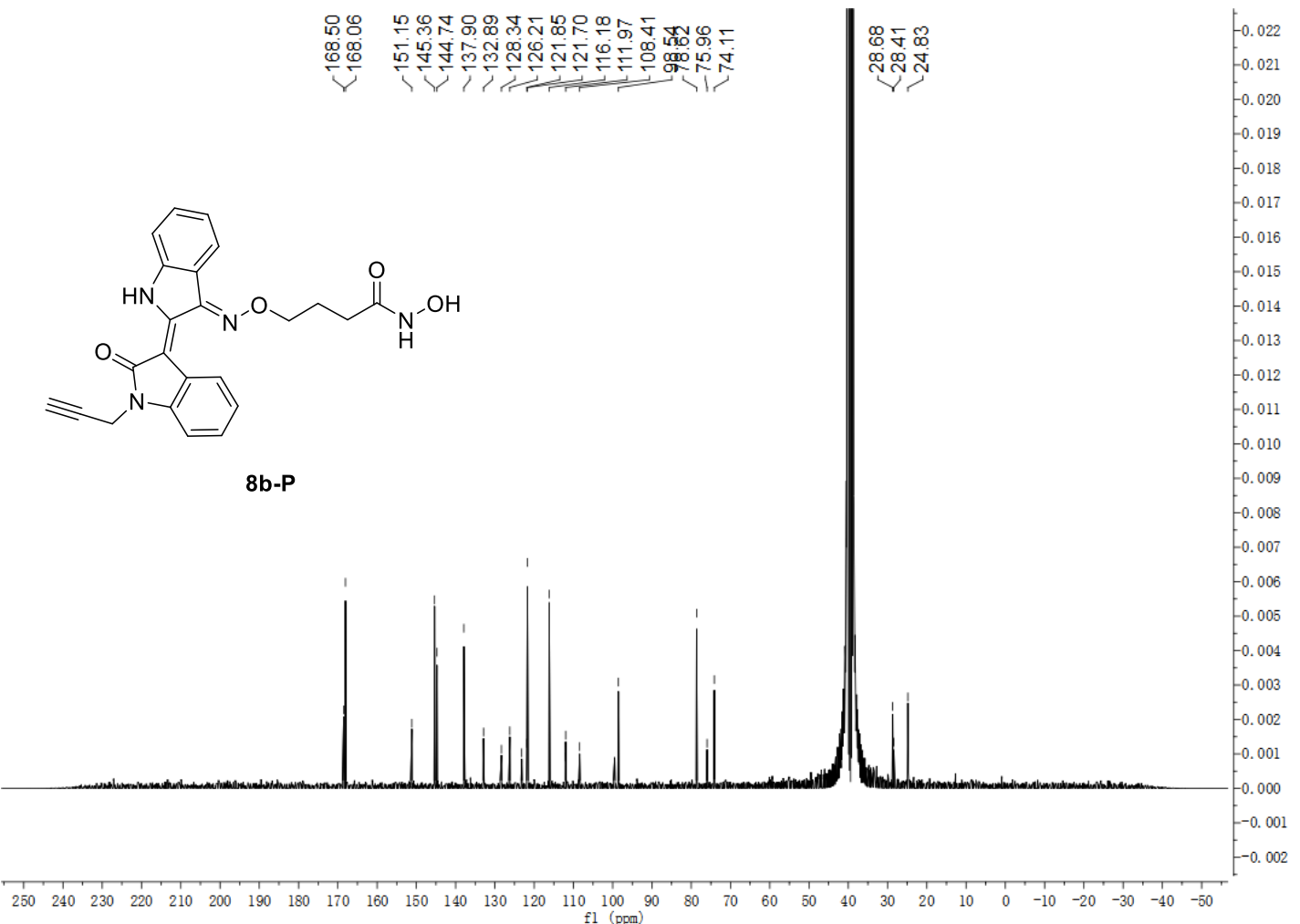


HRMS spectra for compound $8 b$

CZX-024 \#29 RT: 0.31 AV: 1 SB: 10 0.06-0.16 NL: 1.66E7

T: FTMS + p ESI Full ms [100.0000-1000.0000]

379.13983

$\mathrm{C}_{20} \mathrm{H}_{19} \mathrm{O}_{4} \mathrm{Z}=1$

100

95

90

85

80

75

70

65

50

45

40

35

30
25

25
20

15

10

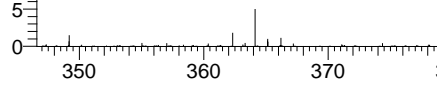

$350 \quad 360$

$$
\begin{gathered}
401.12175 \\
\mathrm{z}=1 \\
\mathrm{C}_{20} \mathrm{H}_{18} \mathrm{O}_{4} \mathrm{~N}_{4} \mathrm{Na}=401.12203 \\
-0.70072 \mathrm{ppm}
\end{gathered}
$$

$$
417.09556
$$$$
\mathrm{C}_{20} \mathrm{H}_{18} \mathrm{O}_{4} \mathrm{~N}_{4}^{\mathrm{Z}=1} \mathrm{~K}=417.09596
$$$$
-0.96821 \mathrm{ppm}
$$

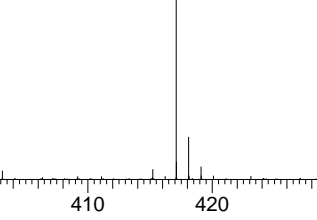

$\mathrm{m} / \mathrm{z}$ 
HPLC purity analysis for compound $8 \mathrm{~b}$

\begin{tabular}{|llll|}
\hline $\mathbf{2} \mathbf{8 b}$ & & & \\
& & & \\
\hline Sample Name: & $\mathbf{8 b}$ & Injection Volume: & 10.0 \\
Vial Number: & GA2 & Channel: & EXT284NM \\
Sample Type: & unknown & Wavelength: & $\mathbf{2 8 4}$ \\
Control Program: & 15min全梯度-HTY-制备-40DU & Bandwidth: & 0 \\
Quantif. Method: & 数据方法1 & Dilution Factor: & 1.0000 \\
Recording Time: & $\mathbf{2 0 2 0 / 1 2 / 2 4} 15: 19$ & Sample Weight: & 1.0000 \\
Run Time (min): & $\mathbf{1 5 . 0 0}$ & Sample Amount: & $\mathbf{1 . 0 0 0 0}$ \\
\hline
\end{tabular}

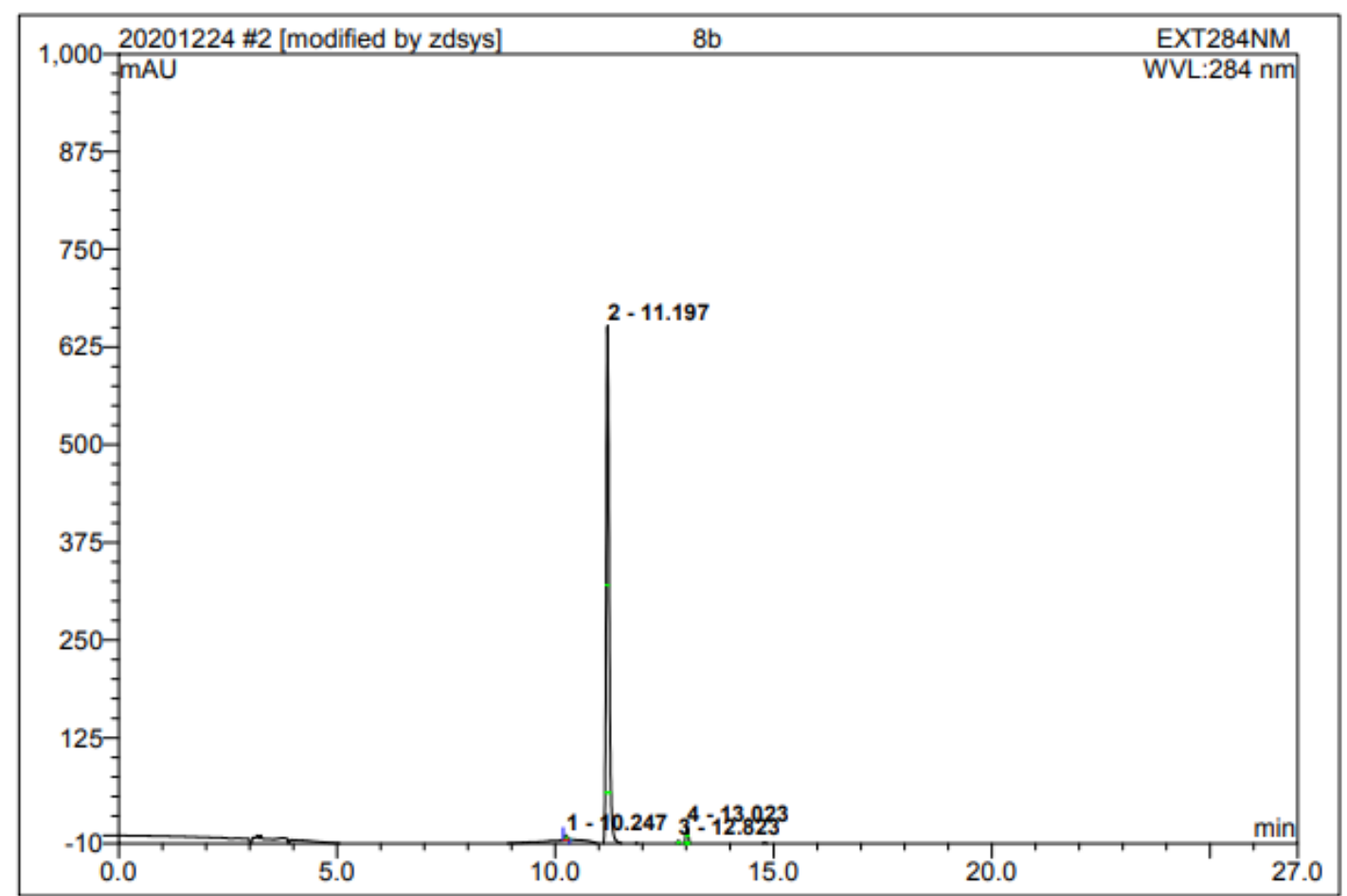

\begin{tabular}{|c|clrrrrr|}
\hline No. & $\begin{array}{c}\text { Ret.Time } \\
\text { min }\end{array}$ & \multicolumn{1}{c}{$\begin{array}{c}\text { Peakname } \\
\text { min }\end{array}$} & $\begin{array}{c}\text { Height } \\
\text { mAU }\end{array}$ & $\begin{array}{c}\text { Area } \\
\text { mAU*min }\end{array}$ & $\begin{array}{r}\text { Rel.Area } \\
\%\end{array}$ & Amount & Resolution(EP) \\
\hline n.a. & n.a. & Peak 1 & n.a. & n.a. & n.a. & n.a. & n.a. \\
1 & 10.247 & n.a. & 6.199 & 0.385 & 0.69 & n.a. & 8.63 \\
2 & 11.197 & n.a. & 663.784 & 53.130 & 95.61 & n.a. & 14.04 \\
3 & 12.823 & n.a. & 5.632 & 0.390 & 0.70 & n.a. & 1.77 \\
4 & 13.023 & n.a. & 23.017 & 1.664 & 2.99 & n.a. & n.a. \\
\hline
\end{tabular}

